\title{
Endometriosis : clinical and experimental aspects
}

Citation for published version (APA):

Dunselman, G. A. J. (1988). Endometriosis : clinical and experimental aspects. [Doctoral Thesis, Maastricht University]. Rijksuniversiteit Limburg. https://doi.org/10.26481/dis.19880617gd

Document status and date:

Published: 01/01/1988

DOI:

10.26481/dis.19880617gd

Document Version:

Publisher's PDF, also known as Version of record

\section{Please check the document version of this publication:}

- A submitted manuscript is the version of the article upon submission and before peer-review. There can be important differences between the submitted version and the official published version of record.

People interested in the research are advised to contact the author for the final version of the publication, or visit the DOI to the publisher's website.

- The final author version and the galley proof are versions of the publication after peer review.

- The final published version features the final layout of the paper including the volume, issue and page numbers.

Link to publication

\footnotetext{
General rights rights.

- You may freely distribute the URL identifying the publication in the public portal. please follow below link for the End User Agreement:

www.umlib.nl/taverne-license

Take down policy

If you believe that this document breaches copyright please contact us at:

repository@maastrichtuniversity.nl

providing details and we will investigate your claim.
}

Copyright and moral rights for the publications made accessible in the public portal are retained by the authors and/or other copyright owners and it is a condition of accessing publications that users recognise and abide by the legal requirements associated with these

- Users may download and print one copy of any publication from the public portal for the purpose of private study or research.

- You may not further distribute the material or use it for any profit-making activity or commercial gain

If the publication is distributed under the terms of Article $25 \mathrm{fa}$ of the Dutch Copyright Act, indicated by the "Taverne" license above, 


\section{Endometriosis}

Clinical and experimental aspects 
Dit proefschrift is gectrukt op papier houtvrij mat machine-coated 90 grams, gezet uit de Letter Times

en gedrukt door Drukkerij Groenevelt BV, Landgraaf 


\title{
Endometriosis \\ Clinical and experimental aspects
}

\author{
Proefschrift
}

ter verkrijging van de graad van doctor aan de Rijksuniversiteit Limburg te Maastricht, op gezag van de Rector Magnificus, Prof. Dr. F.I.M. Bonke, volgens het besluit van het College van Dekanen, in het openbaar te verdedigen op vrijdag, 17 juni 1988 om 16.00 uur

door

Gerardus Antonius Josephus Dunselman

geboren te Helmond in 1951 
Promotor:

Prof. Dr J. de Haan

Co-promotor:

Dr J.L.H. Evers

Beoordelingscommissie: Prof. Dr J.W. Arends

Prof. Dr P.J. Brombacher

Prof. Dr I.A. Brosens

Prof. Dr J.P.M. Geraedts

Prof. Dr J. Schoemaker 
Aan mijn vader mijn moeder mijn echigenote 
No one is so sure of his premises as the man who knows too little

Barbara W. Tuchman

The March of Folly 


\section{Contents}

Voorwoord

CHAPTER

Introduction

CHAPTER 2

Review of the literature

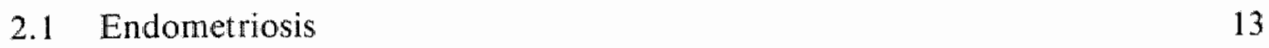

1 Pathogenesis and etiology 13

2 Classification 20

3 Epidemiology 21

4 Symptomatology $\quad 22$

5 Diagnosis $\quad 23$

6 Management $\quad 28$

7 Recurrence $\quad 29$

2.2 Endometriosis and infertility $\quad 30$

1 Endometriosis-associated infertility 30

2 Possible causes of infertility in endometriosis $\quad 32$

2.3 Peritoneal fluid and endometriosis 39

1 Peritoneall fluid volume $\quad 40$

2 Peritoneal fluid constituents 41

2.4 The use of an experimental animal model of endometriosis 48

CHAPTER 3

$\begin{array}{ll}\text { Aims of the study } & 75\end{array}$

CHAPTER 4

The acute-phase response in endometriosis of women

CHAPTER 5

Fibrinolytic properties of peritoneal fluid in endometriosis of women

CHAPTER 6

Functional aspects of peritoneal macrophages in endometriosis of women 


\section{CHAPTER 7}

A rabbit model of endometriosis

CHAPTER 8

Effect of endometriosis on ovulation, owum pickup, fertilization and tubal transport in the rabbit

CHAPTER 9

Effect of endometriosis on early embryonic development in the rabbit

CHAPTER 10

General discussion

Summary

Samenvatting

Curriculum vitae 


\section{Voorwoord}

Dit proefschrift werd bewerkt binnen de afdeling Obstetrie en Gynaecologie van het De Wever Ziekenhuis te Heerlen en de vakgroep Obstetrie en Gynaecologie van het Academisch Ziekenhuis Maastricht. Een gedeelte van het onderzoekmateriaal werd verzameld in de St Elisabethkliniek te Heerlen.

Het dierexperimentele onderzoek werd verricht in het Biomedisch Centrum van de Rijksuniversiteit Limburg te Maastricht.

Het is meer dan een goede gewoonte en tegelijkertijd onmogelijk om allen die hebben meegewerkt aan het tot stand komen van dit proefschrift bij deze gelegenheid te noemen en maar behoren te bedanken.

Allereerst moeten genoemd worden Dr L.A. Schellekens en Prof. Dr J. de Haan die beiden een belangrijk aandeel hadden in mijn opleiding tot vrouwenarts en mij op een overigens zeer verschillende manier hebben gestimuleerd tot het doen van onderzoek en het schrijven van een proefschrift.

Dr J.L.H. Evers en Dr P.X.J.M. Bouckaert stonden aan de basis van respectievelijk het dierexperimentele en het humane gedeelte van de studie en hebben nauwkeurig, met uitzonderlijke inzet en zeer vasthoudend het verloop ervan begeleid en gestuurd. Bijzondere dank gaat uit naar Drs M.G.R. Hendrix die het macrofagenonderzoek voor zijn rekening nam.

Dr E.J.P. Brommer en Dr J.W.J. van Wersch gaven waardevolle aanwijzingen bij het verwerken van de gegevens van de intra-abdominale fibrinolysis.

Van de ervaring van Dr J.A. Land met het konijnemodel werd dankbaar gebruik gemaakt. Haar kritische houding ten aanzien van onderzoek en verslaglegging was een stimulans om het manuscript af te ronden.

Mevrouw M. Bras, Drs J.C.M. Dumoulin en Drs M.H.E.C. Pieters waren behulpzaam bij het doorkweken van de konijne-embryo's.

Drs D. Willebrand werzorgde de histologie van de endometrium- en vetimplantaten. Alle laboratoriumbepalingen werden verricht in de laboratoria van het De Wever Ziekenhuis te Heerlen (Prof. Dr P.J. Brombacher, Dr A.H.J. Gijzen, Dr J.W.J. van Wersch).

De medewerkers van de Centrale Proefdier Voorziening van bet Biomedisch Centrum, in het bijzonder de heer P.H.M.W. Kelderman, waren behulpzaam bij het dierexperimentele werk. De Audliovisuele Dienst van het Academische Ziekenhuis Maastricht verzorgde de zwartwit foto's.

Gewaardeerde secretariële ondersteuning kwam van de kant van mevrouw M.J.P.J. Savelsberg. 
Overigens heb ik ondervonden dat ook een thuisfront op 200 kilometer afstand bij het schrijven van een proefschrift een steun en toeverlaat kan zijn.

Ik dank U allen zeer.

Maastricht, april 1988 


\section{Chapter 1}

\section{Introduction}

Endometriosis may be defined as a disease characterized by the presence of functional endometrial glands and stroma in ectopic locations outside the uterine cavity. The ectopic endometrial tissue responds to ovarian steroids in a way similar to eutopic endometrium. Endometriosis is linked to the reproductive years, it does not occur in premenarcheal girls and it is believed to regress in the postmenopausal years. Patients with endometriosis usually present with either pelvic pain or infertility. The cyclic changes lead to the macroscopic features of the endometriotic lesions on the peritoneum and the ovaries as seen by laparoscopy. By accumulation of menstrual debris an ovarian lesion may become cystic. It is then called an endometrioma. Adhesions secondary to repeated rupture and sealing of endometriomata, should be considered part of the disease. The microscopuc diagnosis asks for the presence of endometrial glands surrounded by endometrial stroma.

The first histological description of a lesion consistent with endometriosis was given by Von Rokitansky in 1860, who described small tumors on the wall of the Fallopian tube as adenomyomata (Ridley, 1968). The term "'Endometriosis"' was first used by Sampson in 1921. Since the classic papers of Sampson on the pathogenesis of endometriosis (Sampson, 1921, 1927, 1940), an overwhelming number of scientific articles has been published on the various problems encountered in this disease.

Nevertheless, despite extensive basic and clinical research, endometriosis remains a disease without precise definition, it has an obscure pathogenesis and etiology, an extremely variable clinical presentation, an unpredictable course, and, except for surgical or physiological menopause, no known cure. Endometriosis tends to recur regardless of the treatment given.

In the first part of the following chapter (2.1) the pertinent literature on pathogenesis and etiology, classification, epiderniology, symptomatology, diagnosis, management and recurrence will be reviewed.

Endometriosis is usually described and studied as a histological entity, rather than a pathophysiological process. The pathophysiology of the endometriotic lesions may shed light on the association between endometriosis and infertility. Changes in the endometriotic lesions secondary to ovarian steroids may alter the intraabdominal environment, in which the early events of reproduction take place. These functional changes are possibly reflected in the peritoneal fluid bathing the reproductive organs in the pelvic cavity. In the second part of the following chapter (2.2 and 2.3) the literature is reviewed and discussed as it pertains to the relation 
between endometriosis and infertility and to the changes that take place in the peritoneal fluid secondary to endometriosis.

Endometriosis has to be considered as a uniquely human condition. Basic research in the different aspects of the disease would require unacceptable human experiments.

Therefore various animal models of endometriosis have been used to unravel problems that cannot be solved by research in human subjects. The third part of chapter 2 (2.4) comprises a review of the literature on animal research in endometriosis.

\section{References}

Ridley JH: The histogenesis of endomentosis. A review of facts and fancies.

Obstet Gyrecol Survey 23: $\|-35,1968$

Sampson. JA: Perforating hemorrhagic (chocolate) cysts of the ovary; their importance and especially their relation to pelvic aclenomas of endometrial type (adenomyoma of the uterus, rectovaginal septum, signaoid, etc.).

Arch Surg 3: 245-323, 1921

Sampson IA: Petitoneal endometriosis due to menstrual dissemination of endometrial tissue into the peritoneal cavility.

Am J Obstet Gynecol 14: 422-469, 1927

Sampsomi JA: The dewelopment of the implantation theory for the origin of peritoneal endometriosis. Am . Obster Gynecol 40: 549-557, 1940 


\section{Chapter 2}

\section{Review of the literature}

\subsection{Endometriosis}

\subsubsection{Pathogenesis and etiology}

\section{Pathogenesis}

Several theories have been developed to explain the pathogenesis of endometriosis. These theories, some of which have historical interest only, can be grouped in three categories as shown in Table 2.1 (Ridley, 1968).

According to the hypothesis of coelomic metaplasia (Meyer, 1919), endometriosis arises as a result of metaplasia of the peritoneal serosa. These metaplastic changes occur secondary to inflammatory processes (Meyer, 1919) or hormonal influences (Novak, 1931). The capacity of the peritoneal serosa to undergo various forms of Müllerian metaplasia has been demonstrated by Lauchlan (1972). Elements of tubal and endocervical mucosa are seen next to endometrial epithelium (Lauchlan, 1966; Schweppe, 1984b). There are seweral problems with the concept of metaplasia. Endometriosis only occurs if endometrium is present. In the few cases that were described in patients with Müllerian agenesis, (Rosenfeld and Lecher, 1981; Kühn et al., 1981) or 46,XY gonadal dysgenesis (Doty et al., 1980) the presence of en-

Table 2.1 Theories on the pathogenesis of Endometriosis, grouped according to Ridley, 1968

1. In situ development

Ectopic endometrium develops in situ fron local tissues

a. Germinal epithelium of the ovary; Waldeyer 1870

b. Mesonephric, Wolffian cell rests; Von Recklinghausen 1895

c. Embryonic cell rests, Müllerian origin; Russell 1899

d. Coelomic metaplasia; Meyer 1919

e. Metaplasia by hormonal stimulation; Novak 1931

f. Metaplasia by induction; Levander and Normann 1955, Merrill 1966

2. Transplantation

Transport of endometrium from the uterine cavity to ectopic locations

a. Implantation, retrograde menstruation; Sampson 1921

b. Implantation, mechanical transplantation; Greenhill 1942

c. Benign metastasis, continuous growth; Cullen 1908

d. Benign metastasis, lymphogenous; Halban 1925, Javert 1949

e. Benign meiastasis, haematogenous; Sampson 1927

3. Combination of the in situ development and transplantation theories 
dometrial or tubal tissue has not been ruled out completely. Furthermore, the disease is not present in males. Three cases of endometriosis have been described in males (Oliker and Harris, 1971; Pinkert et al., 1979; Schrodt et al., 1980). In these cases hypertrophy of remnants of the Mullerian ducts in the prostate, the utricle, developed after high-dose estrogen treatment. It is incorrect to call this endometriosis.

The ind uction theory (Levander and Normann, 1955; Merrill, 1966) is based on the assumption that substances, released by the uterine endometrium and transported by blood and lymph streams, induce the formation of endometriasis in different parts of the body. Levander and Normann (1955) implanted fresh and denaturated endometrium in the abdominal cavity of the rabbit. Histological observations were made daily for 7 days. They observed degeneration of the implant during the first four days, with cyst formation and epithelial differentiation characteristic of endometrium in the surrounding connective tissue during the next three days. Better results were obtained if the tissue was degraded before implantation. They concluded that dying endometrial tissue liberated specific substances activating undifferentiated mesenchyme to form endometrium. They found no evidence that living endometrial cells can grow out from an implant and establish cyst formation in the environment. On the other hand, both reactive granulation tissue in all its forms and true epithelial tissue arose as the result of different stimuli from the implants. Bernhard (1959) implanted decidual tissue, devitalized by trypan blue, subcutaneously in rabbits. In all implantation sites endometriosis developed. Merrill (1966) implanted viable and ischemic endometrial tissue within millipore filters intraperitoneally in the rabbit. The pore size of the filters was such that only chemical substances but no cells could pass. Endometrium-like epithelium and glands were observed in the connective tissue adjacent to the implants, suggesting that endometrium was capable to induce endometrial metaplasia. Since no endometrial stroma was found in the surrounding tissue, these changes do not meet the criteria for the definition of endometriosis.

The concept of endometriosis as a transplantation phenomenon involves different routes of dissemination. Iatrogenic, lymphogenic and hematogenic spread account for rare, extraperitoneal, locations of endometriosis (Javert, 1949, 1952; Scott et al., 1958; Dilts et al., 1965; Ridley, 1968; Hajdu and Koss, 1970; Hibbard et al., 1981). A more obvious route of dissemination is by the Fallopian tubes. According to the theory of implantation by retrograde menstruation endometriosis is a consequence of reflux of endometrial fragments through the Fallopian tubes during menstruation with subsequent implantation and growth on and into the peritoneum and the ovary (Sampson, 1921, 1940). The reflux implantation theory is based on the assumption that retrograde menstruation takes place and that viable endometrial cells reach the abdominal cavity and implant. Sampson based his theory largely on clinical and anatomical observations rather than on experimental evidence.

Goodall (1943) observed spill of blood in about $50 \%$ of laparotomies performed during menstruation. Blumenkrantz et al. (1981) reported that nine of eleven women 
undergoing peritoneal dialysis had blood in the dialysate during their menstrual period. Halme et al. (1984a) obtained peritoneal fluid by laparoscopy in the perimenstrual period. Blood was found in $90 \%$ of the patients with patent tubes. If the Fallopian tubes were occluded only $15 \%$ had evidence of blood in the pelvis. Retrograde spillage of menstrual blood was observed in $76 \%$ of women laparoscoped for sterilization during menses by Liu and Hitchcock (1986).

The viability of cast-off endometrial cells was proven by Keettel and Stein (1951). Willemsen et al. (1985) cultured uterotubal flushings obtained in the proliferative phase of the cycle. The capacity of the epitheloid cells to proliferate in vitro was demonstrated, supporting the seeding theory of Sampson. A difference exists, however, between retrograde menstruation and flushings of uterus and tubes in the proliferative phase of the cycle.

Te Linde and Scott (1950) reported that endometriosis developed in monkeys with artificial uteropelvic fistulas. They showed that menstrually discharged endometrial fragments had the capacity to implant in the abdominal cavity, although the theory that endometrial particles travel through the tubes and implant in the peritoneum was not confirmed by their experiment. A comparable case of endometriosis was reported in the human by Szlachter et al. (1980) secondary to the Estes procedure. Ridley and Edwards (1958) collected menstrual blood cluring the first 24 hours of menstrual flow and implanted these elements into the abdominal wall superficial to the fascia in women scheduled for laparotomy at a later stage for other gynecologic indications. In two patients endometriosis was demonstrated after three and six months. They concluded that the desquamated endometrial cells were viable and capable of establishing endometriosis in ectopic sites. Again, this did not prove the reflux implantation theory. The high prevalence of endometriosis in girls with congenital obstruction of the menstrual outflow tract supports the theory (Hanton et al., 1966; Schifrin et al., 1973; Goldstein et al., 1980; Baker et al., 1982; Sanfilippo et al., 1986). Jenkins et al. (1986) assessed the anatomic distribution of endometriosis by a laparoscopic study of the location of implants, adhesions and uterine position. They concluded that the anatomical distribution of the endometrial implants, governed by the effects of gravity and the proximity to the site of abdominal entry, lends support to the theory of transplantation by retrograde menstruation. The possibility of a factor in the menstrual debris inducing metaplasia can not be excluded by their findings.

In summary, not all locations of endometriosis can be explained by one single theory. The reflux implantation theory of Sampson (1940) is supported by the distribution of the lesions in the abdominal cavity (Jenkins et al., 1986), the demonstration of the viability of shed menstrual endometrium in tissue culture (Keettel and Stein, 1951), the high prevalence of pelvic endometriosis in girls with congenital menstrual outflow obstruction (Sanfilippo, 1986) and animal experiments in which endometriosis was induced by the creation of uteropelvic fistulas (Te Linde and Scott, 1950). The theory of endometrial metaplasia of the peritoneal serosa is not contradictory, but may be supplementary (Levander and Normann, 1955; Bernhard, 1959). En- 
dometrial cells may stimulate metaplasia after they have been transported to a susceptible tissue. The difference between the implantation and induction theories may be characterized by the statement that the former seeks the origin of endometriosis on the cellular, and the latter on the molecular level (Levander and Normann, 1955).

\section{Etiology}

Retrograde menstruation is seen in the majority of women, with and without endometriotic lesions (Halme et al., 1984a). Endometrial cells can be found in the peritoneal fluid in patients with and without endometriosis (Koninckx et al., 1980d; Willemsen et al., 1985; Bartosik et al., 1986). It remains unclear why not all women develop endometriosis. Likewise, the theory of in situ development offers an explanation of the pathogenesis of endometriosis, whereas the factors that initiate the ectopic growth are not known. Mechanical, hormonal, inflammatory, immunological and genetical factors may affect the etiology of endometriosis.

\section{Etiology, mechanical factors}

There are three possible routes of egress of menstrual outflow, the cervix and both Fallopian tubes. Changes in the anatomy of the genital tract, whether congenital or acquired, that impede menstrual outflow are considered to be an etiological factor in endometriosis (Fallas, 1956; Derryberry, 1966; Hanton et al., 1966; Schifrin et al., 1973; Goldstein et al., 1980; Baker et al., 1982; Olive and Henderson, 1987). Sanfilippo et al. (1986) reported on three patients with a uterus didelphys with unilateral imperforate vagina with extensive endometriosis. After creating a vaginal window into the blind pouch the endometriosis regressed. Changes in the genital tract that predispose to menstrual reflux have been described in women with maternal diethylstilbestrol (DES) exposure. Although the prevalence of endometriosis and cervical stenosis appears to be high in infertile women exposed in utero to DES, a significant association could not be established (Stillman and Miller, 1984).

Treatment of ectropion by cautery, cryotherapy or $\mathrm{CO}_{2}$ laser, if carried out too far into the cervical canal can result in stenosis above the external os, with obstruction of natural drainage and subsequent potential retrograde menstruation (Ranney, 1980).

Ayers et al. (1985) investigated possible anatomic-mechanical predispositions for increased endometrial backflow. During laparoscopy transcervical pressure profiles were obtained of the uterotubal junction. From the results obtained, they concluded that pelvic endometriosis was associated with significant uterotubal hypotonia when compared to normal controls or non-endometriosis infertility patients. They hypothesized that this hypotonia could predispose to retrograde menstruation. Along the same line Bartosik et al. (1986) showed, by flushing the Fallopian tubes, that endometrial cells were refluxed more often into the peritoneal cavity of women with endometriosis than in those of the control group, suggesting a deficient uterotubal control mechanism in patients destined to acquire endometriosis. The result of this study indicated that endometrial tissue can be flushed through the Fal- 
lopian tubes. The relevance of these findings remains to be established where spontaneous retrograde menstruation is seen in the majority of women.

In short, changes in the genital tract that favor menstrual reflux either congenital or secondary to surgical manipulation are predisposing factors for the development of endometriosis. The volume of regurgitated menstrual debris is probably important (Olive and Henderson, 1987). Women with short cycle lengths and menses for a week or longer have been reported to have greater than twice the risk of developing endometriosis. The risk for endometriosis may relate to menstrual factors that predispose to greater pelvic contamination with menstrual products (Cramer et al., 1986).

\section{Etiology, hormonal factors}

Endometriosis is a disease of the reproductive years, it is nonexistent in premenarcheal years, while menopause and castration lead to regression of the lesions. The influence of hormones on the development of endometriosis has been postulated by Novak (1931). Cyclic ovarian hormone secretion seems necessary for the growth or proliferation of ectopic endometrial tissue. The existence of hormonal modulation of endometriosis is supported by the presence of estrogen and progesterone receptors in endometriotic lesions (Tamaya et al., 1979; Jänne et al., 1981; Gould et al., 1983; Vierikko et al., 1985). Binns and Banerjee (1983) documented a case of endometriosis in a patient with Turner's syndrome that developed after 10 years of estrogen treatment. The view that estrogens and progesterone have an effect on the development of endometriosis was supported by Meigs (1960). He found more patients with endometriosis among women, who postponed childbearing to a later age. He postulated that continuous action of the ovarian hormones for years in a row, without pregnancies, causes endometriosis.

A distinction should be made between the influence of hormones in initiating and in maintaining endometriosis. The initiation of growth of endometriosis in the monkey has been proven to be independent of estrogens (Scott and Wharton, 1957; DiZerega et al., 1980). Scott and Wharton (1957) showed that the best growth of endometrial implants in castrated monkeys was achieved when they were treated with constant estrogen and intermittent progesterone administration. For maintenance of long-term viability of endometrial implants either estradiol or progesterone, alone or in combination, was required (DiZerega et al., 1980). It should be kept in mind that these studies of the influence of estrogens and progesterone were performed in an animal model with surgically implanted endometrium.

Brosens et al. (1978) found a lower concentration of estradiol and progesterone in the peritoneal fluid of patients with endometriosis, compared to patients without the disease. This lower hormonal content was accompanied by a higher number of luteinized unruptured follicles in endometriosis patients. They hypothezised that the lower concentration of progesterone allows proliferation and implantation of endometrial cells (Koninckx et al., 1980c). 
Sampson (1927b) postulated that the regurgitated menstrual blood acts as an irritant to the peritoneal surfaces and thus facilitates implantation.

Ohtsuka (1980) and Malick (1982) hypothesized that a change in intraabdominal fibrinolysis could play an etiological role in the development of endometriosis and the adhesions seen in this disease. They observed a decreased fibrinolytic activity of the mesothelial cells lining the peritoneal cavity in patients with endometriosis. The fibrin exudate developing as a consequence of peritoneal damage by retrograde menstruation combined with the decreased fibrinolytic activity might lead to adhesion formation. In these adhesions endometrial cells might easily implant. Batzofin et al. (1985) measured peritoneal fluid fibrinolytic activity in patients with and without endometriosis. They could not detect differences and concluded that, if altered fibrinolysis plays a role in the etiology of endometriosis, these differences possibly can be found on tissue level rather than in the peritoneal fluid.

\section{Etiology, immunological factors}

Dmowski et al. (1981) studied the cell-mediated immune response to autologous endometrial antigens in monkeys with spontaneous endometriosis. They found a decrease in the cell-mediated immune response, although the monkeys were overall immunologically competent. They suggested that endometrial cells, after transtubal migration to the peritoneal cavity, only implant in women with a specific alteration in cell-mediated immunity. Steele et al. (1984) studied general and specific immune function in women with endometriosis. Nonspecific parameters of the immune system were the same in patients with and without endometriosis. Both لymphocyte stimulation, the afferent $\operatorname{limb}$ of cellular immunity, and cytotoxicity, the predominant efferent mechanism, were evaluated. The stimulation by autologous endometrial antigen of lymphocytes was reduced. The specific immune response, $T$ lymphocyte-mediated cytotoxicity to autologous endometrial cells was significantly reduced, suggesting an immunological basis for development of endometriosis. Specilfic cellular mechanisms aimed at limiting ectopic growth of the endometrial tissue were supposedly impaired in women with endometriosis. The degree of this impairment seemed to be directly related to the severity of the disease. Startseva (1980) reported reduced $\mathrm{T}$-cell immunity and an increase in $\mathrm{B}$-cell reactivity in women with endometriosis, indicating that both cell-mediated and humoral immunity are altered in endometriosis. Weed and Arquembourg (1980) detected $C_{3}$ and IgG deposits in the uterine endometrium in patients with endometriosis and suggested an alteration in humoral immunity. Wood et al. (1983) reported that in Rhesus monkeys after total body exposure to proton irradiation the prevalence of endometriosis more than doubled compared to normal controls. They suggested that suppression of the immune system facilitated the development of endometriosis. Gleicher et al. (1984) studied the relative number of the effector cells of cell-mediated immunity, the different types of lymphocytes, in the peripheral blood of patients with endometriosis. No difference was found in relative numbers of $T$-, helper $T$-, suppressor $T$ - and 
B-lymphocytes in the peripheral blood of patients with endometriosis compared to patients without the disease. They stated that immune function is, however, only partially dependent on cell counts, and, probably more so, on the level of function of individual cell populations. In contrast to these authors Badawy et al. (1987) reported increased numbers of $\mathrm{T}$ - and B-lymphocytes in the peripheral blood and peritoneal fluid of patients with endometriosis compared to controls. Furthermore, the ratio helper $T$-suppressor $T$-lymphocytes was significantly increased in patients with endometriosis. They suggested that these results lend support to the concept of cell-mediated autoimmune reactions in endometriosis.

Olive and Henderson (1987) combined the theories of retrograde flow and altered cell-mediated lymphocyte cytotoxicity. They suggested that endometriosis develops in women with either an increased retrograde menstruation secondary to outflow obstruction, or an inability to remove the debris.

These observations suggest that the immune system, humoral and cell-mediated, is at least altered in patients with endometriosis. Implantation or rejection of endometrial cells arriving in the abdominal cavity through the Fallopian tubes may be controlled by the cell-mediated immune system. Specific defects in the cell-mediated immunity would allow implantation of endometrial cells.

\section{Etiology, genetical factors}

A hereditary tendency to develop endometriosis has been reported (Henriksen, 1953; Frey, 1957; Van der Velden, 1961). Simpson et al. (1980b) showed a significantly higher prevalence of endometriosis in first degree relatives of patients with endometriosis than in a similar group related to their husbands. Of 123 patients with endometriosis, $5.8 \%$ of female sibs and $8.1 \%$ of mothers were similarly affected. Only $1 \%$ of the husbands' female sibs and only $0.90 \%$ of the husbands' mothers had endometriosis. From their results they calculated that a first degree relative of a patient with endometriosis has a chance of $7 \%$ to develop the disease.

Polygenic/multifactorial inheritance seemed to them the most likely genetical etiology. Their results were confirmedl by Lamb et al. (1986).

Steele et al. (1984) performed HLA-A and HLA-B typing of patients with endometriosis to examine the possibility of a link between these antigens and the disease. No increase nor decrease of particular antigens was observed. From these findings they concluded that further evidence of the multifactorial mode of inheritance was offered.

Simpson et al. (1984) studied 53 patients with endometriosis. There was no association between any HLA antigen (A, B, C, DR) and endometriosis. They concluded that HLA determinations are unlikely to detect endometriosis in relatives at increased risk.

Moen et al. (1984) typed 100 patients for HLA-A, -B and -C, and 24 also for HLADR. No significant deviations from the the antigen frequencies in a normal population were found. They concluded that the development of endometriosis does not seem to be associated with HLA-A, -B, -C or -DR antigens. 


\subsubsection{Classification}

Classification of endometriosis is based on direct observation of the lesions by laparoscopy or laparotomy. The purpose of a classification system is to specify the relationship between extent of disease and outcome of therapy and to create homogeneous patient groups for comparison of treatment outcomes.

Acosta et al. (1973) introduced a staging system based on the site of the endometriotic lesions and the extent of the adhesions. Three classifications, mild, moderate and severe, were thus formed. This classification system proved to be of value in the prognosis of pregnancy after conservative surgery (Acosta et al., 1973). Subsequently Kistner et al. (1977) and Buttram (1978) proposed classification systems. As none of these classification systems attained general acceptance, a committee appointed by the American Fertility Society devised a classification system (1979). In the revised American Fertility Society classification of endometriosis (1985) a more comprehensive point system to differentiate between ovarian and peritoneal disease was employed. In addition, differentiation between superficial and deep endometriosis of peritoneum and ovaries was provided. The characterization of adhesions was more detailed, allowing for differentiation between filmy and dense adhesions. Brosens et al. (1985) pointed at problems in using classification systems in evaluating medical therapy. They stated that the effect of treatment on the staging of endometriosis cannot be compared under two different conditions of ovarian activity. If the second laparoscopy upon completion of the treatment is performed in the presence of weak or completely suppressed ovarian activity, the peritoneal lesions seem smaller than they would be in the presence of normal cyclic ovarian activity. In that case hemorrhage, secretion, inflammatory reaction or fibrosis increase the size of the implants considerably. They also questioned the value of assessing the depth of the peritoneal and ovarian lesions, since in their view there is no reason to believe that deep implants have a worse prognosis in infertility than superficial implants. Olive and Haney (1986) pointed at some problems inherent to all classification systems. They stressed that the parameters used are heterogeneous. Staging includes such different and incomparable items as activity of disease, residual or inactive disease, adhesions, and encapsulated ovarian endometriomata. Moreover, there is no distinction between primary and recurrent disease. According to these authors the assumption that more disease results in lower pregnancy rates has never been verified. They suggested that the use of multivariate logistic regression analysis would indicate the probability that a given location of the endometriotic lesion or the quantity of disease will be associated with pregnancy.

It can be concluded that no classification system serves the purpose of specifying a relationship between extent of disease and outcome of therapy. The major gain of any classification system is that it demands careful and systematic inspection of the abdominal cavity. 


\subsubsection{Epidemiology}

\section{Prevalence}

The true prevalence of endometriosis in the general population is unknown. Many women with endometriosis are asymptomatic and therefore unaware of its presence. Although endometriosis is associated with infertility, women with endometriosis conceive without treatment, and remain undiagnosed. Furthermore, the prevalence depends heavily on the diagnostic tools used, the population studied, the investigator's level of interest in and knowledge of the disease. Consequently the figures obtained do not represent the prevalence of the disease in the general population. In 1953 Scott stated: "If serial section of all pelvic tissue were feasible might not all 40 year old women with patent tubes and normal menstrual cycles regardless of parity reveal some endometriosis?"

In the era before laparoscopy became available, the figures for the prevalence were based on large series of laparotomies. Figures between 5.6 and $52 \%$ were found depending on the indication for laparotomy (Ranney, 1970; Kistner, 1975; Williams and Pratt, 1977; Nikkanen and Punnonen, 1984). Endometriosis was found to be the only cause of infertility in $58 \%$ of 968 consecutive patients undergoing major surgery for the preservation or enhancement of fertility (Buttram and Reiter, 1985b).

The prevalence of endometriosis as diagnosed by laparoscopy varies depending on the indication for the laparoscopy, i.e. tubal sterilization, chronic pelvic pain, unexplained infertility, request for reversal of sterilization.

Hasson (1976) reviewed the findings of 10 studies in 3346 patients who underwent laparoscopy for various reasons; the prevalence of endometriosis ranged from 4 to $33 \%$.

The prevalence of endometriosis as diagnosed by laparoscopy was 1.4 to $5 \%$ in patients undergoing tubal sterilization (Hasson, 1976; Drake and Grunert, 1980a; Strathy et al., 1982; Bouckaert, 1984; Trimbos et al., 1984). In a comparable group of patients this figure rose to 10 to $18 \%$ if special attention was paid to diagnose endometriosis (Kresch et al., 1984; Dodge et al., 1986; Moen, 1987).

Endometriosis was diagnosed at laparoscopy for chronic pelvic pain in 8.5 to $47 \%$. (Chatman, 1976; Goldstein et al., 1980; Kresch et al., 1984; Peters et al., 1986). Endometriosis was diagnosed at laparoscopy in patients with unexplained infertility in 21 to 51\% (Peterson and Behrman, 1970; Hasson, 1976; Goldenberg and Magendantz, 1976; Katayama et al., 1979; Drake and Grunert, 1980a; Strathy et al., 1982). Endometriosis is not a chance finding in women who have undergone tubal sterilization (Fakih et al., 1985); in women requesting reversal of sterilization pelvic endometriosis was diagnosed in 18\% (Dodge et al., 1986). This high prevalence of endometriosis in women with occluded tubes seems difficult to understand if endometriosis is related to retrograde menstruation. These cases of endometriosis were either missed during the laparoscopy for sterilization, or they developed from early non-visible endometriosis. 
Kistner (1975) reported a median age of 37 with $15 \%$ of patients being under 30 . The age at diagnosis by surgery does not reflect age at first recognition of the disease. More recent studies indicated an average age of 27 to 29 at diagnosis (Buttram, 1979; Sulewski et al., 1980; Rock et al., 1981; Wheeler and Malinak, 1981). The average age of patients with mild, moderate and severe endometriosis was not different in 206 patients operated upon by Buttram (1979). Therefore it seems that the age at diagnosis rather reflects the age at which patients seek help than the age at which the disease occurs. Of equal importance is the age at which physicians are willing to perform a laparoscopy in patients presenting with pelvic pain. The youngest histologically confirmed case of pelvic endometriosis in the literature may be the 10.5 year old girl reported by Goldstein et al. (1980).

In adolescents endometriosis was reported, associated (Hanton et al., 1967; Schifrin et al., 1973; Goldstein et al., 1980; Baker et al., 1982; Sanfilippo et al., 1986) or not associated with menstrual outflow obstruction (Moore et al., 1967; Bullock et al., 1974; Chatman and Ward, 1982).

A few cases of recurrence or reactivation of endometriosis in postmenopausal women were reported (Kempers et al., 1960; Punnonen et al., 1980; Djursing et al., 1981; Huybregts et al., 1984).

\section{Ethnic factors}

Initially, endometriosis was thought to be solely a disease of white women (Ridley, 1968). Lloyd (1964) reviewed 803 cases of major gynecologic surgery; the prevalence of endometriosis was $6.9 \%$ in black and $7.7 \%$ in white women. Chatman (1976) reported an prevalence of $21 \%$ in black women laparoscoped for various indications. A slightly higher rate of endometriosis was reported in Japanese than in Hawaiian and Caucasian patients (Miyazawa, 1976). Moeloek et al. (1984) reported a prevalence of $32 \%$ in patients in Jakarta, as diagnosed by laparoscopy for infertility reasons.

Reviewing the studies on ethnic influences it can be concluded that the racial comparisons are confounded by socioeconomic status, age distribution, availability of medical care, access to contraception, cultural differences regarding childbearing patterns, attitudes toward menses and pain and health care-seeking behavior of patients. The differences in the characteristics of available medical care may alter the probability that existing disease will be diagnosed (Houston, 1984). Similarly, the much quoted psychological characteristics linked to the typical patient with endometriosis, i.e. overanxious, intelligent, egocentric and a perfectionist (Kistner, 1975), are probably related to the above-mentioned confounding variables.

\subsubsection{Symptomatology}

The characteristic signs and symptoms associated with endometriosis are listed in Table 2.2. The relative frequency of each of the symptoms depends heavily on the 
Dysmenorrhea

Dyspareunia

Chronic pelvic pain

Infertiliey

population studied. Between 25 and $30 \%$ of women found to have endometriosis at laparoscopy are completely asymptomatic (Kistner, 1984).

The etiology of dysmenorrhea associated with endometriosis is not clear. Direct peritoneal inflammation and irritation by ectopic menstrual debris, mechanical stretching of peritoneal surfaces or hypercontractility secondary to prostaglandins produced by ectopic endometrium may be responsible. Dysmenorrhea is reported in 45 to $94 \%$ of endometriosis patients (Audebert et al,, 1979; Greenblatt and Tzingounis, 1979; Buttram, 1979; Biberoglu and Behrman, 1981). The presence of retrograde spilling of blood in patients with endometriosis was not related to the presence of dysmenorrhea (Liu and Hitchcock, 1986). The severity of pain did not correlate with the severity of the disease in 206 patients studied by Buttram (1979). This discrepancy between pain and severity of the disease as judged by laparoscopy may well be related to different types of endometriosis, intra- and retroperitoneal. In this concept retroperitoneally located endometriosis will be responsible for abdominal pain (Vasquez et al., 1984).

Dyspareunia is a common symptom and may play some role in the reduced fertility (Kistner, 1975). The occurrence but not the degree of dyspareunia correlated with the extent of the disease in the patients studied by Buttram (1979).

Unusual symptoms are catamenial pneumothorax or hemoptysis (Lattes et al., 1956; Foster et al., 1981; Hibbard et al., 1981; Slasky et al., 1982), subarachnoid hemorrhage (Lombardo et al., 1968), compression of the sciatic nerve (Bergqvist et al., 1987b) and acute abdomen secondary to rupture of an endometriotic cyst (Ranney, 1970 ).

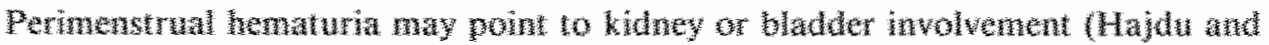

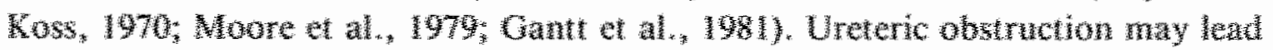
lo kidney loss (lavbe et al, 1985).

The tuterature on the association between endometrosis and intertily will be reviewed in paragraph 2.2

\subsubsection{Dirgnosis}

The dagnosis of endometriosis showd be suspected by history, comoborated by wewic examination and verifed by endoscopy and biopsy (Kistner at at, 1984). The cincal dagnosis may be estabixhed in 30 to $85 \%$ of the cases before surgery (Cray,

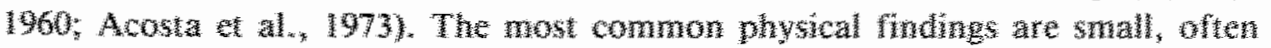


tender, fixed nodules, which may be felt behind the uterine cervix. Conceivably, tenderness of these nodules is more likely to be demonstrated if the pelvic examination is performed during the late luteal phase of the menstrual cycle (Goldstein et a]., 1980). The nodules consist of inflammation and scarring around small endometriomata of the cul-de-sac, the uterosacral ligaments, the posterior peritoneal surface of the cervix, or the anterior peritoneal surface of the rectosigmoid bowel (Ranney, 1980). Nodularity of the cul-de-sac and the uterosacral ligaments was found in approximately $25 \%$ of patients with mild endometriosis, $30 \%$ of patients with moderate and $50 \%$ of patients with severe disease (Buttram, 1979). A tender, semifixed, firmly cystic enlargement of one or both ovaries, usually in the $3-4 \mathrm{~cm}$ range and seldom exceeding $5 \mathrm{~cm}$ in diameter may be palpated (Ranney, 1980). Fixed retroversion or retroflexion of the uterus is a variable finding with a frequency of approximately 40 to $50 \%$ in women with endometriosis, related to the severity of the disease (Buttram, 1979).

Ultrasound proved to be of little help in diagnosing endometriosis. Endometriomata cannot be distinguished from other pelwic masses by ultrasound. (Goldman and Minkin, 1980; Friedman et al., 1985).

If extensive endometriosis of the gastrointestinal tract is suspected, $\mathrm{X}$-ray examination of the colon by barium enema may be performed, but is never conclusive (Gray, 1966). Intravenous pyelography or renal ultrasound may reveal hydronephrosis or renal atrophy secondary to ureteral obstruction (Langmade, 1975; Moore, 1979; Laube et al., 1985).

Chihal et al. (1986) reported on the use of serum endometrial antibodies as an aid in the diagnosis of endometriosis. A significant elevation of antibodies was found in $74 \%$ of patients with endometriosis, whereas fertile control subjects consistently had normal baseline antibody titers. There was no correlation between the endometrial antibody titers and the stage of endometriosis. They also suggested that sequential determination of endometrial antibody titers could be helpful in assessing the efficacy of pharmacological therapy and the possible recurrence in patients with the disease.

$\mathrm{Ca}-125$ is a glycoprotein with a molecular weight of approximately 200,000 daltons that is expressed on the cell surface of some derivatives of embryonic coelomic epithelium. Bast and coworkers (1983) applied an immunoradiometric assay to detect CA-125 in serum. They found that $82 \%$ of patients with ovarian carcinoma, but less than $1 \%$ of apparentlly healthy controls had elevated serum levels of CA-125. Elevated CA-125 values in serum have been observed in benign conditions as well, e.g. in endometriosis, acute pelvic inflammatory disease, unexplained infertility, in pregnant women and during menstruation (Pittaway and Fayez, 1986). Patients with advanced endometriosis have significantly elevated CA-125 serum levels, compared with normal controls (Barbieri et al., 1986). The level of CA-125 appears to be related to the severity of the disease (Pittaway and Fayez, 1986). The sensitivity of the test, however, appears to be too low for it to be of value in screening patients for endometriosis (Patton et al., 1986; Barbieri et al., 1986; Pittaway and Fayez, 


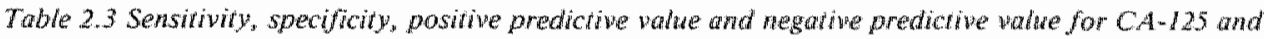
endometrial antibodies determinations and prewahence of endometriosis

\begin{tabular}{|c|c|c|c|c|c|c|}
\hline & sens & spec & ppv & npks & prew & reference \\
\hline$C A-125>35 U / m l$ & 0.14 & 0.93 & 0.50 & 0.69 & 0.32 & Palton et al., 1986 \\
\hline $\mathrm{CA}-125>35 \mathrm{U} / \mathrm{ml}$ & 0.17 & 0.98 & 0.83 & 0.63 & 0.41 & Barbieri el al., 1986 \\
\hline $\mathrm{CA}-125>16 \mathrm{U} / \mathrm{ml}$ & 0.54 & 0.91 & 0.79 & 0.76 & 0.39 & Plitaway and Fayez, 1986 \\
\hline Endom Antibodies + & 0.74 & 1.00 & 1.00 & 0.74 & 0.58 & Chihal at al. 1986 \\
\hline
\end{tabular}

1986). CA-125 may be a useful marker for following the course of disease in endometriosis (Patton et al., 1986).

Table 2.3 shows the sensitivity, the specificity, the positive predictive value, the negative predictive value and the prevalence of endometriosis for the determination of CA-125 at two cut-off levels and for the determination of serum endometrial antibodies, as calculated from the data of Patton et al. (1986), Barbieri et al. (1986), Pittaway and Fayez (1986) and Chihal et al. (1986). Table 2.3 shows a low sensitivity for the CA-125 determination in serum, which is, as expected, higher at a lower cutoff level. The sensitivity for the determination of serum endometrial antibodies is higher than that for CA-125 at either cut-off level. Endometrial antibodies are more specific for endometriosis than the antibodies against CA-125, as shown above. The sensitivity remains too low for it to be of value in the screening for endometriosis in the general population, or even in an infertility population.

Laparoscopy remains the mainstay in diagnosing endometriosis. It has to be kept in mind that laparoscopy is a surgical intervention with certain inherent risks (Peterson et al., 1983; Levy et al., 1985; Bergqvist and Bergqvist, 1987a). Laparoscopy allows grading and classification of the disease and biopsies can be taken to confirm the diagnosis by histology. A high level of suspicion has been shown to be of influence in diagnosing endometriosis during laparoscopy (Dodge et al., 1986). Familiarity with the different macroscopic appearances of early minimal endometriosis (vide infra) is of equal importance (Goldstein et al., 1980; Redwine, 1985). The phase of the cycle during which laparoscopy is performed is important. Liu and Hitchcock (1986) diagnosed endometriosis in $43 \%$ of patients undergoing laparoscopy for sterilization during menstruation. This figure is manifold higher than the normally quoted 1.5 to $5 \%$ for patients undergoing sterilization (Hasson, 1976; Drake and Grunert, 1980a; Strathy et al., 1982; Bouckaert, 1984; Trimbos et al., 1984). During menstruation the productive activity of the lesions is apparently at its highest level. This changes the macroscopic appearance of these lesions considerably.

Brosens et al. (1985) stressed the fact that laparoscopy for staging of endometriosis should be performed in the presence of normal ovarian activity, since the implants are evaluated in terms of activity rather than number of cells. Evers (1987) compared the number and the cumulative size of the implants before and after treatment in two groups of patients. In the first group the second look laparoscopy was per- 
formed at the end of the last treatment cycle, in the second group it was performed in the follicular phase of the second menstrual cycle after the end of treatment. The differences in the parameters measured between the two groups were statistically significant. He pointed out that the second-look laparoscopy for evaluation of the result of medical treatment of endometriosis should not be performed during ovarian suppression.

To ensure complete evaluation, inspection of the pelvis in a standlardized clockwise or counterclockwise fashion is necessary. Number, size and location of endometriotic implants, plaques, endometriomata and/or adhesions should be recorded (RAFS, 1985). In a study by Jenkins et al. (1986) the ovaries were shown to be most commonly involved, followed by the anterior vesicouterine fold, the posterior culde-sac and the uterosacral ligaments.

At laparoscopy, early ovarian endometriotic lesions appear on the surface of the ovary as small reddish-blue implants, later cysts appear that seldom reach a diameter of more than $5 \mathrm{~cm}$. The cysts are filled with a brown or black fluid. Endometriosis should be suspected when adhesions or fixed ovaries are found, together with normal Fallopian tubes. Not infrequently, manipulation of the ovaries reveals endometriosis either on the undersurface of the ovary or on the adjacent peritoneum of the ovarian fossa, a predilection place for endometriosis. Sometimes associated adhesive disease or large ovarian endometriomata may obscure visualization to the extent that evaluation is not possible.

A biopsy of suspected peritoneal lesions with subsequent histological examination confirms the diagnosis in $72 \%$ of the cases (Portuondo et al., 1982). If light microscopy is combined with scanning or transmission electron microscopy this figure rises to 83-85\% (Vasquez et al., 1984; Murphy et al., 1986).

In endometriomata a histological diagnosis of endometriosis based on the presence of endometrial glands and stroma is not always possible, since the epithelial lining of a cyst may have lost its typical appearance. Due to the cyclic hormonal influences bleeding into the lesions can occur with considerable tissue distortion and subsequent adhesions. Histologically these areas cannot be readily diagnosed as endometriosis, since endometrial glands and stroma are not recognizable. In such cases the presence of granulation tissue, fibrous tissue and hemosiderin-laden macrophages are indicative of the diagnosis of endometriosis.

The laparoscopic, macroscopic, appearance of peritoneal endometriosis varies considerably. The laparoscopic diagnosis of peritoneal endometriosis is traditionally made on dark pigmented spots on the peritoneum covering the uterosacral ligaments and cul-de-sac. It can be argued that the black pigmented areas, the classic picture of endometriosis, are the late consequences of the cyclic growth and regression of the endometriotic lesions. One should always keep in mind that at laparoscopy only the sequelae of endometriosis are seen and recognized as endometriosis, such as hemorrhage, adhesions, accumulation of fluid and inflammatory reaction.

Goldstein et al. (1980) noted in adolescents that early endometriosis did not always appear as the characteristic black lesions, but sometimes as hemorrhagic areas. 
Redwine $(1985,1987)$ classified endometriotic implants by color(s) of first impression. He described clear papules, red, white, yellow or black. When specific types of lesions were clustered, an evolutionary change in appearance of endometriosis with advancing age was suggested. The typical black lesions occurred at a later stage in the evolution of the disease.

Jansen and Russell (1986b) reported on the existence of unpigmented endometriosis. They defined several distinctive appearances of these endometriotic lesions: white opafication of the peritoneum, glandular excrescenses on the peritoneal surface, red flamelike lesions of the peritoneum and isolated or otherwise unexplained adhesions between the undersurface of the ovary and the ovarian fossa. They also documented progression from nonpigmented to pigmented lesions, confirming the biologic continuum from nonpigmented to pigmented endometriosis.

Vernon et al. (1986) correlated the macroscopic appearance of endometriotic lesions (petechial or reddish, intermediate or brown and powderburn or black) with prostaglandin $F$ synthesis of these lesions. They found that the petechial lesions were biochemically more active than the black lesions.

Peritoneal defects of the type described by Allen and Masters (1955) are frequently associated with endometriosis (De Brux et al., 1968; Chatman, 1981; Chatman and Zbella, 1986). Brosens et al. (1984b) documented microscopic implants of endometriosis on the surface of the peritoneum by scanning electron microscopy (SEM) in patients with unexplained infertillity in whom no endometriosis was seen at the time of laparoscopy. Likewise, Murphy et al. (1986) diagnosed endometriosis by SEM in $25 \%$ of specimens thought to represent normal mesothelium at laparoscopy. Vasquez et al. (1984), combining the techniques of scanning electron microscopy and light microscopy, revealed three topografically and morphologically different types of endometriosis: intraperitoneal endometriotic polyps with no glandular openings but associated with deeper endometriotic glands and stroma; intraperitoneal endometriotic foci with surface epithelium, glands and stroma; and retroperitoneal small lesions with few glands and scant stroma.

From these observations on the laparoscopic appearance of endometriosis it can be concluded that within the AFS classification of mild endometriosis there is a wide variation in severity of lesions, ranging from submicroscopic retroperitoneal and intraperitoneal lesions to a variety of macroscopically visible lesions. The least impressive lesions are, biochemically, probably the most active (Vernon et al., 1986). Future research might very well learn that the proportion of these "minor macroscopic" lesions in a given patient correlates much better with the severity of the disease than do the stages of the AFS classification which are presently employed to characterize endometriosis. Within individual lesions different histological patterns are found (Vasquez et al., 1984; Schweppe, 1984b). This heterogeneity corresponds well with conflicting reports on peritoneal fluid prostaglandins in mild endometriosis and with the apparent lack of correlation between severity of disease and symptoms. The relative proportion of endometrial glands, stroma and vascularization in the inclividual endometrial implant will depend on previous episodes of bleeding, 
resorption of blood pigments, inflammatory reaction and scarring. Cornillie et al. (1.986) showed that endometriotic secretory changes were different from those seen within the uterine endometrium. Full secretory transformation of endometriotic glands was lacking and a wide variation of cellular differentiation was seen within different foci as well as within the same implant. They also showed that secretory differentiation of endometriotic epithelial cells was present only when the ectopic stroma had a well-developed microvasculature, with blood capillaries present near the glandular epithelium. They suggested that the different microvascular supply of eutopic and ectopic endometrium might account for the differences in hormonally modulated synthesis of steroid receptors and tissue differentiation (Cornillie et al., 1986).

The differences in histological patterns and cyclicity of the ectopic foci, in contrast to eutopic endometrium, correlate with reports of variability in concentration of steroid receptors (Tamaya et al., 1979; Jänne et all, 1981; Gould et al., 1983; Vierikko et al., 1985). Consequently a heterogeneous response to hormonal changes and hormonal herapy can be expected from the different lesions.

Considering these features of mild endometriosis Brosens et al. (1981, 1984a) proposed the Leuven classification of endometriosis. In this classification a clear distinction has been made between the uncomplicated stage and the complicated stage of endometriosis. The uncomplicated stage includes intraperitoneal and retroperitoneal lesions; in the complicated stage the extent and degree of distortion of the pelvic organs can be graded according to a point system as proposed by the AFS. These two stages represent two different diseases, with a different therapeutic approach and a different prognosis with regard to fertility.

\subsubsection{Management}

The management of endometriosis depends on the stage of the disease, the severity of symptoms, the age of the patient and the presence of infertility. Goals of treatment are relief from pain and restoration of childbearing potential. Therapeutic modalities include medical and surgical treatment or a combination of the two. It is beyond the scope of this thesis to discuss in detail the different treatment possibililies. Recent comprehensive reviews on endometriosis treatment are those by Schweppe (1984a), Buttram and Reiter (1985b), Schmidt (1985), Barbieri and Ryan (1985), Daniell (1985), Gordts et al. (1984), Olive and Haney (1986) and Andreyko et al. (1987).

Before the, now widespread, use of laparoscopy only symptomatic endometriosis was treated. Asymptomatic endometriosis diagnosed by laparoscopy is now commonly treated as well, mainly in infertile women. Controversies exist on the necessity to treat asymptomatic mild endometriosis in infertile patients in order to improve their fertility chances (Seibel et al., 1982; Hull et al., 1987; Thomas and Cooke, $1987 \mathrm{~b}$ ). These controversies are related to the discussion whether endometriosis is causally related to infertility. 
Another controversy is the duration of medical therapy. A long-term estrogenprogestogen therapy was based on the supposedly beneficial effect of pregnancy on endometriosis (Kistner, 1975). Conversely, a 2 -month therapy was shown to produce a stronger effect on the implants than a 4-month therapy in a small group of patients (Brosens et al., 1987). It needs further investigation to find out whether the advantages of a short-term medical therapy are supported by increased pregnancy rates.

Less debate exists on the value of treating mild endometriosis in order to prevent deterioration of the disease (Devereux, 1963; Ranney, 1970; Andrews, 1980; Schmidt, 1985; Thomas and Cooke, 1987a), although it has to be emphasized that the natural course of the disease is far from clear.

Reviewing the literature on therapeutic approaches of endometriosis-associated infertility Olive and Haney (1986) found that many medical treatments have proven effective in combating the histological manifestations of endometriosis, but that there is no evidence validating the efficacy of a single medical approach in treating infertility. Regarding surgical therapy they stated that in the presence of anatomical distortion secondary to adhesion formation surgical intervention is crucial to enhance the chances of conception. The value, however, of removal of implants by excision, cauterization or laser vaporization to overcome infertility has yet to be demonstrated. Randomized clinical trials with appropriate controls should be instituted to assess the different therapeutic options for endometriosis-associated subfertility.

In summary, it can be concluded with regard to the management of endometriosisassociated infertility that patients with recently diagnosed mild endometriosis can be managed expectantly for a period of time, provided that every effort is made to correct additional infertility factors (Schenken and Malinak, 1982; Seibel et al., 1982; Portuondo et al., 1983; Kable and Yussman, 1985; Olive et al., 1985a; Hull et al., 1987).

\subsubsection{Recurrence}

Recurrence of endometriosis after conservative surgical treatment varies from $7 \%$ to 47\% (Green, 1966; Andrews and Larsen, 1974; Hammond et al., 1976; Andrews, 1980; Wheeler and Malinak, 1983). At the time of surgery it is not possible to remove all endometriotic lesions. Microscopic endometriosis, not discernible to the naked eye, wil! remain (Acosta et al., 1973; Murphy et al., 1986; Dmowski, 1987). Recurrence of endometriosis after medical therapy varies from $29 \%$ to $51 \%$ (Dmowski and Cohen, 1978; Greenblatt and Tzingounis, 1979; Moore et al., 1981; Barbieri et al., 1982; Dmowski et al., 1982; Buttram, 1985a; Schmidt, 1985). The difference may be explained by the length of the follow-up period and by the way recurrence is diagnosed, i.e. by recurrence of signs and symptoms of endometriosis, by laparoscopy with or without histological confirmation or by the need to perform a repeat laparotomy. 
If is not clear whether the recurrence noted after cessation of treatment represents real recurrence, i.e. de novo formation, or rather persistence of endometriotic lesions. Biopsy specimens taken during repeat laparoscopies at the end of a treatment course for endometriosis repeatedly show occult inactive endometriosis (Steingold et al., 1987) or active disease, even without laparoscopic (macroscopic) signs of endometriosis (Dmowski and Cohen, 1975; Schweppe, 1984c; Murphy et al., 1986). In a prospective study Wheeler and Malinak (1987) showed in 60 patients that in half of the patients so-called recurrence of endometriosis after conservative surgery actually represented persistence of disease.

Schweppe (1984c) showed that persistent disease after 6 months treatment was correlated with the histological differentiation of the endometriotic lesions at the initial diagnostic laparoscopy. Of the highly differentiated endometriotic lesions two-third disappeared after six month treatment, while of the least differentiated lesions threequarter of the cases persisted. It has to be kept in mind that, since most repeat laparoscopies are performed during ovarian suppression and not during normal ovarian activity, the results of therapy may be overestimated. After discontinuation of ovarian suppression the disease will return with time (Evers, 1987). During hormonal therapy implants are usually suppressed but not eliminated, regardless of the type of drug administered (Schweppe et al., 1981; Cornillie et al., 1986; Cornillie et al., 1987). This supports the view that most if not all of the recurrence is in fact better defined as persistent disease.

\subsection{Endometriosis and infertility}

\subsubsection{Endometriosis-associated infertility}

The association between endometriosis and infertility is well established. Reliable figures are hard to find. Before laparoscopy became available only guesses could be made. A much quoted figure of the incidence of infertility in the presence of enclometriosis is 30 to $40 \%$ (Kistner, 1975). This figure is derived from a statement of Rubin in 1933 that the expectation of pregnancy when the disease is present is about one-thalf that in the general population. Assuming that the usual incidence of infertility approximates 15\% Kistner (1975) came to the above-mentioned 30 to $40 \%$. If male factors were excluded, endometriosis would probably represent the most common cause of infertility (Kistner, 1984). Endometriosis was found to be the only cause of infertility in $58 \%$ of 968 consecutive patients undergoing major surgery for the preservation or enhancement of fertility (Buttram and Reiter, 1985b).

The above-mentioned figures are based mainly on findings in patients with symptomatic endometriosis. 
The association of endometriosis, to the extent that it compromises tubo-ovarian contact, with infertility seems beyond doubt. Disagreement exists on the question whether mild endometriosis adversely affects fertility.

The prevalence of endometriosis in the general population is not known, as discussed in the section on epidemiology. The finding of a low prevalence in patients during sterilization laparoscopy as opposed to the higher prevalence found during laparoscopy in the course of an infertility workup (Strathy et al., 1982), supports the assumed association between endometriosis and infertility. It has to be emphasized that the data were obtained in a retrospective study and that the difference in parity between the two groups may have influenced the results.

The infertility seen in patients with endometriosis is a relative one. Fertility is not an all or none phenomenon; it should be defined as probability of conception (Cramer et al., 1979; Koninckx et al., 1984; Leridon and Spira, 1984). Many women with endometriosis are asymptomatic, remain undiagnosed and conceive without treatment. Collins et al. (1983) showed that in the absence of treatment pregnancies occurred in $58 \%$ of 49 couples with endometriosis.

The concept of endometriosis-associated subfertility is supported by the following observations.

Endometriosis was diagnosed at laparoscopy in 15 out of 25 patients who failed to conceive after artificial insemination by donor (AID)(Broekhuizen et al., 1980). Jansen (1986a) assessed the impact of mild endometriosis on fertility in 98 patients treated with AID. All patients underwent a diagnostic laparoscopy prior to the start of AID. The mean monthly probability of pregnancy (fecundability) was significantly higher in normal patients than in patients with untreated endometriosis $(0.12$ versus 0.04). Similar findings were reported by Hammond et al. (1986): they studied factors affecting pregnancy rates in a donor insemination program and found that endometriosis significantly reduced fecundability (0.04), while optimal pregnancy rates were obtained in couples with azoospermia $(0.17)$ or no female infertility factors $(0.20)$.

Studies on the effect of different treatment modalities of mill endometriosis provide comparable figures. These studies look at the monthly fecundity rate (MFR) and the cumulative pregnancy rate after medical and surgical treatment of patients with mild endometriosis in comparison to expectant management. The results in the expectant management group supposedly represent the background pregnancy rate, i.e. the "normal" fecundity of patients with mild endometriosis. The results of expectant management of mild endometriosis are shown in Table 2.4. These data show that the presence of mild endometriosis reduces the monthly probability to get pregnant, since the probability of conception in the normal couple is estimated to be between 0.20 and 0.30 per cycle (Edmonds et al., 1982). This leads for the mild endometriosis patient to a pregnancy rate after one year in the low range of the normal population (Leridon and Spera, 1984; Jansen, 1986a; Olive and Haney, 1986). These data have to be interpreted with some caution. The MFR is known to be influenced by several factors. These include the duration of infertility prior to diagnosis, the time of 


\begin{tabular}{|c|c|c|}
\hline Refertence & $\pi$ & $\mathrm{MFR}$ \\
\hline Garcia and David. 1977 & 17 & 0.050 \\
\hline Sehenken and Malinak, 1982 & 18 & 0.102 \\
\hline Sebel et al., 1982 & 28 & 0.112 \\
\hline Portuondo et at 1983 & 31 & 0.083 \\
\hline Onve et al., $1985 a$ & 34 & 0.057 \\
\hline Kable and Yussman, 1985 & 9 & 0.020 \\
\hline Hull al. 1987 & $\$ 6$ & 0.031 \\
\hline
\end{tabular}

(Modified after Olive and Haney, 1986)

follow-up, the influence of other infertility factors, the influence of previous, surgical or medical, treatment. If other factors are present that contribute to subfertility, like a suboptimal semenanalysis or ovulatory disturbances, the MFR will drop considerably. Not all studies correct for these confounding variables. Additionally, it has to be noted that in most studies expectant management is not the same as no treatment, since the laparoscopy during which endometriosis is diagnosed and the concomitant tubal lavage, peritoneal fluid sampling and the occasional D \& C may well influence future fertility. Moreover, expectant management may and may not include correction of other infertility factors.

In summary, the association between endometriosis and infertility is based on the high prevalence of endometriosis diagnosed during laparoscopy in patients with infertility as compared to the prevalence in patients undergoing laparoscopy for sterilization. As mentioned above these prevalence figures should be interpreted with caution. The association between mild endometriosis and infertility is supported by the fact that mild endometriosis reduces fecundability in patients treated for infertility with artificial insemination by donor and by the finding of a reduced fecundability compared to the general population in patients who are not treated for their endometriosis, but in whom expectant management is pursued for a certain period of time.

\subsubsection{Possible causes of infertility in endometriosis}

The association between endometriosis and infertility is easy to understand when extensive endometriosis with its accompanying adhesions distorts pelvic anatomy and impairs tubo-ovarian relationship and ovarian physiology. Ovarian adhesions may cause entrapment of oocytes despite normal ovulation. Tubal occlusion secondary to endometriosis is rare. Uterotubal obstruction due to intraluminal endometriosis has been reported (Ayers, 1982; Gordts et al., 1983; Fortier and Haney, 1985). The assumed association between mild endometriosis, where Fallopian tubes are patent and their motility not impeded by adhesions, and reduced fecundability is difficult to explain. Despite the fact that a causal relationship has not been proven, 
infertile patients with mild endometriosis are almost invariably treated. Thomas and Cooke (1987b) were not able to show that either treatment or elimination of asymptomatic endometriosis affected future fertility. Nevertheless, the cumulative pregnancy rate of the treated patients was well below that of the general population. It was in the same range as that of the patients with unexplained infertility, i.e. patients without any demonstrable abnormality. Based on their results they questioned a causal role for mild endometriosis in infertility.

In mild endometriosis several mechanisms interfering with fertility potential have been proposed (Muse and Wilson, 1982a). These include disturbances of folliculogenesis, ovulation, ovum pickup and transport, fertilization, preimplantation development and of implantation and/or corpus luteum function.

\section{Folliculogenesis}

A low level of $\mathrm{LH}$ receptors in the granulosa cells of the Graafian follicle and a lack of physiologic increment of the receptor during the follicular phase of the cycle has been demonstrated in patients with endometriosis (Kauppila et al., 1982; Rönnberg et al., 1984). The receptor content was low with and without involvement of the ovaries. From these findings it was concluded that the low $\mathrm{LH}$ receptor concentration could result in suppressed LH action and failure of ovulation and corpus luteum formation.

A functional defect of the oocyte in endometriosis, and presumably of the follicle, was postulated by Wardle et al. (1985). They based their conclusion on the finding of a significant reduction of fertilization in their IVF program of oocytes retrieved from patients with endometriosis, compared to fertilization of oocytes from patients with tubal disease and unexplained infertility. Defective folliculogenesis could lead to immature oocytes and impaired fertilization. A reduced fertilizability of oocytes in endometriosis patients was confirmed by O'Shea et al. (1985), but not by others (Chillick et al., 1985; Matson and Yovich, 1986). The discrepancy may be related to prior treatment (Mahadevan et al., 1983; Wardle et al., 1986) or to the different stimulation regimens used (Matson and Yovich, 1986). In a prospective study (Thomas et al., 1986) defects of the developing or developed follicle were demonstrated in 6 out of 18 cycles in patients with minor degrees of endometriosis: a luteinized unruptured follicle occurred in two cycles, in two patients there was inadequate or abnormal folliculogenesis, in one patient a follicular cyst developed and in one patient the follicle ruptured prematurely. Likewise Doody et al. (1988) demonstrated abnormal follicular growth patterns using ultrasound in patients with endometriosis. They found a significant slowing of follicular growth rate and lengthening of the time to ovulation.

\section{Ovulation}

The combination of endometriosis and ovulatory dysfunction has been reported to range from 10 to 27\% (Grant, 1966; Acosta et al., 1973; Soules, 1976; Dmowski 
et al., 1976; Starks and Grimes, 1985). The true incidence of endometriosis coexisting with ovulatory dysfunction could not be determined because of the retrospective nature of the studies. In a small prospective study on follicle growth patterns and minor degrees of endometriosis using ultrasonography and endocrinology Thomas et al. (1986) detected anovulation in 11\%. Dmowski et al. (1986) showed that treatment of endometriosis more than doubled the effectiveness of ovulation induction in patients with anovulation and endometriosis.

A high frequency of the luteinized unruptured follicle (LUF) syndrome has been associaled with endometriosis (Brosens et al., 1978). This high frequency has not been confirmed by others (Marik and Hulka, 1978; Dmowski et al., 1980). The LUF syndrome is defined as the entrapment of the ovum in the follicle at the time of ovulation, while signs of luteinization, i.e. elevated progesterone levels, temperature shift and luteal endometrial maturation, are present and within the normal range. The importance of LUF cycles with regard to infertility asks for repeated occurrence of these LUF cycles. Repeated LUF cycles as diagnosed by serial ultrasound in the same patient are infrequently found (Kerin et al., 1983; Daly et al., 1984; Hamilton et al., 1985), and are mostly restricted to patients with a history of PID and to patients with ovulation induction (Hamilton et all, 1985).

The conflicting data on the incidence of LUF cycles in endometriosis patients mainly depend on the different ways of diagnosing LUF cycles, i.e. laparoscopy to detect an ovulation stigma, steroid concentrations of peritoneal fluid or serial ultrasound of the ovaries (Brosens et al., 1978; Marik et al., 1978; Koninckx et al., 1980b; Dmowski et al., 1980; Donnez et al., 1983; Dhont et al., 1984; Lesorgen et al., 1984; Liukkonen et al., 1984; Thomas et al., 1986).

The etiology of LUF cycles in patients with endometriosis is not known. The occurrence of LUF cycles may be possibly explained by the finding of a low concentration of LH receptors in Graafian follicles in patients with endometriosis (Rönnberg et al., 1984). Another explanation for the occurrence of LUF cycles in endometriosis patients was proposed by Malick (1982), who found a decreased serosal plasminogen activator activity in a patient with endometriosis. Plasminogen activator activity supposedly plays an important role in follicular rupture (Beers, 1975a; Beers et al., 1975b; Strickland and Beers, 1976). When the ovaries are involved in endometriosis, as is the case in more severe forms of the disease, ovarian function has been shown to be disturbed (Brosens et al., 1978).

From the above-mentioned observations on repetition and on incidence of LUF cycles in patients with endometriosis, it can be concluded that a causal role of LUF cycles in endometriosis-associated infertility has yet to be ascertained.

As has been mentioned in the section on the etiology of endometriosis, it has been hypothesized that LUF cycles allow endometrial cells to implant by creating an intraabdominal hormonal environment with a low concentration of progesterone. In this hypothesis LUF cycles are the cause rather than the consequence of endometriosis (Brosens et al., 1978; Koninckx et al., 1980d). 


\section{Ovum pickup and transport}

In advanced cases of endometriosis disturbances of ovum pickup due to adhesions and defective tubo-ovarian contact are obvious. Also a peritoneal factor has been implicated: Suginami et al. (1986) demonstrated that, in contrast to peritoneal fluid of controls, peritoneal fluid of patients with endometriosis inhibited ovum capture by the oviductal fimbriae of the golden hamster in vitro.

Transport of fertilized ova through the Fallopian tube is effectuated by both muscular and ciliary activity. Ovarian steroids, adrenergic innervation and prostaglandins interact to influence oviductal contractility. Altered tubal transport of fertilized ova resulting in an untimely arrival in the uterine cavity causing implantation failure has been implicated as a cause of infertility in endometriosis patients (Drake et al, 1981). It has been postulated that altered tubal transport is caused by an increased intraabdominal concentration of prostaglandins; in endometriosis patients prostaglandins may be produced by endometriotic implants (Moon et al., 1981; Ylikorkala and Viinikka, 1983; Vernon et al., 1986) or macrophages (Nathan, 1987). Conflicting data, however, have been reported on peritoneal fluid prostaglandin concentration, as will be reviewed in the section on peritoneal fluid constituents. Moreover, attempts to modify ovum transport in vivo have failed to show that prostaglandins accelerate ovum transport, even in the presence of increased tubal contractility (Croxatto et al., 1979). Finally, accelerated tubal transport resulting in earlier entry of the embryo into the uterine cavity as a cause of infertility is not supported by the clinical results of in vitro fertilization and embryo transfer.

\section{Fertilization and preimplantation embryonic development}

Phagocytosis of spermatozoa and oocytes by intraabdominal and intrauterine macrophages has been demonstrated (Austin, 1960; Moyer et al., 1970; Hurst et al., 1977; Weissman et al., 1978; Ball et al., 1984; London et al., 1985). Increased phagocytosis of spermatozoa by tubal and intraabdominal macrophages and hence a decreased fertilization rate in women with endometriosis has been suggested by Muscato et al. (1982) and Haney et al. (1983). Halme et al. (1984b, 1987a) documented the presence of more, and more active, intraabdominal macrophages in patients with endometriosis. No significant differences were found regarding phagocytic capabilities of macrophages harvested from peritoneal fluid of endometriosis patients versus controls (Halme et al, 1984b). In another study peritoneal macrophages from patients with endometriosis were shown to exhibit more active phagocytosis of sperm within the first 24 hours in vitro than an equivalent number of macrophages from fertile controls (Stuyt et al., 1987). The remaining spermatozoa, however, were highly motile in both groups, and capable of penetrating hamster ova. From these findings the role of increased phagocytosis by peritoneal macrophages was questioned as a mechanism of infertility in endometriosis. On the other hand, especially in those infertile couples where subfertile semen and endometriosis occur together, increased phagocytosis by macrophages in an advanced stage of activation may bring the number of spermatozoa below a certain threshold level. 
It has been postulated that secretory products of macrophages in a more advanced stage of activation may affect spermatozoa, oocytes and early embryos. Peritoneal fluid of endometriosis patients has been reported to decrease sperm penetration of oocytes in the hamster (Chacho et al., 1985, 1987) or mouse (Sueldo et al., 1987), whereas heat inactivated peritoneal fluid has no effect (Halme and Hall, 1982; Sueldo et al., 1987).

Stone and Himsl (1986) determined the rate of sperm recovery at the time of laparoscopy for infertility in 29 patients with and in 77 patients without endometriosis. The number of patients with motile sperm in both groups was similar. The presence of mild endometriosis did not impair sperm motility up to 4 hours after insemination.

A positive influence of peritoneal fluid of normal women on sperm viability and motility has been documented (Balin, 1958; Maathuis et al., 1973; Schellekens et al., 1983). Conversely, Dorez et al. (1985), Oak et al. (1985) and Burke (1986) documented an adverse effect of peritoneal fluid of endometriosis patients on sperm motility and velocity. These effects of peritoneal fluid on sperm velocity have been related to the presence of interferon (IFN) and tumor necrosing factor (TNF). IFN and TNF, products of activated macrophages, present in the abdominal cavity of patients with endometriosis, have been shown to inhibit sperm velocity, while interleukin-1 did not influence sperm motion parameters. Spermatozoa with a decreased motility would become easier targets for macrophages (Hill et al., 1.987).

In vitro studies showed that peritoneal fluid of patients with endometriosis adversely affected mouse embryo cleavage and viability in comparison with peritoneal fluid of controls (Morcos et al., 1985; Gerrity et al., 1985). This could not be confirmed by others (Awadalla et al., 1987). Recombinant interleukin-1 was found to be toxic to the growth of 2-cell mouse embryos in vitro (Fakih et al., 1987). The embryotoxicity of interleukin- 1 and -2 , tested in an in vitro mouse embryo system, was not confirmed by others (Schneider et al., 1987).

In short, peritoneal fluid of patients with endometriosis possibly has an adverse effect on spermatozoa and preimplantation embryos. An increased number of intraabdominal macrophages in an advanced stage of activation may affect fertilization by phagocytosis or by the effect of their secretory products, especially in couples with coincidental male subfertility. It has to be stressed that all the abovementioned studies except the one by Stone and Himsl (1986) regard in vitro and/or animal experiments with all the related shortcomings.

\section{Implantation}

That endometriosis-related infertility is caused by factors interfering with implantation and with events in the early postimplantation period has been supported by studies of endometriosis in animal models (Vernon and Wilson, 1985; Hahn et al., 1986) and by reports on a high spontaneous abortion rate in patients with endometriosis (vide infra). The rate of spontaneous abortion in the general population 
has been reported between 10 and 20\% (Glass and Golbus, 1978; Simpson, 1980a), although this figure rises sharply when spontaneous abortion is defmed as early embryonic loss based on measurements of human chorionic gonadotropin (Edmonds et al., 1982; Sharp et al., 1986).

Several studies have reported a high rate, between 31 and $52 \%$, of spontaneous abortion in patients with endometriosis. Following conservative surgical or hormonal treatment of endometriosis the fetal wastage has been reported to be significantly lower (Petersohn, 1970; Naples et al., 1981; Rock et al., 1981; Olive et al., 1982; Wheeler et al., 1983; Groll et al., 1984; Wheeler and Malinak, 1985). Metzger et al. (1986) reported an equally impressive and significant decrease in the spontaneous abortion rate among patients who underwent expectant management. They stressed the importance of inclusion of an appropriate control group to interpret the spontaneous abortion rate in endometriosis patients before and after treatment. Women attempting to achieve a pregnancy are a preselected group, distinct from the general population, in whom spontaneous abortions may be diagnosed more readily (Jansen, 1982). Moreover, the spontaneous "cure-rate" of women with a history of early pregnancy loss is high (Glass and Golbus, 1978). FitzSimmons et al. (1987), in reviewing data on pre- and postdiagnosis spontaneous abortion rates in endometriosis, concluded that the selection bias for women with a history of spontaneous abortion together with a preponderance of women with a single loss or a previous successful pregnancy could contribute to an apparently high rate of spontaneous loss before evaluation and the appearance of improvement after treatment.

Several theories have been postulated to explain a possible relationship between endometriosis and early abortion. These theories are mainly centered around a supposedly increased concentration of prostaglandins in the abdominal cavity secondary to endometriosis. Prostaglandins might lead to implantation problems and early pregnancy loss by acting as luteolytic factors and by increasing uterine contractility (Drake et al., 1981; Pittaway and Wentz, 1984). The role of prostaglandins in luteolysis in the human is far from clear (review by Chaudhuri, 1985).

An increased incidence of luteal phase abnormalities has been found in patients with endometriosis (Grant, 1966, 1981; Brosens et al., 1978; Hargrove, 1980; Levine et al., 1983; Cheesman et al., 1983; Groll, 1984). Brosens et al. (1978), using midcycle LH peak as the reference point, noted shortening of the luteal phase of the cycle and a delay in the luteal rise of progesterone in women with endometriosis. A defective luteal phase is consistent with the finding of a second LH surge (Cheesman et al., 1982) and with the finding of a low luteinizing hormone receptor concentration in the Graafian follicle (Rönnberg et al., 1984) in endometriosis patients. Inadequate corpus luteum function has been associated with the presence of ovarian autoantibodies in patients with endometriosis (Mathur et al., 1982). Incomplete luteolysis with maintenance of an active corpus luteum secreting significant amounts of progesterone well into the subsequent follicular phase has been documented in pa. tients with endometriosis by measuring progesterone in the ovarian veins and the peripheral circulation. This failure of adequate luteolysis was supposed to be 
another aspect of the luteal phase dysfunction seen in endometriosis patients (Ayers et al., 1987). Finally, the presence of luteal phase defects in patients with endometriosis has been attributed to hyperprolactinemia (Hirschowitz et al., 1978; Hargrove and Abraham, 1980; Muse et al., 1982b; Radwanska et al., 1987). The finding of hyperprolactinemia in patients with endometriosis could not be confirmed by others (Balasch and Vanrell, 1985).

Other investigators have not been able to demonstrate an increased frequency of luteal phase defects in patients with endometriosis (Rosenfeld et al., 1980; Radwanska and Dmowski, 1981; Pittaway et al., 1983; Balasch and Vanrell, 1985), based on either mid-luteal progesterone levels or on late luteal endometrial biopsy. Finally, no data exist regarding successful treatment of the infertility associated with endometriosis by therapy directed toward luteal phase insufficiency.

All in all, the association between luteal phase defects and endometriosis is not well defined.

An autoimmune response to ectopic endometrium has been proposed as a possible cause of implantation failure in endometriosis patients. Weed and Arquembourg (1980) documented the presence of complement, $C_{3}$, in uterine endometrium of patients with endometriosis and not in endometrium of patients without the disease. They postulated that an autoimmune response to ectopic endometrium results in a reaction against uterine endometrium eventually leading to implantation failure. In contrast, Bartosik et al. (1987) documented that the presence of complement was not specific for patients with endometriosis, although the absence of complement in eutopic endometrium appeared to be a good predictor of subsequent pregnancies. Based on these findings Bartosik et al. (1987) postulated that although the presence of endometrial complement is not specific, it may be that complement-fixed endometrial autoantibodies could induce a cytolytic, anti-implantation effect in the endometrium. These specific autoantibodies against endometrium, primarily of $\operatorname{IgG}$ and $\operatorname{IgA}$ type, were reported to be present in uterine endometrium of endometriosis patients and not of controls (Mathur et al., 1982). At the same time they found endometrial autoantibodies to be significantly elevated in serum, cervical mucus and vaginal secretions in patients with endometriosis compared to controls. The finding of serum autoantibodies to normal endometrium in patients with endometriosis was confirmed by Wild and Shivers (1985). No correlation between the level of autoantibodies and the severity of endometriosis could be detected. Halme and Mathur (1987b) did not find significant levels of endometrial autoantibodies in peritoneal fluid of patients with mild endometriosis.

Saifuddin et al. (1983) reported that both IgG and IgA were more commonly found in endometrium of patients with endometriosis than in controls. There was, however, no difference in immunoglobulin content between fertile and infertile patients, making a causal relation between endometrial antibodies and infertility questionable. Bartosik (1985) could not detect differences in immunoglobulin $G$ in endometria between patients with endometriosis, patients with pelvic inflammatory disease and patients with laparoscopically normal pelves. Kreiner et al. (1986) 
demonstrated anti-immunoglobulin $G$ in a high percentage of patients with endometriosis and of patients with pelvic inflammatory disease. In the absence of disease one false positive test was found. They concluded that endometriosis-associated infertility might be an immune mediated event.

Results of studies on nonspecific immunological functions display a wide discrepancy. Serum complement has been reported to be decreased (Weed and Arquembourg, 1980), increased (Badawy et al., 1984) and not changed (Steele et al., 1984) in patients with endometriosis compared to controls. Quantitative immunoglobulin determinations revealed no differences between patients with and without endometriosis (Badawy et al., 1984; Steele et al., 1984).

Although the hypothesis of implantation failure secondary to autoimmunity in endometriosis is an attractive one, no clear picture arises on the place of autoimmunity in relation to endometriosis-associated infertility from the available literature. The results reported are not unequivocal. Moreover, only a few studies (Mathur et al., 1982; Wild and Shivers, 1985; Halme and Mathur, 1987b) concern parameters of the immune response that are specific for endometrium, i.e. anti-endometrial antibodies. Finally, most findings were not studied in relation to infertility, but only to the occurrence of endometriosis.

In summary, when endometriosis reaches the stage of periadnexal adhesions or tubal occlusion mechanical factors are clearly present. The possible causes of infertility related to minimal and mild endometriosis are multiple as reviewed above. The diversity of the findings in the cited reports is probably primarily due to patient selection. Prior treatment, duration of infertility, stage of the disease, heterogeneity within stages, inappropriate control groups, all influence the different parameters studied.

The whole range of ovulatory disturbances, i.e. anovulation, luteinized unruptured follicle cycles, luteal phase abnormalities, seems to play a role in endometriosis-associated infertility. It is not clear, however, to what extent the incidence of ovulatory disturbances is influenced by patient selection.

The importance of an altered intraabdominal environment secondary to endometrial implants, with consequent changes in macrophages, prostaglandins, immunoglobulins, complement factors, in relation to endometriosis-associated infertility remains to be established.

\subsection{Peritoneal fluid and endometriosis}

The peritoneal environment, in which (peri)conceptional events like folliculogenesis, ovulation, fertilization and tubal transport of spermatozoa, oocytes and preimplantation embryos take place, has received considerable attention in endometriosis patients in recent years. Peritoneal fluid volume and changes in peritoneal fluid consti- 
tuents have been studied to elucidate possible causes of endometriosis-associated infertility, especially in the milder forms of endometriosis, where infertility is not easily explained.

\subsubsection{Peritoneal fluid volume}

Peritoneal fluid is mainly the result of ovarian exudation. Peritoneal exudation, follicular rupture and tubal secretion contribute only a small volume. Peritoneal fluid volume increases from the proliferative to the secretory phase of the cycle (Maathuis, 1977; Maathuis et al., 1978; Koninckx et al., 1980a; Bouckaert et al., 1986a).

Conflicting results have been reported on the influence of endometriosis on peritoneal fluid volume. In the first place this is due to lack of control for the phase of the cycle studied. Secondly, in some of the studies the control group is composed of patients with unexplained fertility, while in other studies patients with endometriosis are compared with fertile controls without endometriosis. Decreased volumes were noted by Koninckx et al. (1980a) in patients with severe endometriosis in the luteal phase of the cycle. Increased volumes have been reported irrespective of cycle dating (Drake et al., 1980b), in the early follicular phase (Koninckx et al., 1980a), in the periovulatory phase (Haney et al., 1981) and in the luteal phase of the cycle (Halme et al., 1984b; Chacho et al., 1985; Oak et al., 1985). Syrop and Halme (1987) examined peritoneal fluid volume in 426 patients in a retrospective study. Women with endometriosis had a greater peritoneal fluid vollume than fertile controls, patients with adhesive disease or unexplained infertility. The volume in the group with unexplained infertility was higher than that in controls. Several other reports have demonstrated no difference in peritoneal fluid volume between patients with and without endometriosis (Rock et al., 1982; Crain and Luciano, 1983; Dawood et al., 1984; Damon et al., 1984; Badawy et al., 1985; Mudge et al., 1985; De Leon et al., 1986; Olive et al., 1985b; Rezai et al., 1987; Awadalla et al., 1987) neither in the follicular nor in the luteal phase of the cycle. If increased peritoneal fluid volume is found, it seems to be associated not only with endometriosis, but also with unexplained infertility. Therefore it is tempting to suggest that patients with unexplained infertility may be suffering from microscopic endometriosis, not yet discernible to the naked eye.

Syrop and Halme (1986) correlated peritoneal fluid volume with the subsequent occurrence of pregnancy in patients with endometriosis in a large retrospective study. Endometriosis patients who achieved pregnancy had a significantly lower mean peritoneal fluid volume than those who did not get pregnant. They concluded that peritoneal fluid of patients with endometriosis, through an as yet unknown mechanism or substance, appears to be associated with reduced fertility.

An increased peritoneal fluid volume in patients with endometriosis may be caused by peritoneal irritation secondary to endometrial implants. Peritoneal irritation may 
lead to increased vascular permeability and exudation of fluid.

The conflicting results of studies on peritoneal fluid volume in endometriosis patients questions the relative importance of the extent to which endometrial implants cause irritation to the peritoneal lining and change peritoneal vascular permeability, resulting in an increased peritoneal fluid volume.

\subsubsection{Peritoneal fluid constituents}

\section{Macrophages}

Macrophages play an important role in maintaining homeostasis. They are involved in phagocytosis and, through their numerous secretory products, in inflammatory and immunological reactions, in remodeling of tissues and healing of wounds. In addition to their regulatory functions macrophages play a central role in cellmediated immune response; they are both involved in the initiation of the response as antigen-presenting cells, and in the effector phase as inflammatory, tumoricidal and microbicidal cells. Elements of the mononuclear phagocyte system originate in the bone marrow. Mononuclear phagocytes, after development over several days, leave the marrow, pass into the circulation as monocytes, and subsequently within hours to days into the various tissues and compartments of the body, as for instance the peritoneal cavity, where they survive for months as resident macrophages. Functional heterogeneity exists in most populations of macrophages, as a result of variable degrees of differentiation. Once established in the tissues, macrophages can be subjected to a myriad of stimulatory and suppressive signals, particularly in instances of disturbed homeostasis such as inflammation. This alters their morphology, metabolism, and physiology and activates them to adopt various functions (Van Furth et al., 1979; Nathan et al., 1980; Adams and Hamilton, 1984). Their responses include the secretion of some hundred different substances and their biologic activity ranges from induction of cell growth to cell death (Nathan, 1987).

By appropriate stimulation profound alterations can be induced in the physiology of the resident cells. Secondary to nonspecific, nonimmunological inflammatory stimuli, humoral and cellular, resident macrophages produce substances that cause proliferation of monocytes in the bone marrow. These monocytes, with specific functions, after reaching the peritoneal cavity are called inflammatory macrophages.

The alterations that take place in the physiology of the macrophages occur in a stepwise fashion (Cohn, 1978; Adams and Hamilton, 1984; Nathan, 1987):

1. increase in size

2. increase in capacity to spread

3. stimulation of metabolism as reflected by increased numbers of mitochondria, increased aerobic glycolysis, oxygen consumption, hexose monophosphate shunt activity, and increased production of highly reactive intermediate products of oxygen reduction, i.e. superoxide anion, singlet oxygen and the hydroxyl radical 
(called the respiratory burst and estimated by measuring the concomitant light emission or chemiluminescence)

4. increased expression of specific surface receptors on the plasma membrane:

- receptors involved in phagocytosis

complement-, FC- and mannose-fucose-receptors

- receptors mediating nonphagocytic functions

5. secretion of enzymes and other secretory products:

- Iysosomal hydrolases

- lysozyme

- neutral proteases

- arachidonic acid metabolites, prostaglandins

- complement components

- interferon

- interleukin-1

- plasminogen activator and inhibitor

6. modification of plasma membrane ectoenzymes

Macrophages exposed to lymphokines and other signals are competent to present antigen to T-lymphocytes, and to display microbicidal and tumoricidal activity. The mediation of macrophage activation by specifically sensitized lymphocytes is achieved by way of soluble mediators collectively referred to as lymphokines.

Important factors in regulating development and function of macrophages are the secretory products released from the macrophages themselves, which initiate many complex positive and negative feedback loops. Most functions can be down- as wel] as up-modulated (Bonney and Davies, 1984).

An important concept in understanding macrophage function and regulation is the heterogeneity of macrophages within any given population. Individual capacities are not necessarily expressed uniformly by all cells (Nelson, 1981; Bursuker and Goldman, 1983). The various capacities of macrophages do not all develop synchronously but rather asynchronously and even disparately (Adams and Hamilton, 1984). Normally peritoneal fluid contains 0.5 to $2.6 \times 10^{6} / \mathrm{ml}$ leukocytes, of which more than $85 \%$ are macrophages (Van Furth et al., 1979; Haney et al., 1981; Muscato et al., 1982; Halme et al., 1983; Olive et al., 1985b). Their physiologic function is maintenance of homeostasis, as reviewed above. They are involved in phagocytosis of decaying spermatozoa, removal of blood cells after retrograde menstruation and ovulation.

Haney et al. (1981) reported an increased total number of macrophages in infertile patients with endometriosis compared to infertile patients without endometriosis. The total number of macrophages in both infertile groups was higher than that of a fertile control group. The peritoneal fluid volume was higher as well in the infertile patients with endometriosis. Macrophage concentration did not differ. Muscato et al. (1982) documented in the same patient groups an increased phagocytosis of spermatozoa in vitro by the macrophages of the endometriosis patients, compared to 
those of fertile controls. This could not be confirmed by Awadalla et al. (1987) in another study involving two large groups of infertile patients with and without endometriosis, nor did they find an increased total count or concentration of macrophages in endometriosis patients. Studying the number of macrophages inside the oviducts Haney et al. (1983) found a higher number of oviductal macrophages in endometriosis patients. They suggested that oviductal and peritoneal macrophages in endometriosis patients interfere with fertility by increased sperm-phagocytosis. Halme et al. (1982, 1983, 1984b, 1987a) published a series of observations on peritoneal macrophages in endometriosis patients. In fertile patients with open Fallopian tubes they noted a high concentration of macrophages during menstruation which gradually decreased and remained stable during the rest of the cycle. In contrast, infertile patients with occluded tubes had a low concentration compared to fertile controls and to infertile patients with endometriosis. They concluded that macrophages are attracted by retrograde menstruation (Halme et al., 1982). Furthermore, they noted an increased concentration of two proteins, acid phosphatase and neutral protease, in the peritoneal fluid of patients with endometriosis compared to fertile controls. Additionally the macrophages in the patients with endometriosis had higher acid phosphatase expression, which is associated with macrophages of a larger size. They concluded that the macrophages of patients with endometriosis were in a more advanced stage of activation, possibly leading to either phagocytosis of gametes or rellease of active compounds into the surrounding peritoneal fluid (Halme et al., 1983). Subsequently they reported on a cyclic activation of macrophages in normal women: the activational status of peritoneal macrophages changes during the cycle, showing an increase toward the luteal phase. This cyclic activation appeared to be more pronounced in patients with endometriosis. They suggested that retrograde menstruation or bleeding from ectopic endometrial implants, acting as irritating agents, could attract macrophages and induce differentiation (Halme et al., 1984b). In a larger group of patients they found a significantly higher total number of macrophages in patients with endometriosis compared to fertile controls and compared to patients with unexplained infertility. Furthermore, they extended their observations that macrophages of endometriosis patients were in a more advanced stage of maturation. They suggested that these more advanced macrophages, apart from interfering with reproductive events, may produce factors that might facilitate growth of endometrial implants (Halme et al., 1987a). Peritoneal macrophages of patients with endometriosis were shown to produce increased levels of fibronectin in vitro (Kauma et al. "1987). It was suggested that such an increase might facilitate the implantation of endometrial cells and their subsequent growth in the pelvis.

The concept of more advanced macrophages in peritoneal fluid of patients with endometriosis has been supported by the finding of interleukin-1 (IL-1) in peritoneal fluid of patients with endometriosis, and not in peritoneal fluid of patients without the disease. Peritoneal macrophages of patients with endometriosis and not of controls produced IL-1 when cultured in vitro. Recombinant IL-1 adversely affected 
mouse embryo growth (Fakih et al., 1987). As outlined above IL-1 is one of the proteins that is secreted by macrophages in an advanced stage of differentiation. IL-1 concentration in the peritoneal fluid and in vitro $\mathrm{IL}-1$ production did not differ between 49 patients with and 73 patients without endometriosis (Awadalla et al., 1987). It has to be noted that in this last study both groups consisted of infertile patients.

Conflicting data have been reported on the concentration in peritoneal fluid of other secretory products of macrophages in an advanced stage of differentiation, i.e. prostaglandins and complement components (vide chapter 2.3.2, Peritoneal fluid constituents).

Olive et al. (1985b) reported that elevated numbers of macrophages are not exclusive to patients with endometriosis but rather correlate with infertility in the absence of endocrinologic or mechanical disorders. They suggested that patients with high macrophage counts represent a distinct group of which women with endometriosis are only a subset. Syrop and Halme (1986) related peritoneal fluid parameters to subsequent pregnancy outcome. They found that peritoneal fluid macrophage count was not a significant predictor variable. It has to be noted that only macrophage count and not macrophage activity was used as parameter.

Zeller et al. (1987) documented that not only peritoneal macrophages but also peripheral monocytes of patients with endometriosis were in an advanced stage of activation. They suggested that endometriosis may be a systemic autoimmune disease rather than a local disorder. They based their conclusion on the advanced stage of activation of peripheral monocytes and peritoneal fluid macrophages, on the finding of a decrease in the cell-mediated immune response to autologous endometrial antigens (both in vivo and in vitro in rhesus monkeys and in women with endometriosis) and on the finding of an abnormal autoantibody profile in a high percentage of women with endometriosis (Gleicher et al., 1987; Zeller et al., 1987; Dmowski, 1987).

In summary, macrophages in the abdominal cavity are derived from peripheral monocytes arriving there from the bloodstream. They are continuously reacting to stimuli like retrograde menstruation and spermatozoa, provided that the Fallopian tubes are patent. In patients with endometriosis macrophages may also react to bleeding from the ectopic implants. Many studies have found increased numbers and/or concentrations of peritoneal and oviductal macrophages in patients with endometriosis compared to fertile or infertile controls. Macrophages of patients with endometriosis apparently are in an advanced stage of activation. Consequently they may facilitate implantation of endometrial cells and they may influence periconceptional events, either directly by phagocytosis of gametes or indirectly by their secretory products. 


\section{Sieroid hormones}

In regularly cycling women peritoneal fluid estradiol and progesterone levels are comparable to serum levels in the follicular phase of the cycle (Bouckaert, 1984). After the LH surge and subsequent ovulation the peritoneal fluid levels of estradiol and progesterone rise sharply. The increase in estradiol concentration in the postovulatory phase is more gradual than the increase in the progesterone concentration. Postovulatory levels of estradiol in peritoneal fluid rise to 8 to 10 times those of serum, those of progesterone to 20 to 50 times. (Maathuis et al., 1978; Koninckx et al., 1980c; Donnez et al., 1982; Zorn et al., 1982; Loumaye et al., 1985; Bouckaert et al., 1986b). The cyclic changes in peritoneal fluid concentrations of estradiol and progesterone are directly related to ovarian activity. Women with anovulatory cycles have low values of these steroids (Donnez et al., 1982). The sources of the steroids in the peritoneal fluid are the developing follicle, the contents of the follicle and the luteinized theca interna (Bouckaert et al, 1986b). In LUF cycles the postovulatory peritoneal fluid levels of progesterone and estradiol remain relatively low, since the steroid rich contents of the follicle do not reach the peritoneal cavity. Measurement of these steroids may aid in the diagnosis of LUF cycles (Koninckx et al., 1980b; Koninckx and Brosens, 1982; Bernardus et al. , 1983; Lesorgen et al., 1984). A considerable overlap exists, however, in peritoneal fluid steroid concentrations between normal and LUF cycles (Koninckx and Brosens, 1982). As noticed above (2.2.2) there are conflicting reports on the occurrence and mportance of LUF cycles in endometriosis patients.

No significant differences were found in peritoneal fluid concentrations of estradiol and progesterone comparing patients with and without endometriosis, neither in the follicular, nor in the early and late luteal phase of the cycle (Koninckx et al., 1980b; Crain and Luciano, 1983; Dhont et al., 1984; Lesorgen et al., 1984; Ylikorkala et al., 1984b; De Leon et al., 1986). In contrast, Donnez et al. (1983) reported decreased concentrations of estradiol and progesterone in peritoneal fluid of patients with moderate and severe disease in the peri- and postovulatory phase of the cycle.

\section{Prosuaglandins}

Prostaglandins are biosynthesized from polyunsaturated fatty acids, predominantly arachidonic acid. Arachidonic acid is liberated from cellular phospholipids by the action of phospholipases. After formation of $\mathrm{PGG}_{2}$ and $\mathrm{PGH}$, the prostaglandins $\mathrm{PGE}_{2}, \mathrm{PGD}_{2}, \mathrm{PGF}_{2 \alpha}, \mathrm{PGI}_{2}$ and $\mathrm{TxA}_{2}$ are synthesized. The more stable metabolites of $\mathrm{PGI}_{2}$ and $\mathrm{TxA}_{2}$ are 6-keto-PGF ${ }_{1 \alpha}$ and $\mathrm{TxB}$. Biosynthesis and release of prostaglandins from tissues occur in response to various stimuli. Prostaglandins are rapidly metabolized in the lungs.

The role of prostaglandins in ovulation, corpus luteum function and tubal transport has been reviewed by Chaudhuri (1985). Prostaglandins play a role in the mechanism of ovulation, although the exact mechanism is not yet known. The induction of LUF cycles with prostaglandin synthetase inhibitor drugs has been reported (Kil. 
lick and Elstein, 1987). The exact mechanism and the role of prostaglandins, if any, in luteolysis in the human remains to be elucidated (Chaudhuri, 1985). In the rabbit the role of prostaglandins in oviductal motility is fairly well established (Chang and Hunt, 1972; Salomy and Goldstein, 1978; Harper et al., 1980). In the human the role of endogenous and exogenous prostaglandins is less clear (Elder et al., 1977; Croxatto et al, 1978, 1979).

The study of peritoneal fluid prostaglandins in relation to endometriosis has received considerable attention in recent years. Sources of prostaglandins in peritoneal fluid are the ectopic endometrium and peritoneal macrophages (Nathan, 1987). Ylikorkala and Tenhunen (1984a) reported that human follicular fluid contains prostaglandins, but that the concentrations of these prostaglandins were not elevated in endometriosis patients. They concluded that the increased concentration of prostaglandins found by some in the peritoneal fluid of patients with endometriosis does not originate from the follicle.

The uterine endometrium produces several different prostaglandins (Willks et al., 1972; Levitt et al. 1975; Willman et al., 1976; Abel and Kelly, 1979). Likewise ectopic endometrium produces prostaglandins. Moon et al. (1981) measured the PGF content of ovarian tissue with and without endometriosis and found that the endometriotic lesions produced significantly more PGF. Ylikorkala and Viinikka (1983) reported on the production of 6-keto- $\mathrm{PGF}_{\text {locr }}$ and $\mathrm{TxB}_{2}$ by endometriotic implants. De Leon et al. (1983) demonstrated that peritoneum involved with endometriosis produced significantly more $\mathrm{PGF}_{2 \alpha}$ and $\mathrm{PGE}_{2}$ than adjacent normal peritoneum. Vernon et al. (1986) measured PGF concentration and in vitro production by endometriotic implants, endometrium and normal peritoneum. They found that endometriotic implants contained and produced significantly more PGF than normal peritoneum. Endometrium contained twice the amount and exhibited five times the capacity to produce PGF than endometrial implants. They also correlated PGF production with different types of endometrial implants, i.e. petechial, intermediate and powderburn lesions. As judged by PGF production petechial implants were biochemically more active than intermediate implants, which in turn were more active than powderburn implants.

Initial studies on peritoneal fluid prostaglandins and endometriosis showed increased concentrations of 6 -keto- $\mathrm{PGF}_{2 \alpha}$ and $\mathrm{TxB}_{2}$ in peritoneal fluid of patients with endometriosis compared to controls (Drake et al., 1981). It was suggested that these prostaglandins could alter tubal function and thus explain infertility in endometriosis patients. Likewise, peritoneal fluid $\mathrm{PGF}_{2 \alpha}$ and $\mathrm{PGE}_{2}$ were found to be significantly increased in patients with endometriosis (Badawy et al., 1982, 1984). De Leon et al. (1986) compared peritoneal fluid $\mathrm{PGF}_{2 \alpha}, \mathrm{PGE}_{2}, 6-\mathrm{keto}-\mathrm{PGF}_{1 \kappa e}$ and $\mathrm{TxB}_{2}$ in the proliferative and the secretory phase of the cycle between patients with and without endometriosis. In both phases of the cycle significantly higher concentrations of all four prostaglandins were found in endometriosis patients. Other studies could not confirm these findings (Rock et al., 1982; Sgarlata et al., 1983; Dawood et al., 1984; Mudge et al., 1985; Rezai et al., 1987). In patients with en- 
dometriosis, tubal disease or unexplained infertility Ylikorkala et al. (1984b) found significantly elevated levels of 6 -keto-PGF ${ }_{1 \alpha}$ and $\mathrm{TxB}_{2}$ compared to controls. Drake et al. (1983) found a marked elevation of 6-keto-PGF $1 \times$ and $T \times B_{2}$ in a subgroup of patients with unexplained infertility.

In summary, the available literature on peritoneal fluid prostaglandin concentration in endometriosis patients shows either an increase or no changes compared to patients without the disease. Some of the confusion may be attributed to methodological differences, collection procedures, contamination of peritoneal fluid samples with blood, patient- and controlgroup selection and the time of the cycle studied. The presence of invisible microscopic endometriosis may account for high levels of prostaglandins in some patients with unexplained infertility. Within the AFS classification of mild endometriosis different types of lesions are apparently present (Vasquez et al., 1984), characterized by a specific biochemical potential (Vernon et al., 1986).

\section{Proteins}

The total protein concentration in peritoneal fluid has been reported to be below that of serum (Maathuis et al., 1978; Koninckx et al., 1980a). The concentrations of total protein and of various individual proteins in the peritoneal fluid exhibited a cyclic pattern with a significant increase in the luteal phase of the cycle (Koninckx et al., 1980a; Bouckaert et al., 1986a). The peritoneal fluid/serum $(\mathrm{p} / \mathrm{s})$ ratio of each individual protein showed a significant inverse correlation with its molecular weight (Bouckaert et al., 1986a).

There are few data on the protein content of peritoneal fluid in patients with endometriosis. Bernard and Baumstark (1983) measured total protein concentrations and specific protein concentrations in peritoneal fluid and serum and could not detect differences between patients with and without endometriosis. In patients with endometriosis $\alpha_{1}$-antitrypsin was elevated in peritoneal fluid versus serum. They concluded that the elevation of the acute-phase reactant $\alpha_{i}$-antitrypsin supported the suggestion of a local inflammatory process. Comparable results were reported by Fazleabas et al. (1987). They found a significantly higher total protease inhibitory activity in the peritoneal fluid of patients with endometriosis compared to controls in the early luteal phase of the cycle. They suggested that this increase was in dicative of a local inflammatory reaction. Since they used total protease inhibitory activity rather than protease concentration, the increase they found is most probably due to the increased peritoneal fluid volume that was found in the early luteal phase of the cycle.

CA-125 levels were ten fold higher in peritoneal fluid compared with serum in both patients with minimal endometriosis and in controls. There was no significant difference in the ratio of peritoneal fluid/serum ( $p / s)$ CA- 125 levels between endometriosis patients and controlls respectively (Williams et al., 1987). The high $\mathrm{p} / \mathrm{s}$ ratio for CA-125, a glycoprotein with a molecular weight of approximately 200,000 daltons, can only be explained by active production of CA-125 in the peritoneal 
cavity. A much lower $p / s$ ratio has been documented for $C_{3}$ and $C_{4}$, wo proteins with a comparable molecular weight $(180,000, \mathrm{p} / \mathrm{s}$ ratio 0.25 and $260,000, \mathrm{p} / \mathrm{s}$ ratio 0.31 respectively; Bouckact et al, 1986 a) that reach the peritoneal cawity by transudation. Apparently the active production of CA-125 into the peritoneal cavity is not different between pattents with minimal endometriosis and controls. The authors did not mention, however, whether the controls were normal fertile women. If also women with "unexplained infertility" were included the presumed occurrence of microscopic active endometriosis in this group may have affected the results. It is of utmost importance to know whether in normal fertile women also high $\mathrm{p} / \mathrm{s}$ ratios of CA-125 can be found.

The studies on those peritoneal fluid proteins that are part of the fibrinolytic system (Malick, 1982; Batzofin et al., 1985) have been discussed in the section on etiology.

\subsection{The use of an experimental animal model of endometriosis}

Besides naturally occurring endometriosis in nonhuman primates, surgically induced endometriosis in animals has been used to study pathogenesis, etiology and treatment of endometriosis and to study the role of endometriosis in infertility. Successful autotransplantation of endometrial tissue in the peritoneal cavity has been documented for the rabbit (Jacobson, 1922; Schenken and Asch, 1980; Hahn et al., 1985), rat (Vernon and Wilson, 1985; Golan et al., 1986) and monkey (Scott and Wharton, 1957; DiZerega et al., 1980). Surgically induced endometriosis in the monkey is markedly similar in gross and histological appearance to human endometriosis. Moreover, the monkey has a spontaneous menstrual cycle. Most research has been performed on smaller, less costly, animals like the rabbit and the rat.

In addition, heterologous transplants of human uterine and ectopic endometrial tissue to athymic mice were found to implant, grow and respond to steroids (Zamah et al., 1984; Bergquíst et al., 1985a, 1985b).

\section{Pathogenesis and etiology}

To test Sampson's theory of retrograde menstruation as the cause of endometriosis, Scott, Te Linde and Wharton $(1950,1953)$ conducted several experiments in the monkey. They surgically diverted the cervix from the vagina to the peritoneal cavity in onder to create intraabdominal menstruation. Five out of ten monkeys developed adhesions adjacent to the cervix that histologically contained endometriosis. One animal developed endometriosis on the bowel wall and the peritoneum, confirming the ability of menstrual components to induce endometriosis.

Spontaneously occurring and induced endometriosis in the monkey was also used 
to study the role of steroids in controlling the growth and the development of endometriotic implants (Scott and Wharton, 1957; DiZerega et al., 1980). It was concluded that autotransplanted endometrial tissue was dependent on steroids for maintenance of growth but not for initiation of implantation. Conversely, steroids appeared to play an obligatory role in the development of ectopic endometrial inplants in the rat (Vernon and Wilson, 1985).

Another contribution to the pathogenesis and etiology of endometriosis was the observation of the development of endometriosis in Rhesus monkeys secondary to irradiation (McClure et al., 1971; Splitter et al., 1972; Wood et al., 1983). The irradiation supposedly altered the immunological response in the host, promoting proliferation of endometriosis. The decrease in cell-mediated immune response to autologous endometrial antigens found in monkeys with spontaneous endometriosis supports this view (Dmowski et al., 1981).

The ideal animal model to study pathogenesis and etiology of endometriosis will be a cyclically menstruating animal, in which different levels of immunodeficiency, humoral and cellular, and different levels of impeded menstrual egress anc/or increased uterotubal reflux can be effectuated independently. This model does not exist.

\section{Treatment}

The efficacy of various drug regimens, i.e. progestins, DES, danazol, has been tested in surgically induced endometriosis in the monkey (Scott and Wharton, 1955, 1962), the rat (Jones, 1984; Golan et al., 1986) and the rabbit (Hahn et al., 1985). Treatment by medical (GnRH-analogs) or surgical oophorectomy has been shown highly effective in induced endometriosis in monkeys (Werlin and Hodgen, 1983), rabbits (Hahn et al., 1985) and rats (Jones, 1984).

The efficacy of laser-treatment has been demonstrated in surgically induced endometriosis in the rabbit (Keye et al., 1983).

\section{Infertility}

Schenken and Asch (1980) induced endometriosis surgically in the rabbit and determined the number of corpora lutea and the number of intrauterine pregnancies 14 days after hCG administration and artificial insemination. They found significantly impaired fertility rates $(25 \%)$ as compared with controls $(75 \%)$, primarily due to a defect in ovulation. They suggested that the increased peritoneal fluid prostaglandin F levels that were found in rabbits with surgically induced endometriosis could alter follicular rupture, ovum transport, corpus luteum function or implantation, and thus contribute to the infertility seen in endometriosis. In a subsequent study Schenken and Walters (1986) demonstrated a reduced ovulation and recovery rate in rabbits with induced endometriosis. The reduced recovery rate was primarily due to adhesions. Tubal transport of owa was not disturbed.

Hahn et al. (1986) showed in a rabbit model of endometriosis that, in the absence of adhesions, ovulation, fertilization, embryonic cleavage and embryonic transport 
were not influenced by the presence of endometrial implants. However, on day 14 of pregnancy only $38 \%$ of the embryos had implanted in the experimental group as compared to $83 \%$ in intact controls. Likewise, the fertility of normal animals was impaired secondary to intraabdominal installation of peritoneal fluid from rabbits with induced endometriosis. From these results they concluded that the infertility in endometriosis may be associated with a factor in the peritoneal fluid that either prevents implantation or induces early spontaneous abortions.

Donnez et al. (1987) autografted endometrial tissue in rabbits and studied the effect of the implants on ovulation. They recorded the number of corpora lutea three, five and seven days after the administration of hCG, and found a significant decrease of corpora lutea in rabbits with endometrial implants, compared to controls. Histological examination also revealed a high incidence of entrapped ova. These investigators recorded the number of ovulation stigmata only several days after ovulation. Reepithelialization of the stigma may have taken place already at that moment, rendering the recognition of all recent ovulations more difficult. Furthermore, they studied only a small number of animals, while adhesions, distorting the genital tract, were present in 3 out of 5 of these animals.

Werlin et al. (1981) assessed follicular rupture and ovum recovery in the presence of ectopic endometrial tissue in monkeys. If adhesions secondary to endometriosis involved ovaries and fimbriae, ovum recovery and follicular rupture were impaired. Schenken et al. (1984) studied the cycles and fecundity of monkeys with induced endometriosis. In monkeys with moderate and severe endometriosis they observed LUF in $50 \%$ of the cycles. The chemical and term pregnancy rates were lower in monkeys with moderate and severe endometriosis compared with controls. The impaired feriility was primarily mediated by failure of follicular rupture and pelvic adhesions.

Vernon and Wilson (1985) showed that the presence of ectopic endometrial tissue in the peritoneal cavity of the rat interfered with fertility. There was a reduction of $30 \%$ in the number of embryos at midgestation and a $50 \%$ reduction of pups at term. It was suggested that the decreased fecundity was due to impairment of ovulation, fertilization and implantation.

In summary, the studies reviewed show that endometrial implants in animals are associated with decreased fertility primarily due to concomitant adhesions. These adhesions impair ovulation and recovery of the ova. Only few carefully conducted studies have been published employing microsurgical techniques in an attempt to prevent adhesion formation secondary to faulty surgical technique. In the absence of adhesions implantation failure or early embryonic loss appear to affect fertility in animals with endometrium implants. 


\section{References}

Abel MH, Kelly RW: Differential production of prostaglandins within the twuman uterus.

Prostaglandins 18: 821-828, 1979

Acosta AA, Buttram VC Jr, Besch PK, Malinak LR, Franklin RR, Vanderheyden JD: A proposed clas sification of pelvic endometriosis.

Obstet Gynecol 42: 19-25, 1973

Adams DO, Hamilton TA: The cell biology of macrophage activation.

Ann Rev Immunol 2: 283-318, 1984

Allen WA, Masters WH: Traumatic laceration of uterine support.

Am J Obstet Gynecol 70: 500-513, 1955

American Fertility Society: Classification of endometriosis.

Fertil Steril 32: 633-634, 1979

American Fertility Society: Revised American Fertility Society Classification of Endometriosis: 1985. Fertil Steril 43: 351-352, 1985

Andreyko JL, Marshall LA, Dumesic DA, Jaffe RB: Therapeutic uses of gonadotropin-releasing hormones,

Obstet Gynecol Surv 42: 1-21, 1987

Andrews WC, Larsen GD: Endometriosis: treatment with hormonal pseudopregnancy and/or operation. Am J Obstet Gynecol 118: 643-651, 1974

Andrews WC: Medical versus surgical treatment of endometriosis.

Clin Obstet Gynecol 23: $917-924,1980$

Audebert AJM, Larrue-Charlus S, Emperaire JC: Endometriosis and infertility. A review of sixty-two patierts treated with danazol.

Postgrad Med I 55: 10-13, 1979

Austin CR: Fate of spermatozoa in the female genital tract.

J Reprod Fert I: 151-156, 1960

Awadalla SG, Friedman CI, Haq AU, Roh SI, Chin NOW, Kim MH: Local peritoneal factors: "Their role in infertility associated with endometriosis.

Am J Obstet Gynecol 157: 1207-1214, 1987

Ayers JWT: Hormonal therapy for tubal occlusion: danazol and tubal endometriosis.

Fertil Steril 38: 748-750, 1982

Ayers JWT, Friedenstab AP: Utero-tubal hypotonia associated with pelvic endonetriosis.

American Fertility Society Annual Meeting: 131 (abstract), 1985

Ayers JWT, Birenbaum DL, Menon KMJ: Luteal phase dysfunction in endometriosis: ellewated progesterone levels in peripheral and ovarian veins during the follicullar phase.

Fertil Steril 47: 925-929, 1987 
Bad wy SZA, Marthall L, Gabal AA. Nabam ML: The concentration of 13,14-dibydro-15-keto prostaglandin $F_{2 \alpha}$ and prostaglandin $\mathbb{E}_{2}$ in periconeal fluid of infertile patients with and without endometrosis.

Herill steril 38: 166-170, 1982

Badawy S2A, Cuenca $V$, Marshall $L_{,}$Manchback R, Rinas AC, Coble DA: Cellular components in peritoneal nuid in infertile patients with and without endometriosis.

Fetul Steril $42: 704-708,1984$

Hawa SZA, Marshall L, Cuenca W: Peritoneal fluid prostaglandins in various stages of the nenstrual cycle: role in infertile patients with endometriosis.

Int I Fert $30: 48-52,1985$

Hadawy SZA, Cuenca $V$, Stifzell $A$, Tice DG: T and B lymphocytes in patients with endometriosis. Contr Gynec Obstet 16:317, 1987

Baker CR, Horger III EO, Williamson HO; Congentall atresia of the uterine cervix.

J Reprod Med 27: 39-43, 1982

Balasch $\mathbb{J}$, Vanrell $\mathbf{J A}$ : Mild endometriosis and luteal function.

Lnt J Fejtil 30:4-6, 1985

Batlin H: Follicular and lubal thids in the reproductive process.

Am J Obstet Gynecol 76: 30-3,6, 1958

Ball RY, Scott N, Mitchinson MJ: Further observations on spermiophagy by murine peritomeal macrophages in vitro.

J Reprod Fert $71: 221-226,1984$

Barbieri RL, Ryan KJ: Medical therapy for endometriosis: endocine pharmacology.

Sem Reprod Endocrinol 3: 339-352, 1985

Batbieri RL, Niloff JM, Bast RC Jr, Schaetzl E, Kistner RW, Knapp RC: Elevated serum concentrations of CA-125 in patients with adwanced endometriosis.

Fertil Steril 45:630-634, 1986

Bartosik D: Immunologic aspects of endometriosis.

Sem Reprod Endocrinol 3: 329-337, 1985.

Tartosik D, Jacobs SL, Kelly Ld: Endometrial tissue in peritoneal fluid.

Fertil Steril 46: 796-800, 1986

Bartosik D, Damjanov I, Viscarello RR, Riley JA: Immunoproteins in the endometrium: Clinical correlates of the presence of complement fractions $\mathrm{C} 3$ and $\mathrm{C} 4$.

Arir $₫$ Obstet Gynecol 156: $11-15,1987$

Batzolin JH, Holmes SD, Gibbons WE, Buttram VC Jr: Peritoneal hluid plasminogen activator activity in endometriosis and pelwic adhesive disease.

Fertil Steril 44: 277-279, 1985

Bast RC Jr, Klug TL, St John E, Jenison E, Niloff JM, Lazarus H, Berkowitz RS, Leavitt T, Griffiths T. "Parker L, Zurawski VR Jr, Knapp RC: A: radioimmunoassay using a monoclonal antibody to monjlor the course of epithelial ovarian cancer.

N Engll I Med 309: 883-887, 1983

Beers WH: Follicular plasminogen and plasminogen activator and the effect of plasmin on ovarian follicle wall,

Cell 6: 379-386, $1975 \mathrm{a}$ 
Beers WH, Strickland S, Reich E: Ovarian plasminogen activator. Relation to ovulation and hormonal regulation.

Cell $6: 387-394,1975 b$

Bergqvist A, Jeppson $S_{*}$ Kullander $S$, Ljundberg $O$ : Human endometrium transplanted into mude mice. Histologic effects of various sterolid hormones.

Am J Pathol 119: 336-344, 1985ia

Bergqvist A, Jeppson S, Kullander S, Ljundberg O: Human uterine endometrium and endometriotic tissue transplanted into nude mice. Morphologic effects of various steroid hormones.

Am J Pathol 121: 337-341, 1985b

Bergqvist D, Bergqvist A: Vascular injuries during gynecologic surgery.

Acta Obstet Gynecol Scand 66:19-23, 1987a

Bergqvist A, Bergqvist D, Lindholm K, Linell F: Endometriosis in the uterosacral ligament giving orthopedic symptoms through compression of the sciatic nerve and surgically treated via an extraperitoneal approach keeping the pelvic organs intact.

Acta Obstet Gynecol Scand 66: 93-94, 1987b

Bernard TM, Baumstark JS: Protein profile in peritoneal fluid and serum of women with endometriosis. Sac Gyn Invest 30: 192 (abstract), 1983

Bernardus RE, Dop PA van, Kessel H wan, Schoemaker J: New evidence for the existence of the luteinized unruptured follicle syndrome as a cause of infertility: a case report.

Fertil Steril 39: 376-378, 1983

Bernhard J: Tierexperimentelle Studien zur Genese der Endometriose.

Z Geburtish u Gyn 153: 112-136, 1959

Biberoglu KO, Behrman SJ: Dosage aspects of danazol therapy in endometriosis: shori-term and longterm effectiveness.

Am J Obstet Gynecol 139: 645-654, 1981

Binns BAO, Banerjee R: Endometriosis with Turner's syndrome treated with cyclical oestrogen/progestogen. Case report.

Br J Obstet Gynaecol 90: 581-582, 1983

Blumenkrantz MJ, Gallagher N, Bashore RA, Tenckhoff H: Retrograde menstruation in women undergoing chronic peritoneal dialysis.

Obstet Gynecol 57: 667-670, 1981

Bonney RJ, Davies P: Possible autoregulatory functions of the secretory products of mononuclear phagocytes.

Contemp Top Immunobiol 14: 199-223, 1984

Bouckaert PXJM: Peritoneumvloeistof. Biochemische veranderingen tijdems de menstruele cyclus. Thesis, Nijmegen, 1984

Bouckaert PXJM, Evers JLH, Doesburg WH, Schellekens LA, Brombacher PJ, Rolland R: Patterns of changes in proteins in the peritoneal fluid of women during the periovulatory phase of the mensirual cycle. I Reprod Fert 77: 329-336, 1986a

Bouckaert PXJM, Evers JLH, Doesburg WH, Schellekens LA, Rolland R: Patterns of changes in glycoproteins, polypeptides, and steroids in the peritoneal fluid of women during the periovulatory phase of the cycle.

I clin Endocrinol Metab 62: 293-299, 1986b 


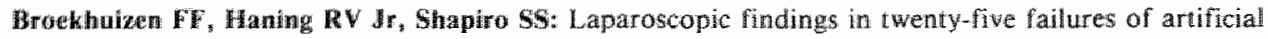
insemination.

Fertil Steril 34: 351-355, 1980

Brosens 1A, Koninckx PR, Corveleyn PA: A study of plasma progesterone, oestradiol-178, prolactin and. LH theves and of the luteal phase appearence of the ovaries in patients with endometriosis and infertility: Br J Obstet Gynaecol $85: 246-250,1978$

Brosens IA, Koninckx PR, Boeckx W: Endometriosis.

In: Clinics in Obstetrics and Gynecology, edited by MGR Hull, WB Saunders, London, 639-651, 1981

Brosens IA: Physiopathology of endometriosis in infertility and its treatment.

In: Medical management of endometriosis, edited by JP Raynaud et all, Raven Press, New York, 1-16, $1984 a$

Brosens IA, Vasquex, $G$, Gordts S: Scanning electron microscopic study of the pelwic peritoneum in unexplained infertility and endometriosis.

Fertil Steril 41:21S (abstract), 1984b

Brosens IA, Cornille F, Koninckx PR, Vasquez G: Evolution of the Revised American Fertility Society Classification of Endometriosis.

Fertil Steril 44: 714-715, 1985

Brosens IA, Verleyen A, Cornillie F: The morphologic effect of short-term medical therapy of endometriosis.

Am J Obstet Gynecol 157: 1215-1221, 1987

Bullock JL, Massey FM, Gambrell RD: Symptomatic endometriosis in teen-agers.

Obstet Gynecol 43: 896-900, 1974

Burke RK: Effect of peritoneal washings from women with endometriosis on sperm velocity.

I Reprod Med 32: 743-746, 1987

Bursuler 1, Goldman R: On the origin of macrophage heterogeneoty: A hypothesis.

I Reticuloendo Soc 33: 207-220, 1983

Buttram VC Ir: An expanded classification of endometriosis.

Fertil Steril 30: 240-242, 1978

Buttram VC Jr: Conservative surgery for endometriosis in the infertile female: a study of 206 patients with implications for both medical and surgical therapy.

Fertil Steril 31: 117-123, 1979

Buttram VC Jr: Treatment of endometriosis with danazol: report of a 6-year prospective study.

Fertil Steril 43: $353-360,1985 a$

Buttrum VC Jr, Reiter RC: Endonetriosis.

In: Surgical treatment of the infertile female, edited by Buttram VC Jr and Reiter RC, Baltimore, Williams \& Wilkins, 89-147, 1985b

Chacho KJ, Stronkowski Chacho M, Andresen PJ, Scommegna A: Peritoneal fluid in patients with and without endometriosis: Prostanoids and macrophages and their effect on the spermatozoa penetration assay.

Am J Obstet Gynecol 154: 1290-1299, 1985

Chacho KJ, Andresen PJ, Scommegna A: The effect of peritoneal macrophage incubates on the spermatozon assay.

Fertil Stertil 48: 694-696, 1987. 
Chang MC, Hunt DM: Effect of prostaglandin $F_{2 a r}$ on the early pregnancy of rabbits.

Nature (London) 236: 120-121, 1972

Chatman DL: Endometriosis in the black woman.

J Reprod Med 16: 303-306, 1976

Chatman DL: Pelvic peritoneall defects and endometriosis: Allen Masters syndrome revisited.

Fertil Steril 36: 751-756, 1981

Chattman DL, Ward AB: Endometriosis in adolescents.

J Reprod Med 27: 156-160, 1982

Chatman DL, Zbella EA: Pelwic peritoneal defects and endometriosis: further observations.

Frertil Steril 46: 711-714, $\mathbb{1 9 8 6}$

Chaudhuri G: Physiologic aspects of prostaglandins and leukotrienes.

Sem Reprod Endocrinol 3: 21.9-230, 1985

Cheesman KL, Ben-Nun I, Chatterton RT Jr, Cohen MR: Relationship of luteinizing hormone, pregnanediol-3-glucuronide, and estriol-16-glucuronide in urine of infertile women with endometriosis. Fertil Steril 38: 524-548, 1982

Cheesman KL, Day Cheesman S, Chatterton RT Jr, Cohen MR: Alterations in progesterone metabolism and luteal function in infertile women with endometriosis.

Fertil Steril 40: 590-595, 1983

Chihal HJ, Mathur S, Holtz GL, Williamson HO: An endometrial antibody assay in the clinical diagnosis and management of endometriosis.

Fertil Steril 46: 408-411, 1986

Chillick CF, Acosta AA, Garcia JE, Perera S, Uem JFHM van, Rosenwaks Z, Jones HW Jr: The role of in vitro fertilization in infertile patients with endometriosis.

Fertil Steril 44: 56-61, 1985

Cohn ZA: The activation of mononuclear phagocytes: fact, fancy and future.

J Immunol 121: 813-816, 1978

Collins JA, Wrixon W, Janes LB, Witson EH: Treatment-independent pregnancy among infertile couples.

N Engl J Med 309: 1201-1206, 1983

Cornillie FJ, Brosens IA, Vasquex G, Riphagen I: Histologic and ultrastructural changes in human en. dometriotic implants treated with the antiprogesterone steroid ethy/norgestrinone (Gestrinone) during two months.

Int J Gynecol Path 5: 95*109, 1986

Cornillie FJ, Puttemans P, Brosens IA: Histology and ultrastructure of human endometriotic tissues treated with dydrogesterone (Duphaston).

Eur J Obstet Gynecol Reprod Biol 26: 39.55, 1987

Crain JL, Lnciano AA: Peritoneal fluid evaluation in infertility.

Obstet Gynecol 61: 159.164, 1983

Cramer DW, Walker AM, Schiff I: Statistical methods in evaluating the outcome of infertility therapy. Fertil Steril 32: 80-86, 1979 


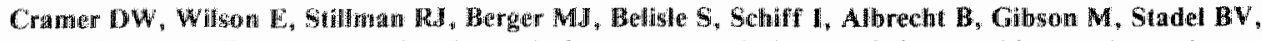
Solwenban $6 \mathrm{C}$ : The velation: of endometrosis to menstrial characteristics, smoking, and exercise. IAHA 25: 1904:1908, 1986

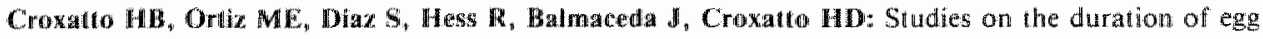
Iransport by the human oviduct.

Am J Obstet Gynecol 132:629-634, 1978

Croxatto HB, Ortz ME, Dialz 9 , Hess R: Attempts to modify owum transport in women.

J Reprod Fert $55: 231-237,1979$

Daly DC, Soto-Albors C, Walters C, Ying YK, Riddick DH: Ultrasonographic assessment of luteinizad urruptured follicle syndrome in tonexplained infertility.

Fertil Steril $43: 62-65,1985$

Daniell J: Operative laparoscopy for endometriosis.

Sem Reprod Endocrinol 3: 353-359, 1985

Damon M, Thater H, Mercklein L, Denjean R, Hedon B, Craster de Paulet A: Prostanoids in the peritoneal fluid of infertile women.

In: Medical management of endometriosis, edited by JP Raynaud et al., Raven Press, New York, $107.124,1984$

Dawood MY, Khan-Dawood, FS, Wilson I Jr: Peritoneal fluid prostaglandins and prostanoids in women with endometriosis, chronic pelvic inflammatory disease, and pelvic paun.

Anin J Obsitet Gymecol 148: 391-395, 1984

De Brux JA, Bret IA, Demay C, Bardiaux M: Recurring pelvic peritonitis.

Am J Obstet Gynecol $102: 501-505,1968$

De Leon FD, Vijayakuma $R_{*}$ Rao $C h V$, Yussman MA: Production of prostaglandin ( $\left.P G\right) F_{2}$ and PGE, by peritoneum involved with and without andometriosis.

Soc Cyn Invest 30: 16! (abstract), 1983

De Leon FD, Vijayakumar R, Brown M, Ra ChV, Yussman MA, Schultz G: Peritoneal fluid wolume, estrogen, progesterone, prostaglandim, and epidermal growh factor concentrations in patients with and without endometriosis.

Obstet Gynecol $68: 189-194,1986$

Derryberry WE, Bonney WA Jr: Pelvic endometriosis in a 15-yearmold.

Obutet Gyncol 27: $558-561,1966$

Deveretux WP: Endometriosis: long-term observation with particular reference lo incidence of pregnan$c y$.

Obstet Gynecol 22: 444-450, 1963

Dhont $\mathbf{M}$, Serreyn $\mathbf{R}$, Duvivier $\mathbf{P}$, Vanhuchene F, De Boever $J$, Vandekercklove $D$ : Ovelation and concontration of progesterone and estradiol in peritoneal fluid: relation with fertilty and endometriosis. Fertill Steril $41: 872-877,1984$

Dills PV Jr, Greene RR: Mulliple areas of endometriosis of the ectocervix and vagina. Anr J Obstet Cynecol $91: 292-295,1965$

Dizerega GS, Barber DL, Hodyen GD: Endometriosis: role of owarian steroids in initiation, mainrenance and suppression.

Fertil Steril 33: 649-653, 1980 
Djursing $\mathrm{H}_{\text {, Peterson }} \mathrm{K}$, Weberg $\mathrm{E}$ : Symptomatic postmenopausal endometrosis.

Acta Obstei Gynecol Scand 60: $529-530,1981$

Dnowski WP, Cohen MR: Treatmen of endometrosis with an antigonadotropin, danazol: a laparoscopic and histologic evaluation.

Obstet Gynecoll 46: 147-154, 1975

Dmowski WP, Cohen MR, Wilheim JL: Endometriosis and ovulation failure: Does it occur? Should ovulctory stimulating agents be used?

In: Recent advances in Endometriosis, edited by RB Greablat, Princeton, Excerpta Medica, 129-136. 1976

Dmowski WP, Cohen MR: Antigonadotropin (danazol) in the treatment of endometriosis. Evaluation of postreatment fertility and three-year follow-up data.

Am J Obstet Gynecol 130:41-48, 1978

Dmowski WP, Rao R, Scommegna A: The luteinized unruptured follicle syndrome and endometriosis. Fertil Steril $33: 30-34,1980$

Dmowski WP, Steele RN, Baker GF" Deficient cellular immunity in endometriosis.

Am I Obstet Gynecol 141: 377-383, 1981

Dmowski WP, Kapetanakis E, Scommegma A: Variable effects on endometriosis at 4 low dosis levels. Obstet Gynecol 59: 408-415, 1982

Dmowski WP, Radwanska E, Binor Z, Rana N: Mild endometriosis and ovulatory dysfunction: effect of danazoll treatment on success of ovulation induction.

Fertil Sterill $46: 784-789,1986$

Dmowski WP: Visual assessment of peritomeal implants for staging endometrosis: do number and cum mulative size of lesions tellect the severity of a systemic disease?

Fertil Steril $47: 382-384,1987$

Dodge ST, Pumphrey RS, Miyazawa K: Peritoneal endometriosis in women requesting reversal of sterilization.

Feril Steril $45: 774-777,1986$

Donnez J, Langerock S, Thomas K: Peritoneal fluid volume and $17 \beta$-estradion and progesterone concentrations in ovulatory, anovulatory and postmenopatusal women.

Obstet Gynecol 59: 697-692, 1982

Donnez J, Langerock $\$$, Thomas K: Peritoneal fluid volume, 17B-estradiol and progesterone concenträtioms in women with endometriosis and/or luteinized unruptured follicle syndrome.

Gynecol Obstet Invest $16: 210-220,1983$

Donnez J, Casanas-Ronx F, Caprasse J, Ferin J, Thomas K: Cyclic changes in ciliation, cell height, and mitotic actiwity in human tubal epithelium during areproductive life.

Fertil Steril $43: 554 \times 59,1985$

Donnez J, Wayembergh M, Casanas-Roux $\mathbf{F}$, Karaman $\mathbf{Y}$, Willems 1 , Ferin J: Effect on ovulation of surgically induced endometriosis in rabbits.

Gymecol Obstet Invest $24: 131-137,1987$

Doody MC, Gibbons WE, Butiram VC Jr: Linear regression analysis of ulirasound follicular growih series: evidence for an abnormality of follicular growth in endometriosis patients.

Fertil Steril $49: 47-51,1988$ 


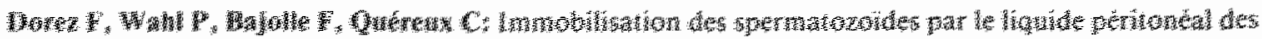

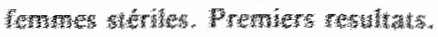

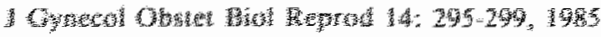

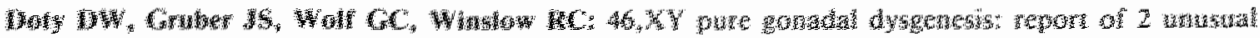

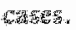

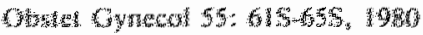

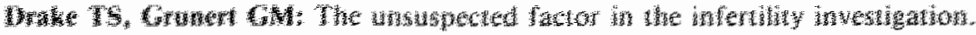

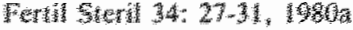

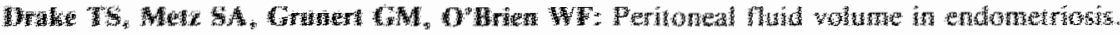

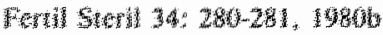

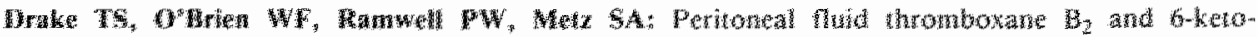

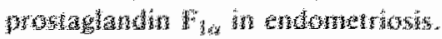

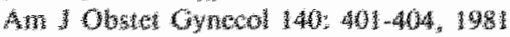

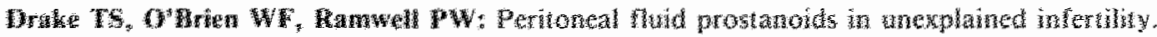

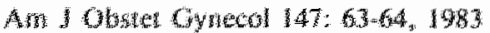

Ed

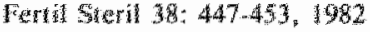

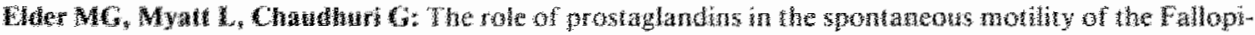

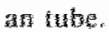

Fertil Steril 28: 86-90, 1977

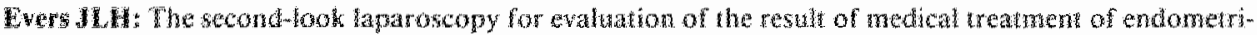
oxis showd not be performed during ovariat suppression.

Tertil Stent 47: $302-504,1987$

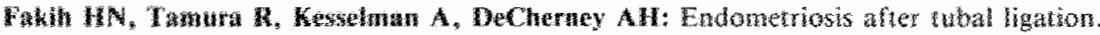

1 Reprod Med 30: 939-94, 1985

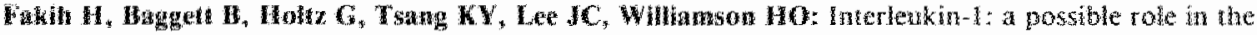
inferibly associated with endometriosis.

Fertil sterit 47; 213-217, 1987

Faltus RE: Endometriosis. Demonstration for the Sampson theory by a human anomaly.

Am J Obstet Gynecol 72: $557-561,1956$

Fazleabas AT, Khan-Dawood FS, Dawood MY: Protein, progesterone, and protease inhibitors in uterine and peritoneal fluids of women with endometriosis.

Fertil Steril 47: 218-224, 1987

FitzSimmons $\mathfrak{J}_{\text {, Stahl }} \mathbf{R}$, Gocial $\mathbf{B}$, Shapiro SS: Spontaneous abortion and endometriosis.

Fertil Steril 47: 696-698, 1987

Fortier KJ, Haney AF: The pathologic spectrum of uterotubal junction obstruction.

Obstet Gynecol 65: 93-98, 1985

Foster DC, Stern JL, Buscema $\mathbb{N}$. Rock JA, Woodruff JD: Pleural and parenchymal pulmonary en. dometriosis.

Obstet Gynecol 58: $552-556,1981$ 
Trey $\mathrm{GH}$ : The familial occurence of endometriosis.

Am I Obstet Gynecol $73 ; 418-421,1957$

Friedman H, Vogelzang $\mathrm{RL}_{4}$ Mendelson EB, Neiman HL Cohen N: Endometriosis detection by US with laparoscopic cortelation.

Radiology $157: 217-220,1985$

Gant PA, Hunt JB, McDonough PG: Progestin teversal of uneteral endometriosis.

Obstet Gynecoll 57: $665-667,1981$

Garcia CR, David SS: Pelvic endometriosis: infertility and pelvic pain.

Am J Obsiet Gynecol 129:740-747, 1977

Gerrity M, Rinehart JS, Shapiro SS: The effect of human peritoneal thuid on embryonic development. Anerican Fertility Society Annual Meeting: 58 (abstract), 1985

Gubbons WE, Buttram VC Jr, Rossavik IK: The observed incidence of luteinized unruptured tollicles in a population of infertile women andergoing ovulation monitoring by ultrasound.

Fertil Steril $41: 195,1984$

Glass RH, Golbus MS: Habutual abortion.

Fertil Steril 29:257-265, 1978

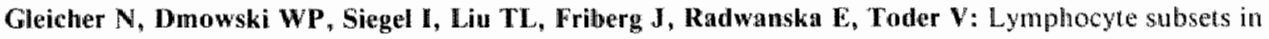
endometriosis.

Obstet Gynecol 63: $463-466,1984$

Cleicher N, El-Roeiy A, Confino E, Friberg I: Is cndometriosis an autoimmune disease?

Obstet Gynecol 70: 115-122, 1987

Golan A, Dargemio R, Winston RML: The effect of treatment on experimentally produced andonetrial implants.

Fertil Steril $46: 954-958,1986$

Goldenberg RL, Magendanta HG: Laparoscopy and the infertility evaluation.

Obstei Gynecol 47: 410 414, 1976

Goldman SM, Minkin SI: Diagnosing endometriosis with ultrasonnd. Accuracy and specificilly.

I Reprod Med 25: 178-182, 1980

Goldstein DP, deCholnoky $\mathbf{C}$, limans $\mathbf{S}$, Leventhal $\mathbf{I M}$ : Latparoscopy in the diagnosis and ananagement of pelvic pain in adolescents.

J Reprod Med 24: $251-256,1980$

Coodall JR: A study of endometriosis, endosalpingosis, endocervicosis, and peritoneomavarian scterosis: a clinical and pathologic suludy.

Philadelphia: JB Lippincot, 1943

Gordts S, Boeckx W, Vasquez G, Brosens IA: Microsurgical resection of intramural fubal polyps. Fertill Steril $40: 258-259,1983$

Gordits S, Boeckx W, Brosens IA: Microsurgery of endometriosis in infertile patients. Feril Steril 42: $520-525,1984$

Gould SF, Shannon JM, Cunha GR: Nuclear estrogen binding sites in human endometriosis. Fertil Steril 39: $520-524,1983$ 
Grant A: Additional sterility lactors in endometriosis.

Fertil Steril 17: $514-519,1966$

Grant A: Abnormal luteal function in endometriosis.

Fertil Steril 35: 592,1981

Gray LA: Surgical treatment of endometriosis.

Clin Obstet Gynecol 3: 4,2-491, 1960

Green TH: Conservative surgical treatment of endometriosis.

Clin Obster Gynecol 9: 293-308, 1960

Greenblat RB, Tzigoumis $\mathbf{V}$ : Danazol treatment of endomeriosis: longterm follow up.

Fertil Steril 32: $518-520_{n} 1979$

Greenhill JP: Endometriosis

In: The yearbook of Obstetrics and Gynecology, 431, 1942

Groll M: Endometriosis and spontaneous abortion.

Fertil Steril 41: 933-935, 1984

Guzick DS, Bross DS, Rock JA: Assersing the efficacy of the American Fertility Society's classification of endometriosis: application of a dose response methodology.

Fertil Sterii 38: 171-176, 1982

Hajdln S1, Koss LG: Endometriosis of the kidney.

Am J Obstet Gynecol 106: 314-315, 1970

Hahn DW, Carraher RP, Foldesy RG, McGuire JL: Development of an anmal model for evaluating effects of drugs on endometriosis.

Fertill Steril 44: 410-415, 1985

Hahn DW, Carraher RP, Foldesy RG, McGuire JL: Experimental evidence for failure to implant as a mechanism of infertility associated with endometriosis.

Ann J Obstet Gynecol 155: 1109*1113, 1986

Halme J, Hall JL: Effect of pelvic fluid from endometriosis patients on human sperm penetration of zona free hamster ova.

Fertil Steril 37: 573-576, 1982

Halme J, Becker S, Hammond MG, Raj HMG, Raj S: Increased activation of pelvic macrophages in infertile women with mild endometriosis.

Am J Obstet Gynecol 145: 333.337, 1983

Halme J, Hammond MG, Hulka JF, Raj SG, Talbert LM: Retrograde menstruation in healthy women and in patients with endometriosis.

Obstet Gynecol $64: 151-154,1984 a$

Halme J, Becker S, Wing R: Accentuated cyclic activation of peritoneal macrophages in patients with endometriosis.

Am J Obsiet Gynecol 148:85-90, 1984b

Halme J, Becker S, Haskill S: Altered maturation and function of peritoneal macrophages: Possibie role in pathogenesis of endometriosis.

Arru J Obstet Gynecol 156: 783-789, 1987a 
Halne $\mathbb{J}$, Mathur S: Local autommunity in mild endometriosis.

Int J Fert 32: $309-311,1987 \mathrm{~b}$

Hamilton CICM, Wetzels ILCG, Exers JLH, Hoogland HJ, Muijtjens A, Haan J dfe: Follicle growth curves and hormonal patterns in patients with the luteinized unruptured follicle syndrome.

Fervil Steril 43: $541-548,1985$

Hammond CB, Rock JA, Parker RT: Conservative ireatment of endometriosis: the effects of linited surgery and hormonal pseudopregnancy.

Fertil Steril 27: 756-766, 1976

Hammond MG. Jordan S, Sloan CS: Factors affecting pregnancy rates in a donor insemination program using frozen semen.

Am J Obstet Gynecol 155:480-485, 1986

Haney AF, Muscato JJ, Weinberg JB: Peritoneal fluid cell populations in infertility patients.

Fertil Steril 35: 696*698, 1981

Haney AF, Misukonis MA. Weinberg JB: Macophages and infertility: oviductal macrophages ats potential mediators of infertility.

Fertil Sterill 39: 310-315, 1983

Hanton EM, Malkasian GD Jr, Dockerty MB, Pratt JH: Endometriosis associated with complete or partial obstruction of menstrual egress.

Obstet Gynecol 28: 626-629, 1966

Hanton EM, Malkasian GD Jr, Dockerty MB, Pratt JH: Endometriosis in young women.

Am J Obstet. Gynecol 98: 116-120, 1967

Hargrove MJK, Valenzuela G, Hodgson BJ: Abnormal luteal function in endometriosis.

Fertil Steril 34: 302, 1980

Harper MKJ, Coons LW, Radicke DA, Hodgson BJ, Valenzuela G: Role of prostaglandins in contractie activity of the ampulla of the rabbit oviduct.

Am J Physiol 238: E157-166, 1980

Hasson HM: Incidence of endomeiriosis in diagnostic laparoscopy.

If Reprod Med 16: 135-138, 1976

Henriksen E, in discussion, Scott RB, Te Linde RW, Wharton LR Jr: Further studies on experimental endometriasis.

Am J Obstet Gynecol 66: 1082-1103,1953

Hibbard LT, Schumann WR, Goldstein GE: Thoracic endonuetriosis: an review and report of lwo cases. Am J Obstet Gynecol 140: 227-232, 1981

Hibbard J, Schreiber JR: Footdrop due to sciatic nerve endometriosis.

Am J Obstet Gynecol 149: 800-801, 1984

Hill JA, Haimovici F, Politch JA, Anderson DJ: Efrects of soluble products of activated macrophages (lymphokines and monokines) on human sperm motion parameters.

Fertil Steril 47: 460.465, 1987

Hirschowiz JS, Soler NG, Wortsman J: The galactorrhoca-endometriosis syndrome.

Lancet i: 896-898, 1978 
Houston WE: Evidence of the risk of pethe endometrosis by age, race and socioeconomic status. Epid Reviews 6: 167-191, 1984

Hull ME, Moghisgi: KS, Magyar DF, Hayes MF: Comparison of different treament modalities of endometriosis in infertile women.

Feriil sicrill $47: 40-44,1987$

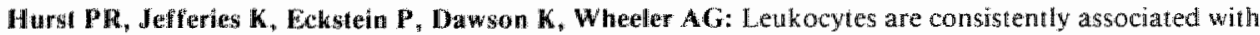
degenerating mbryos in UD-bearing rhesus monkeys.

Nalure 269: $331-333,1977$

Huybregts. PJM, Meumissen JHMM, Wiegerinck MAHM: Endometriosis en climacterium.

Ned Tijdsch Geneesk 128: 714-716, 1984

Jacobson VC: The autotransplantation of endometrial tissue in the rabbit.

Arch Surg: 5: 281-300, 1922

Jánne O, Kaupilla $\mathbf{A}$, Kokko $\mathbf{E}$, Lantto $\mathbf{T}$, Rönnberg $\mathbb{L}_{\text {, }}$ Vilhko $\mathbb{R}$ : Estrogen and progestin receptors in endometriosis lesions: comparison with endometrial tissue.

Am J Obstat Gynecol 141:562,566, 1981

Jansen RPS: Spontaneous abortion incidence in the treatment of infertility.

Am J Obstet Gynecol 143:451:473, 1982

Jansen RPS: Minimal endometriosis and reduced lecundability: prospective evidence from an artificial insenination by donor program.

Fertil Steril $46: 141-143,1986 a$

Jansen RPS, Russell P: Nonpigmented endometriosis: Clinical, laparoscopic, and pathologic definition. Am J Obstet Gynecol 155: 1160-1』63,1986b

Javert CT: Pathogenesis of endometriosis based on endometrial homeoplasia, direct extension, exfoliation and implantation, lymphatic and hematogenous metastasis.

Cancer 2: 399-410, 1949

Javert CT: The spread of benign and malignant endometrium in the lymphatic system with a mote of coexisting vascular involvement.

Am J Obstet Gynecol 64: 780-802, 1952

Jenkins S, Mive DL. Haney AF: Endometriosis: pathogenefic implications of the anatomic distribution. Obstet Gynecol 67: $355-338,1986$

Jones RC" The effect of luteinizing hormone releasing (LRH) agonist (Wy-40,972), levonorgestrel, danazol, and owariectomy on experimental endometriosis in the rat.

Acta Endocrinol 106: 282-288, 1984

Kable WT Ill, Yussman MA: Fertility after conserwative treatmen of endometriosis.

I Reprod Med 30:857 863,1985

Katayama KP, Ju KS, Manuel M, Jones GS, Jones HW Jr: Computer analysis of efology and pregnanoy rate in 636 enses of primary infertility.

Am J Obstet Gyruecol 135:207-2141979

Kauma S, Clark M. White C, Halme J: Fibronectin production by human peritoneal macrophages in patients with endometriosis.

American Fentily Society Anmual Meeting: 19 (abstract), 1987 
Kaupila A. Rajanieni H, Rönberg L: Low LH (hCG) rectotor concentration in ovarian follides in endometriosis.

Acta Obstet Gynecol Scand 61: $81-83,1982$

Keettel WC, Stein RJ: The viability of the cast-off menstrual endomatrium.

Am 1 Obstet Gynecol 61: $440-442,1951$

Kempers RD, Dockerty MB, Hunt AB, Symmonds RE" Significant postmenopalusal endometriosils. Surg Gynec Obstet 111:348-356, 1960

Kerin JF, Kirby L, Morris D, MeEvoy M, Ward B, Cox L: Incidence of the luteinized unruptured follicle plrenomenon in cyolling women.

Fertil Sieril 40:620-626, 1983

Keye WR, Matson GA, Dixon J" The use of the argon laser in the treatment of experimemal andomatriosis.

Fertil Steril 39:26-29, 1983

Killick S, Elstein M: Pharmacologic production of luteinized unruptured follicles by prostaglandin synthetase inbibitors.

Fertil Steril $47: 773 \times 777,1987$

Kistmer $\mathbb{R W}$ : Management of endometriosis in the infertile patient.

Fertil Steril 26: 1151-1166, 1975

Kistner RW, Siegler AM, Behrman SJ: Suggested classilication for endometriosis: relationship to inferthility.

Fertil Steril 28: 1008-1010, 1977

Kistner RW: Infertility. Endometriosis 1984.

In: Yearbook of Obstetrics and Gynecology, edited by RM Pitkin and FJ Zlatnik, Chicago, Yearbook medical publishers Inc, $365-380,1984$

Koninckx PR, Renaer M, Brosens IA: Origin of peritoneal fluid in women: an ovarian exudation. product.

Br J Obstet Gynaecol 87: 177-183, 1980a

Koninckx PR, De Moor P, Brosens IA: Diagnosis of the luteinized unruptured follicle syndrome by steroid homone assays in peritoneal fluid.

Br J Obstet Gynaecol 87: 929-934, $1980 \mathrm{~b}$

Koninckx PR, Heyns W, Verloeven G, Baclen H wan, Lissens WD, Moor P de, Brosens IA: Biocthomical characterization of peritoneal fluid in women during the menstruall cycle.

J cllin Endocrinol Metab 51: 1239-1244, 1980c

Konitrekx PR, Ide P, Vandenbroucke W, Brosens IA: New aspects of the pathophysiology of endomettiosis and associated infertility.

I Reprod Med 24, 257-260, $1980 d$

Koninckx PR, Brosens IA: Clinical significance of the Itteinized unruptured follicle syndrome as a cause of infertillity.

Eur J Obstet Gynecol Reprod Biol 13: 355-368, 1982

Koninckx PR, Muyldermans M, Brosens 1A: Unexplained infertility: 'Leuven' considerations.

Eur J Obstet Gynecol Reprod Biol 18: 403-413, 1984 
Heiner D, Fromowitz H, Richardson D. Keniggberg D: Endometrial immunofluorescence associated with endometriosis and pelvic inflammatory disease.

fertil Stern $46: 243 \cdot 246,1986$

Kresch Ad, Seifer DA, Sachs LB, Harese I: Laparoscopy in 100 women with chronic pelvic pain. Obstet Gynecol 64:672-674, 1984

Kühn W, Stammler HI, Nedkel E: Endometriose: Implantation oder Metaplasie. Geburish u Fraubnbeilk 41:698-701, 1981

Lamb K. Hoffman RG, Nichols TR: Family trat analysis: A case control study of 43 women with endometriosis and their best friends.

Am J Obstet Cynecol 154:596-601, 1986

Langmade Clf: Pelvic endometriosis and ureteral obstruction.

Am J Obstet Gynecol 122:463-469, 1975

Lattes $\mathbf{R}$, Shepard 7 , Tovell $\mathbf{H}_{3}$ Wylie $\mathbf{R}$ : A clinical and pathological study of endometriosis of the lung. Sury Gynecol Obstet 103: 552-558, 1956

labe DW, Calderwood GW, Benda JA: Endometriosis causing ureteral obstuction. Obsitet Gynecol $65: 695-715,1985$

Lauchinn SC: The cytology of endometriosis.

An J Obster Gynecol 94:533-535, 1966

Lauchlan SC: The secondary Muillerian system.

Obstet Gynecol Survey 27: 133-146, 1972

Loridon H, Spira A: Problems in measuring the effectiveness of infertility therapy.

Fertil Steril 41: $580-586,1984$

Lesorgen PR, Wu CH, Green PJ, Gocial B, Lerner La: Peritoneal fluid and serum steroids in inferility patients.

Fertil Steril $42: 237-242,1984$

Levander G, Normann P: The pathogenesis of endometriosis. An experimental study. Acta Obstet Gymecol Scand 34:366-398, 1955

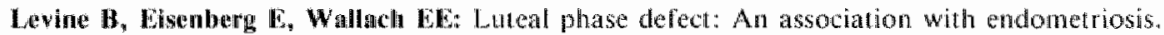
Fertil Steril 39: 394-395, 1983

Levilt MJ, Tobon H, Josimovich $\mathbf{J B}$ "Prostaglandin content of human endometrium. Fertil Steril 26: 296-300, 1975

Levy BS, Sodwstrom RM, Dall DH: Bowel injuries during laparoscopy. Gross anatomy and histology. I Reprod Med $30: 168-172,1985$

Lat DTY, Hitencok A: Endometriosis" ats association with revograds menstruation, dysmenorthoea and tubal pathology.

Br J Obstet Gynaecol 93: 859-862, 1986

Línkkonew S, Koskinnies Al, Tenhumen A, Ylöstalo P: Diagnosis of luteinized unruptured follicle (LUF) syndrome by ultrasound.

Fartil Steril $41: 26-30,1984$

Loyd FP: Endometriosis in the Negro woman.

An IObstet Gynecol $89: 468-469,1964$ 
Lomedon SN, Haney AF, Weinberg MB: Macrophages and infertility: enhancement of human macrophage mediated sperm killing by antisperm antibodies.

Feriil Steril 43: 274-278, 1985

Lombardo L, Mateos JH, Barroeta FF: Subarachnoid hemorrage due to endometriosis of the spinal canal.

Neurology 18: 423-426, 1968

Loumaye E, Donnez J, Lees DAR: Ovulation instantaneously modif fies women's peritoneal fluid charactheristics: a demonstration from an in vitro fertilization program.

Fertil Steril 44: 827-829, 1985

Maathuis JB, Houx PCW, Bastiaans LA, Mastboom JL: Some properties of peritoneal fluid obtained by laparoscopy from fertile and infertile women.

J Reprod Fert 35: 630-632, 1973

Maathuis JB: Studies on cyclic changes in the human female genital tract.

Thesis, Leiden, 1977

Maathuis JB, Van Look PFA, Michie EA: Changes in wolume, total protein and ovarian steroid concentration of peritoneal fluid throughou the human menstrual cycle.

J Endocrinol 76: 123-133, 1978 .

Mahadevan MM, Trounson AO, Leeton JF: The relationship of tubal blockage, infertility of unknown cause, suspected male infertility, and endometriosis to success of in vitro fertilization and embryo transfer.

Fertil Steril 40: 755-762, 1983

Malick JE: The etiology of endometriosis.

Journal of A A 81 : 407-412, 1982

Malinak LR, Buttram VC Jr, Elias S, Simpson JL: Heritable aspects of endometriosis. HI. Clinical characteristics of familial endometriosis.

A.m J Obstet Gynecol 137: 322-337, 1980

Marik J, Hulka J: Luteinized unruptured follicle syndrome: a subtte cause of infertility.

Fertil Steril 29: 270-274, 1978

Mathur S, Peress MR, Willianson HO, Youmans CD, Maney SA, Garvin AJ, Rust PI, Fudenherg HH: Autoimmunity to endometrium and ovary in endometriosis.

Clin exp Immunol 50: 259-266, 1982

Matson PL, Yovich JL: The treatment of infertility associated with endometriosis by in vitro fertilization.

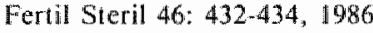

Meigs JV: An interest in endometriosis and its consequences.

Am J Obstet Gynecol 79:625-635, 1960

Merrill JA: Endometrial induction of endometriosis across millipore filters.

Am J Obstet Gynecol 94: 780-789, 1966

Metzger DA, Otive DL, Stohs GF, Franklin RR: Association of endometriosis and spontaneous abortion: effect of control group selection.

Fertil Steril 45: 18-22, 1986 
Meyer R: Ueber den Stand der Frage der Adenomyositis und Adenomyome in algemeinen und insbesondere über Adenomyositis serosoepithelialis und Adenomyometritis sarcomatosa.

Ztb॥ O Oynaek 43: 745-750, 1919

McClure HM, Ridley JH, Graham CE: Disseminated endometriosis in a Rhesus monkey (Macaca Mulat(a). Histogenesis and possible relationship to irradiation exposure.

J Med Assoc Ga $60: 11 \cdot 13,1971$

Miyazawa K: Incidence of endomeiriosis among Japanese women.

Obstei Gynecol 48: 407-409, 1976

Moeloek FA, Affandi B, Samil RS: Peritoneal factors in infertile women in Jakarta, Indonesia. J Reprod Med 29: 603-608, 19.84

Moen MH, Bratlie A, Moen T: Distribution of HLA-amtigens among patients with endometriosis. Acta Obstet Gynecol Scand 123: 25-27, 1984

Moen MH: Endometriosis in wromen at interval sterilization.

Acta Obstet Cynecol Scand 66: 451-454, 1987

Moon YS, Leung PCS, Ho Yuen B, Gomel V: Prostaglandin F in human endometriotic tissue. Ann J Obstet Gynecol 141:344-345, 198 I

Moore JG, Schifrim BS, Erex S: Ovarian tumors in childhood and adolescence.

Am IObstet Gynecol 99: 913-922, 1967

Moore JG, Hibbard LT, Growdon WA, Schifrim BS: Urinary tract endometriosis: enigmas in diagnosis and managennent.

Am 』 Obstet Gynecol 134: 162-172, 1979

Morces RN, Gibbons WE, Findley WE: Effect of peritoneal fluid on in vitro cleavage of 2-cell mouse embryos: possible role in infertility associated with endometriosis.

Fertil Steril 44: 678-683, 1985

Moyer DL, Rimdusit S, Mishell D: Sperm distribution and degradation in the human female reproductive tract.

Obstet Gynecol 35: 831-840, 1970

Mudge TI, James MJ, Jones WR, Walsh JA: Peritoneal fluid 6-keto prostaglandin Fta levels in women with endometriosis.

Am $\sqrt{ }$ Obstet Gynecol 152: 901 904, 1985

Murphy A, Green WR, Bobbie D, Cruz ZC dela, Rock JA: Unsuspected endometriosis documented by scanning electron microscopy in visually normal peritoneum.

Fertill Steril 46: $522-524,1986$

Muscato JJ, Haney AF, Weinherg JB: Sperm phagocytosis by human peritoneal macrophages: a possible caluse of infertility in endometriosis.

Am 『 Obstet Gynecol 144: 503-510, 1982

Muse K, Wilson EA: How does mild endometriosis cause infertility?

Fertil Steril $38: 145-152,1982 \mathrm{a}$

Muse K, Wilson EA, Jaward $\mathbf{H J}_{*}$ Prolactin hyperstimulation in response to thyrotropin-releasing hormone in patients with endometriosis.

Fertil Steril 38: 419-422, $1982 \mathrm{~b}$ 
Naples JD, Batt RE, Sadigh H: Spontaneous abortion rate in patients with endometriosis.

Obstet Gynecol $57: 509-512,1981$

Nathan CF, Murray HW, Cohn ZA: The macrophage as an effector cell.

N Engl J Med 303: 622-626, 1980

Nathan CF: Secretory products of macrophages.

$\mathrm{J}$ clin Invest $79: 319-326,1987$

Nelson DS: Macrophages: progress and problems.

Clin exp Immunol 45: 225-233, 1981

Nikkanen V, Punnonen R: External endometriosis in 801 operated patients.

Acta Obstet Gynecol Scand 63: 699-701, 1984

Nowak E: Pelvic endometriosis. Spontaneous rupture of endometrial cysts, with a report of three cases.

Am J Obstet Gynecol 22: 826-837, 1931

Oak MK, Chantler EN, Vaughan Williams CA, Elstein M: Sperm survival studies in peritoneal fluid from infertile women with endometriosis and unexplained infertility.

Clin Reprod Fert 3: 297-303, 1985

Ohtsuka N: Study on pathogenesis of adhesions in endometriosis.

Acta Obst Gynaec Jpn 32: 1758-1766, 1980

Oliker AJ, Harris AE: Endometriosis of the bladder in a male patient.

J Urol 106: 858-861, 1971

Olive DL, Franklin RR, Gratkins LV: The association between endometriosis and spontaneous abortion.

A retrospective clinical study.

J Reprod Med 27: 333-336, 1982

Olive DL, Stohs GF, Metzger DA, Franklin RR: Expectant managenent and hydrotubations in the treatment of endometriosis-assiociated infertility.

Fertil Steril 44: 35-41, 1985 a

Olive DL, Weinberg JB, Haney AF: Peritoneal macrophages and infertility: the association between cell number and pelvic pathology.

Fertil Steril 44: 772-777, 1985b

Olive DL, Haney AF: Endometriosis-associated infertility: A critical review of therapeutic approaches. Obstet Gynecol Surv 41: $538-555,1986$

Olive DI, Henderson DY: Endometriosis and Müllerian anomalies.

Obstet Gynecol 69:412-415, 1987

O'Shea RT, Chen C, Weiss T, Jones WR: Endometriosis and invitto fertilisation.

Lancet ii: 723,1985

Patton PE, Field CS, Harms RW, Coulam CB: CA.125 levels in endometriosis.

Fertil Steril 45: 770 773, 1986

Peters AAW, Trimbos JB, Elie HJM, Van Hall EV: De betekenis van laparoscopie bij chronische buik. pijn.

Ned Tijdschr Geneeskd 130: 1319-1321, 1986

Petersohn L: Fertility in patients with ovarian endometrio-sis before and after treatunent.

Acta Obstet Gynecol Scand 49: 331-333, 1970 
Peterson $\mathbf{E}$, Bethman Sil Laparoscopy of the infertile patient.

Obstel Cynecol $36: 363-367,1970$

Peterson HB, Destefano F, Rubin GL, Greengan JR, Lee NC, Ory HW: Deaths attributable to ubal sterifization in the United states, 1977 to 1981.

Am J Obstet Cynecol 146: 131-136, 1983

Pinkert TC, Catlon EE, Straus A: Endometriosis of the urinary bladder in a man with prostatic carcinomai.

Cancer $43: 1562-1567,1979$

Pillaway DE, Maxson W, Daniell J, Herbert $C$, Wentz AC: Luteal phase defects in infertility patients with endometriosis.

Fertill Steril $39: 712-713,1983$

Pitlaway DE, Wentz AC: Endometriosis and corpus luteum function. Is there a relationship?

J Reprod Med 29: 712-716, 1984

Phtlaway DE, Fayez JA: The use of CA-125 in the diagnosis and management of endometriosis.

Fertil Steril 46: $790.795,1986$

Portenondo JA, Herran C, lichanojiauregui AD, Riego AG: Peritoneal flushing and biopsy in laparoscopically diagnosed endometriosis.

Fertill Steril 38: $538-541,1982$

Portuondo JA, Echanojauregui AD, Herran C, Alijarte I: Early conception in patients with untreated nild endometriosis.

Fertil Steril 39: 22-25, 1983

Punnonen R, Klemi P., Nükanen V: Postmenopausal endometriosis.

Eur J Obstet. Gymaecol Reprod Biol 11: 195-200, 1980

Radwanska E, Henig I, Dmowski WP: Nocturnal prolactin levels in infertile women with endometriosis. J Reprod Med 32: 605 608, 1987

Ranney B: Endometriosis: 11. Emergency operations due to hemoperitoneum.

Obstet Gynecol 36: 437-440, 1970

Ranney B: Endometriosis: IV. Heriditary tendency.

Obstet Gynecol 37: 734-737, 1971

Ranney B: Endometriosis: pathogenesis, symptoms, and findings.

Clin Obstet Gynecol 23: 865-874, 1980

Redwine Dn: Atypical endometriosis.

American Fertility Society Annual Meeting: 64 (abstract), 1985

Redwine DB: Age-related exolution in color: appearence of endometriosis.

Fertill Sterid 48: $1062,1063, \| 987$

Rezai N, Ghodgaonkar RB, Zacur HA, Rock JA, Dubin NH: Cul-de-sac fluid in women with endornetriosis: flud volume, protein and prostanoid concentration during the periovulatory period-days 13 to 18 . Fertil Steril 48: 29.32, 1987

Ridley JH, Edwards IK: Experimental endometriosis in the human.

Am I Obstet Gynecol 76: 783-790, 1958 
Ridley $\mathbf{J H}$ : The histogenesis of endometriosis. A review of facts and fancies. Obstet Gynecol Survey 23: $1-35,1968$

Rock JA, Guzick DS, Sengos C, Schweditsch M, Sapp KC, Jones HW Jr: The conserwative surgical treatment of endometriosis: evaluation of pregnancy success with respect to the extent of disease as categorized using contemporary classification systems.

Fertil Steril 35: 131-137, 1981

Rock JA, Dubin MH, Ghodgankor RB, Berquist CA, Erozan YS, Kimball AW: Cul-de-sac fluid in women with endometriosis: fluid volume and prostanoid concentration during the proliferative phase of the cycle-days 8 to 12 .

Fertil Steril 37: $747-752,1982$

Rönnberg L, Kaupilla A, Rajaniemi H: Luteinizing hormone receptor in endometriosis. Fertil Steril $42: 64-68,1984$

Rosenfeld DL, Chudow S, Bronson RA: Diagnosis of luteal phase inadequacy. Obstet Gynecol 56: 193-196, 1980

Rosenfeld DL, Lecher BD: Endometriosis in a patient with Rokitansky-Kuster-Hauser syndrome. Am J Obstet Gynecol 139: 105, 1981

Saifuddin A, Buckley CH, Fox H: Immunoglobulin content of the endometrium in women with endometriosis.

Int. J Gynecol Pathol 2: 255-263, 1983

Salomy M, Goldstein PJ: Prevention of pregnancy in rabbits using vaginal application of prostaglandin F $2 \alpha$.

Fertil Steril 29: 456-458, 1978

Sanfilippo JS, Wakin NG" Schikler KN, Yussman MA: Endometriosis in association with uterine anomaly.

Am J Obstet Gynecol 154: 39-43, 1986

Sampson JA: Perforating hemorrhagic (chocolate) cysts of the ovary; their importance and especially their relation to pelvic adenomas of endometrial type (adenomyoma of the uterus, rectovaginal septum, sigmoid, etc.).

Arch Surg 3: 245-323, 1921

Sampson JA: Peritoneal endometriosis due to menstrual dissemination of endometrial tissue into the peritoneal cavity.

Am J Obstet Gynecol 14: 422-469, 1927a

Sampson JA: Metastatic or embolic endometriosis due to menstrual dissemination of endometrial tissue into the venous circulation.

Am J Pathol 3: 93-109, 1927b

Sampson JA: The dewelopment of the implantation theory for the origin of peritoneal endometriosis. Am J Obstet Gynecol 40: $549-557,1940$

Schellekens LA, Bouckaert PXJM, Yan der Cruys MFHA: The contraceptive effect of the pill is not mediated by the quality of the peritoneal fluid.

XIth World congress on Fertility and Sterility Dublin, Ireland: 324 (abstract) 1983

Schenken RS, Asch RH: Surgical induction of endonetriosis in the rabbit: effects on fertility and concen* trations of peritoneal fluid prostaglandins.

Fertil Steril 34: $581-587,1980$ 
Schenken IS, Malinats, LR: Constervative surgery versus expectant management for the infertile patient whth mild endometriosis.

Fertil Steril 37: 183-186, 1982

Schenthen RS, Asch RH, Williams RF, Hodgen GD: Exiology of infertility in monkeys with endometriosis: luteinized unruptured follicles, luteal phase defects, pelvic adhesions, and spontaneous abortions. Fertil Steril 41: 122-130, 1984

Schenken RS, Walters MD: Ovulation and tubal ovum tramsport in rabbits with endometriosis. Proc Soc Gynecol Invest: 215 (abstract), 1986

Schifrin BS, Erez S, Moore JG: Teen-age endometriosis.

Am J Obstet Gynecol 116: 973-980, 1973

Schmidt CL: Endometriosis: A reappraisal of pathogenesis and treatment.

Fertill Steril $44: 157-173,1985$

Schneider EG, Daniele AE, Polan ML: Lymphokines (interleukins 1 and 2) are not toxic to early mouse embryo development.

Americar Fertility Society Annual Meeting: 21 (abstract) 1987

Schrodt GR, Alcorn MD, Ibanez J: Endometriosis of the male urinary system: a case report. J Urol 124: $722-723,1980$

Schweppe KW, Dmowski WP, Wynn RN: Ultrastructural changes in endometriotic tissue during danazol treatment.

Fertil Steril 36: 20-26, 1981

Schweppe KW: Morphologie und Klinik der Endometriose.

FK. Schattauer Verlag, Stuttgart-New York, 35-74, 1984a

Schweppe KW: Morphologie und Klinik der Endometriose.

FK Schattauer Verlag, Stuttgart-New York, 103-112, 1984b

Schweppe KW: Morphologie und Klinik der Endometriose.

FK Schattauer Verlag, Stuttgart-New York, 198-207, 1984c

Scott RB, Te Linde RW, Wharton LR Jr: Further studies on experimental endometriosis.

Am J Obstet Gynecol 66: 1082-1099, 1953

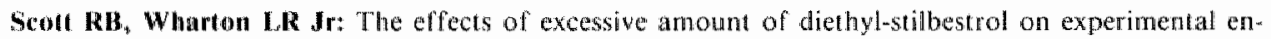
donetriosis in monkeys.

An J Obstet Gynecol 69: 573-591, 1955

Scott RB, Wharion LR Ir: The effect of estrone and progesterone on the growth of experimental endomerriosis in Rhesus Monkeys.

Am J Obstet Gyneed 74: 852-865, 1957

Seott RB, Nowak R., Tindale RM: Umbihical endometriosis and the Cullen sign.

Obstet Gynecoll 11: 556-563, 1958

Scott RB, Wharton LR: Effects of progesterone and norethindrone on experimental endometriosis in monkeys.

Am J Obstet Gynecol 84: 867-875, 1962

Seibel MM, Berger MJ, Weinstein FG, Taymor ML: The effectiveness of danazol on subsequent fertility in minimal endometriosis.

Fertil Steril 38: 534-537, 1982 
Sgarlata CS, Hertelendy F, Mikbail $G$ : The prostanoid content in peritoneal fluid and plasma of women with endometriosis.

Am J Obstet Gynecol 147: $563-565,1983$

Sharp NC, Anthony F, Miller JF, Masson GM: Early conceptual loss in subfertile patients.

Br J Obstet Gynaecol 93: 1072-1.077, 1986

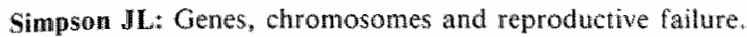

Fertil Steril 33: 107-116, 1980a

Simpson JL, Elias S, Malinak LR, Buttram VC Jr: Heritable aspects of endometriosis. 1. Genetic studies. Am J Obstet Gynecol 137: 327-331, 1980b

Simpson JL, Malinak LR, Elias S, Carson SA, Radivany RA: HLA associations in endometriosis. Am 』 Obstet Gynecol 148: 395-397, 1984

Slasky BS, Siewers RD, Lecky JW, Zajko A, Burkholder JA: Catamenial pneumothorax: the role of diaphragmatic defects and endometriosis.

Am J Reprod Med 29: 1072-1076, 1982

Soules MR, Malinak LR, Bury R, Poindexier A: Endometriosis and anovulation: a coexisting problern in the infertile female.

Am J Obstet Gynecol 125: 412-417, 1976

Splitter GA, Kirk JH, Mackenzie WF, Rawlings CA: Endometriosis in four irradiated monkeys. Vet Pathol 9: 249-262, 1972

Starks GC, Grimes EM: Clinical significance of focal pelvic endometriosis.

J Reprod Med 30: 481-484, 1985

Startseva NV: Clinico-immunological aspects in genital endometriosis.

Akush Ginekol 3: 23-26, 1980

Steele RW, Dmowski WP, Marmer DJ: Imnunologic aspects of endometriosis.

Am J Reprod Immunol 6: 33-36, 1984

Steingold KA, Cedars M, Lu JKH, Randle D, Judd HL, Meldrum DR: Treatment of endometriosis with a long-acting gonadotropin-releasing hormone agonist.

Obstet Gynecol 69: 403-411, 1987

Stillman R.J, Miller $\mathbf{L} \mathbb{R}$ : Diethylstilbestrol exposure in utero and endometriosis in infertile females. Fertill Steril $41: 369-372,1984$

Stone SC, Himsl K: Peritoneal recovery of motile and nonunotile sperm in the presence of endometriosis. Fertil Steril 46: 338-339, 1986

Strathy JH, Molgaard CA, Coulam CB, Melton III LJ: Endometriosis and infertility: a laparoscopic study of endometriosis among fertile and infertile women.

Fertil Steril 38: $667-672,1982$

Strickland S, Beers WH: Studies on the role of plasminogenactivator in ovulation. In vitro respons of granulosacells to gonadotropins, cyclic nucleotides and prostaglandins.

J Biol Chem 251: 5694-5702, 1976

Stuyt EB, Usun OE, De Leon FD, Word A, Word L, Dorsett M, Heine MW: Eflect of peritoneal macrophages and fluid on the viability and motility of sperm in vitro.

American Fertility Society Amual Meeting: 20 (abstract), 1987 
Sueldo $\mathrm{CE}_{\text {, Lamber }} \mathrm{H}$, Steinieiter $\mathrm{A}$, Rathwick $\mathbf{G}$, Swanson $\mathbf{J}$ : The effect of peritoneal fluid from patients with endometriosis on murine sperm-oocyte interaction.

Feriil Steril 48: 697-699, 1987

Suginami H, Yano K, Watanabe $K$, Matsuura $\$$ : A factor inhibiting ovum capure by the oviductal fimbriae present in endometriosis peritoneal fluid.

Fertil Steril 46: 1140.1146, 1986

Sulewski JM, Curcio FD, Bronitsky C, Stenger VG: The treatment of endometriosis at laparoscopy for infertility.

Am J Obstet Gynecoll 138: 128-132, 1980

Syrop CH, Halme I: A comparison of peritoneal fluid parameters of infertile patients and the subsequent occurrence of pregnancy.

Fertil Steril 46: 631-635, 1986

Syrop CH, Halme J: Cyclic changes of peritoneal fluid parameters in normal and infertile patients.

Obstet Gynecol 69: 416-418, 1987

Szlachter NB, Moskowitx J, Bigelon B, Weiss G: Iatrogenic endometriosis: substantiation of Sampson hypothesis.

Obstet Gynecol 55: 52-53S, 1980

Tamaya T, Motoyama T, Ohono $\mathbf{Y}$, Ide $\mathbf{T}$, Tsurusaki T, Okada H: Steroid receptor levels and histology of endometriosis and adenomyosis.

Fertil Steril 31: 396-400, 1979

Te Linde RW, Scott RB: Experimental endometriosis.

Am J Obstet Gynecol 60: 1147-1173, 1950

Thomas EJ, Lenton EA, Cooke ID: Follicle growth patterns and endocrinological abnormalities in infertille women with minor degrees of endometriosis.

Br J Obstet Gynaecol 93: 852-858, 1986

Thomas EJ, Cooke ID: Impact of gestrinone on the course of asymptomatic endometriosis. Br Med J 294: 272-274, 1987a

Thomas EJ Cooke ID: Successful treatment of asymptomatic endometriosis: Does it benefit infertile women?

Br Med J 294: 1117-1119, $1987 b$

Trimbos JB, Trimbos-Kemper GCM, Pelers AAW, Van Hall EV: Laparoscopische bevindingen bij gezonde vrouwen.

Ned Tujdschr Geneesk 128: 2341-2343, 1984

Van der Velden WH: Familiaire endometriose, een erfelijke aandoening?

Ned T $\vee$ Verlosk en Gyn 61: 374 375, 1961

Van Furth $\mathbf{R}$, Raeburn JA, Van Zwet TL: Characteristics of human mononuclear phagocytes. Blood 54: 485-500, 1979

Vanrell JA, Balasch J, Fuster JS, Fuster R: Ovulation stigma in fertile women.

Fertil Steril 37: 712-713, 1982

Vasqunez G, Cornillie F, Brosens IA: Peritoneal endometriosis: scanning electron microscopy and histology of minimal pelvic endometriotic lesions.

Fertil Steril 42: 696-703, 1984 
Vernon MW, Wilson EA: Studies on the surgical induction of endometriosis in the rat.

Fertil Steril 44: 684-694, 1985

Vemon MW, Beard JS, Graves $\mathrm{K}$, Wilson EA: Classification of endometriotic implants by norphologic appearence and capacity to synthesize prostaglandin $\mathrm{F}$.

Fertil Steril 46: 801-806, 1986

Vierikk $\mathbb{P}$, Kauppila A, R-148-nmberg L, Vihko R: Steroidal regulation of endometriotis tissue: lack of induction of $17 \beta$-hydroxysteroid dehydrogenase activity by progesterone, medroxyprogesterone acetate, or danazol.

Fertil Sterill 43: 218-224, 1985

Wardle PG, McLaughlin EA, McDermott A, Mitchell JD, Ray BD, Hull MGR: Endometriosis and ovulatory disorder: reduced fertilisation in vitro compared with tubal and unexplained infertility.

Lancet ii: $236-239,1985$

Wardle PG, Foster PA, Mitchell JD, McLaughlin EA, Sykes JAC, Corrigan E, Hull MGR, Ray BD, McDermott A: Endometriosis and IVF: Erfect of prior therapy.

Lancet i: $276-277,1986$

Weed JC, Arquembourg PC: Endometriosis: can it produce an autoimmuun response resulting in infertility?

Clin Obstet Gynecol 23: $885-893,1980$

Weissman G, Finkelstein MC, Csernansky $\mathbf{J}$, Quigley JP, Quinn RS, Techner $\mathbf{L}_{\text {, }}$ Troll W, Dunham PB: Attack of sea urchin eggs by dogfish phagocytes: Model of phagocyte-mediated cellullar cytotoxicity. Proc Natl Acad Sci USA 75: 1825-1829, 1978

Werlim L.B, DiZerega GS, Hodgen GD: Endometriosis: effect on ovulation, ovum pickup, and transport in monkeys: an interim report.

Fertil Steril 35: 263 (abstract), 1981

Werlin LB, Hodgen GD: Gonadotropin-releasing hormone agonist suppresses ovulation, menses, and endometriosis in monkeys: An individualized, intermittent regimen.

J clü Endocrinol Metab 56: 844-848, 1983

Wheeler JM, Malinak LR: Postoperative Danazol therapy in infertility patients with severe endometriosis.

Fertil Steril 36: 460-463, 1981

Wheeler IM, Johnston BM, Malinak LR: The relationship of endometriosis to spontaneous abortion. Fertil Sterii 39: 656-660, 1983

Wheeler JM, Malinak LR: Recurrent endometriosis: Incidence, management, and prognosis. Am J Obstet Gynecol 146: 247-253, 1985

Wheeler JM, Malinak LR: Computer graphic pelvic mapping, second look laparoscopy, and the distinction of recurrent versus persistent endometriosis.

American Fertility Society Annual Meeting: 79 (abstract), 1987

Wild RA, Shivers CA: Antiendometrial antibodies in patients with endometriosis.

Am J Reprod Immunol Microbiol 8: 84-86, 1985

Wilks MW, Forbes KK, Norland JF: Synthesis of prostaglandin F2ox by the ovary and uterus.

J Reprod Med 9: 271-276, 1972 
Willemsen WNP, Mengyer $\mathbf{G}$, Smets H, Rolland $\mathbf{R}$, Vemer $\mathbf{H}$, Jap $\mathbf{P}$ : Behavior of cultured glandular cells obtanted by thaning of the roterine cavity.

fortil Steril $44: 92.95,1985$

Wilians TJ, Pratt JH: Endometriosis in 1000 consecutive celiotomies: incidence and management. An J Obstet Gunecol 129:245-250, 1977

Wilman EA, Collins WP, Clayton SG: Studies in the involvement of prostaglandins in uterine symptonatology and pathology.

Br J Obster Gynaecol 83:337-341, 1976

Wood DH, Yochmowitz MG, Salmon YI, Eason RL, Boster RA: Proton irradiation and endometriosis. Aviat Space Enwiron Med 54: 718-724, 1983

Vlikorkala O, Vinikka L: Prostaglandins and endomerriosis.

Acta Obstel Gynecol Scand 113: 105-1107. 1983

Ylikorkala O. Tenhunen A: Follicular fluid prostaglandins in endometriosis and ovarian hyperstimulation.

Fertil Steril $41: 66-69,1984 \mathrm{a}$

Ylikorkala 0, Koskimies A, Laatkainen $\mathbf{T}$, Tenhunen A, Viinikka L: Peritoneal fluid prostaglandins in endonetrosis, tubal disorders and unexpikined infertility.

Obstet Gynecol 63: 616-620, 1984b

Zamah NM, Dodson MG, Stephens LC, Buttram VC Jr, Besch PK, Kaufman RH: Transplantation of normall and ectopic human endometrial tissue into athymic nude mice.

An J Obstet Gynecol 149: 591-597, 1984

Zaller JM, Henig I. Radwanska E, Dmowski WP: Enhancement of human monocyte and peritoneal macrophage chemiluminescence activities in women with endometriosis.

Am I Reprod Immunol Microbiol 13: 78-82, 1987

Zorn "IR, Roger M, Savale M, Grenier J: Steroid hormone levels in peritoneal fluid during the periovulatory period.

Fetril Steril 38: 162-165, 1982 


\section{Chapter 3}

\section{Aims of the study}

Endometriosis continues to be an enigmatic disease. Most of its etiology and pathogenesis remain obscure. The relation between endometriosis and subfertility is accepted but not understood. Much effort has been directed to elucidate these problems. One way of approach has been the study of peritoneal fluid and its constituents. Peritoneal implants of endometriosis, undergoing monthly changes under the influence of hormones, supposedly evoke inflammatory changes in the abdominal cavity and hence changes in the peritoneal fluid. The presence of inflammatory changes was suggested by an increased peritoneal fluid wolume, increased concentrations of prostaglandins, macrophages and proteases and by the presence of adhesions. Changes in the intraperitoneal milieu secondary to peritoneal implants have been incriminated as causal factors in the infertility seen in patients with mild endometriosis, and as etiological factors in the development of endometriosis. Total number, concentration and function of peritoneal macrophages in patients with endometriosis have been correlated both with the development of the disease and with endometriosis related infertility. Likewise, changes in the intraabdominal fibrinolytic system and changes in prostaglandins and proteases have been held responsible for the development of endometriosis and for infertility.

We decided to further characterize the intraabdominal milieu in patients with endometriosis.

The first goal of the present study was to delineate to what extent endometriosis changes the intraabdominal milieu as reflected in changes in peritoneal fluid. The hypothesis was tested that inflammatory changes of the peritoneum secondary to endometrial implants affect the degree of exudation of certain proteins, with concomitant increased peritoneal fluid volume. Additionally the presence of secretory active and continuously changing endometrial implants possibly evokes an acute-phase response. In chapter 4 the results will be presented of measurements of peritoneal fluid volume and peritoneal fluid/serum ratios of acute-phase proteins in patients with and in patients without endometriosis.

Changes of intraabdominal fibrinolysis have been correlated with the development of endometriosis and with the infertility seen in this disease. To test the hypothesis that a decreased fibrinolytic activity favors the development of endometriosis, we determined factors of the fibrinolytic system in the peritoneal fluid of patients with and of patients without endometriosis. In chapter 5 the results of these studies will be discussed.

Furthermore, we characterized the functional activity of macrophages, besides total cell number and concentration of these cells, in the peritoneal fluid of patients with 
endometriosis as compared to patients without the disease. The results of these function tests, the capacity of the macrophages to phagocytose sheep red blood cells and the emission of light after phagocytosis of opsonized zymosan, chemiluminescence, will be discussed in chapter 6.

The influence of endometriosis on peritoneal fluid constituents may be measured directly. Infertility in endometriosis patients can be and has been correlated with intraabdominal changes secondary to the presence of endometriosis. The interference, however, of endometriosis and possibly peritoneal fluid with ovum development and maturation, ovulation, fertilization, tubal transport and implantation cannot be observed directly in the human.

We therefore used an animal model of mild endometriosis to study the influence of endometriosis on these processes. The model used will be described in chapter 7 . In chapter 8 the influence of endometrium implants in the rabbit on ovulation, ovum pickup, fertilization and tubal transport will be reported.

The influence of endometrium implants in the rabbit on embryonic development in the first 24 hours after mating and the results of additional culturing of these embryos in a culture medium will be presented in chapter 9 . 


\title{
Chapter 4
}

\section{The acute-phase response in endometriosis of women}

\author{
G.A.J. Dunselman, P.X.J.M. Bouckaert, J.L.H. Evers \\ (Journal of Reproduction \& Fertility, accepted for publication)
}

\section{Summary}

Peritoneal fluid volume was determined and concentrations of C-reactive protein, $\alpha_{1}$-antitrypsin, acid- $\alpha_{1}$-glycoprotein, $\alpha_{2}$-macroglobulin, haptoglobin, complement factors $\mathrm{C}_{3}$ and $\mathrm{C}_{4}, \mathrm{IgG}, \operatorname{IgA}$ and $\operatorname{IgM}$ were measured in the supernatant of the peritoneal fluid and in serum by means of a radial-immunodiffusion technique in 25 patients with and in 45 patients without endometriosis. Peritoneal fluid volume was not different between the two groups. The peritoneal fluid:serum ratios for the proteins determined showed a significant inverse correlation with their molecular weight in both groups, indicating that their presence in peritoneal fluid is governed by exudation according to their molecular weight, rather than by active production in, or selective release into the peritoneal cavity. In control patients only, the ratios of most of the individual proteins studied were significantly higher in the luteal then in the follicular phase. We suggest that the high ratio of peritoneal fluid:serum values in endometriosis patients in the follicular phase reflects an additional contribution by peritoneal implants of endometriosis and peritoneal macrophages. The cycle-dependent increase of proteinexudation in the luteal phase of the cycle obscures this additional contribution.

We conclude that endometriosis does not cause marked intraabdominal inflammatory changes. If the presence of peritoneal implants of endometriosis lowers fecundity, the mechanism likely does not involve acute-phase protein synthesis. 


\section{Introduction}

There is circumstantial evidence that a relationship exists between endometriosis, even in its milder forms, and subferility, but the cause of this subfertility remains unclear. It has been suggested that peritoneal implants of endometriosis cause an inflammatory reaction of the pelvic peritoneum (Drake et al., 1980; Haney et al., 1981; Halme et al., 1987; Fazleabas et al., 1987). This inflammatory reaction may lead to subfertility by causing changes in the peritoneal environment, in which follicular development, ovulation, fertilization and tubal transport take place, analogous to the intrauterine inflammatory reaction present in intrauterine device users, which lowers the probability of conception by similarly postulated mechanisms (Casslén and Ohlsson, 1981).

Inflammation, as a local response to tissue injury, results in changes in vascular callibre and flow, increased vascular permeability and attraction of leucocytes. Accordingly, an inflammatory reaction secondary to endometriosis may result in increased production of peritoneal fluid (Drake et al., 1980; Haney et al., 1981; Syrop and Halme, 1987a), secretion of prostaglandins (PG) (Ylikorkala et al., 1984; De Leon et al., 1986; Vernon et al, 1986) and protease inhibitors (Fazleabas et al., 1987) and attraction and differentiation of macrophages (Haney et al., 1981; Halme et al., 1987). Conflicting results have been reported on the influence of endometriosis on peritoneal fluid volume and the concentration of PG. More agreement exists on the increased number and on the increased activation of intraabdominal macrophages in patients with endometriosis (see Syrop and Halme, 1987b for review).

Additionally a number of systemic and metabolic changes occur during the acutephase of inflammation. The ultimate goal of the acute-phase response is the removal of damaged tissue and the repair of the affected organ (Kushner, 1982). In patients with pelvic inflammatory disease acute-phase proteins were shown to be present in serum (Künzig et al., 1985). If peritoneal implants of endometriosis cause intraperitoneal inflammatory changes, this possibly will be reflected in measures of the acute-phase response.

To delineate the extent of inflammatory changes secondary to the presence of peritoneal implants of endometriosis we determined, in addition to peritoneal fluid volume, various indicators of the acute-phase response.

\section{Materials and Methods}

Peritoneal fluid was collected during laparoscopy in 70 patients from the pouch of Douglas and the vesicouterine space under direct vision as described by Bouckaert et al. (1986a). The laparoscopies were planned in the early luteal phase of the men- 
strual cycle, based on information regarding the length of the previous cycles and the first day of the last menstrual period. The indication for laparoscopy was infertility in 40 patients, abdominal pain in 9 and sterilization in 21 . They all had regular cycles, ranging from 23 to 35 days. None of the patients had used oral contraceptives or ovulation inducing drugs or an intrauterine contraceptive device for at least 3 months before the laparoscopy. Patients with occluded Fallopian tubes were excluded. At laparoscopy all patients were carefully screened for the presence of endometriosis. The diagnosis was made on morphological grounds. Endometriosis was identified according to the classification of the American Fertility Society (AFS)(1979).

After collection of the peritoneal fluid, the volume was measured, the fluid was centrifuged and the supernatant stored at $-70^{\circ} \mathrm{C}$ until assayed. Before induction of anaesthesia a $5-\mathrm{ml}$ blood sample was withdrawn, centrifuged and the supernatant stored at $-70^{\circ} \mathrm{C}$ until assayed. In serum and in the supernatant of the peritoneal fluid oestradiol-17 $\beta$ and progesterone concentrations were determined. The values of oestradiol-17 $\beta$ and progesterone measured in serum and related to those in peritoneal fluid served to divide the cycle into two phases, i.e. the follicular and the luteal phase (Bouckaert et al., 1986b).

Concentrations of C-reactive protein, $\alpha_{1}$-antitrypsin, acid- $\alpha_{1}$-glycoprotein, $\alpha_{2}$-macroglobulin, haptoglobin, complement factors $C_{3}$ and $C_{4}, \operatorname{IgG}, \operatorname{IgA}$ and $\operatorname{IgM}$ were measured in the supernatant of the peritoneal fluid and in serum by means of a radial-immunodiffusion technique based on the radial diffusion and precipitation of a protein with its corresponding monospecific antiserum in an agar gel layer (MPartigen and LC-partigen immunodiffusion plates: Behring Institut, Amsterdam, The Netherlands)(Mancini et al., 1965). The interassay variabilities $(\%)$ for the proteins that were anallysed were 6.4 for C-reactive protein, 3.9 for $\alpha_{1}$-antitrypsin, 2.3 for acid- $\alpha_{1}$-glycoprotein, 7.5 for $\alpha_{2}$-macroglobulin, 4.3 for haptoglobin, 5.5 for $\mathrm{C}_{3}$-protein, 4.6 for $\mathrm{C}_{4}$-protein, 2.5 for $\operatorname{IgA}, 2.3$ for $\operatorname{IgG}$, and 3.0 for $\operatorname{IgM}$.

The ratio of peritoneal fluid concentration $/$ serum concentration $(\mathrm{p} / \mathrm{s}$ ratio) was determined for the individual proteins. Peritoneal fluid volume and the $\mathrm{p} / \mathrm{s}$ ratios were compared between patients with and without endometriosis and between the follicular and the luteal phase of the cycle for patients with endometriosis and controls. The results were tested statistically by the Wilcoxon rank sum test for unpaired samples. Statistical significance was defined as $\mathrm{P}<0.05$. Spearman's rank correlation test was applied to test the correlation between the $\mathrm{p} / \mathrm{s}$ ratio of the individual proteins and their molecular weight.

\section{Results}

At laparoscopy endometriosis was diagnosed in 25 patients (AFS score 1, $N=16$; AFS score $2, N=9$ ). The controls were 45 patients without the disease. Based on 


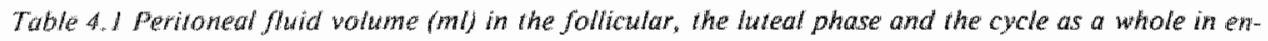
dometriosis and comtrol patients

\begin{tabular}{|c|c|c|c|c|c|c|}
\hline & \multicolumn{3}{|c|}{ Endometriosis patients } & \multicolumn{3}{|c|}{ Control patients } \\
\hline & $\mathrm{n}$ & Median & Range & $\mathrm{n}$ & Median & Range \\
\hline Follicular phase & 6 & 9.5 & $6-20$ & 4 & 6.5 & $4-25$ \\
\hline Luteal phase & 19 & $24^{*}$ & $5-42$ & 41 & 12 & 3.70 \\
\hline Whole cycle & 25 & 18 & $5-42$ & 45 & 12 & 3.70 \\
\hline
\end{tabular}

* $P=0.051$, compared with follicular phase value.

Table 4.2 The ratios of various proteins in peritoneat fluid and serum in endometriosis and control patients

\begin{tabular}{|c|c|c|c|c|c|c|}
\hline & \multicolumn{3}{|c|}{ Endometriosis patients } & \multicolumn{3}{|c|}{ Control patients } \\
\hline & $\mathrm{n}$ & Median & Range & $\mathrm{n}$ & Median & Range \\
\hline $\operatorname{IgG}$ & 25 & 0.48 & $0.32 \cdot 0.84$ & 41 & 0.51 & $0.07-0.76$ \\
\hline $\operatorname{IgA}$ & 25 & 0.40 & $0.24-0.56$ & 41 & 0.42 & $0.15-0.69$ \\
\hline $\operatorname{IgM}$ & 25 & 0.20 & $0.14-0.34$ & 41 & 0.21 & $0.06-0.36$ \\
\hline $\mathrm{C}_{3}$ & 25 & 0.44 & $0.23-0.81$ & 41 & 0.48 & $0.12-0.81$ \\
\hline $\mathrm{C}_{4}$ & 25 & 0.43 & $0.21-0.88$ & 41 & 0.45 & $0.24-0.88$ \\
\hline Haptoglobin & 25 & 0.29 & $0.06-0.56$ & 41 & 0.30 & $0.07-0.61$ \\
\hline$\alpha_{2}$ Macroglobulin & 25 & 0.16 & $0.05-0.74$ & 41 & 0.16 & $0.04-0.30$ \\
\hline Acid-a 1 -glycoprotein & 25 & 0.75 & $0.63-1.04$ & 41 & 0.77 & $0.40-1.65$ \\
\hline$\alpha_{\mid i}$-Antitrypsin & 25 & 0.70 & $0-28-0.96$ & 41 & 0.69 & $0.23-0.95$ \\
\hline
\end{tabular}

the information from serum and peritoneal fluid determinations of oestradiol-17 $\beta$ and progesterone, 6 patients in the endometriosis group were classified in the follicular and 19 in the luteal phase of the cycle. The figures for controls were 4 and 41 respectively.

C-reactive protein was below the level of detection $(5 \mathrm{mg} / \mathrm{l})$ in peritoneal fluid and serum in all patients studied.

In patients with endometriosis there was an increase of the peritoneal fluid volume in the luteal phase of the cycle (Table 4.1: $\mathbb{P}=0.051$ ). No significant differences were noted between patients with and without endometriosis for the ratio of individual proteins in peritoneal fluid and serum (Table 4.2). Values for these ratios in the follicular and luteal phase of the cycle are shown in Table 4.3. In patients with endometriosis only the $\operatorname{lgG}$ value differed significantly between the two phases of the cycle, but in the controls all the values except those for $\alpha_{1}$-antitrypsin, IgG and $\operatorname{IgM}$ were increased in the luteal phase of the cycle.

Correlating the results of the peritoneal fluid:serum ratio for the individual proteins with their molecular weights a significant inverse relationship was found in the endometriosis patients $(\mathrm{N}=9, \mathrm{r}=-0.93, \mathrm{P}<0.01)$ and in the controls $(\mathrm{N}=9, \mathrm{r}$ 


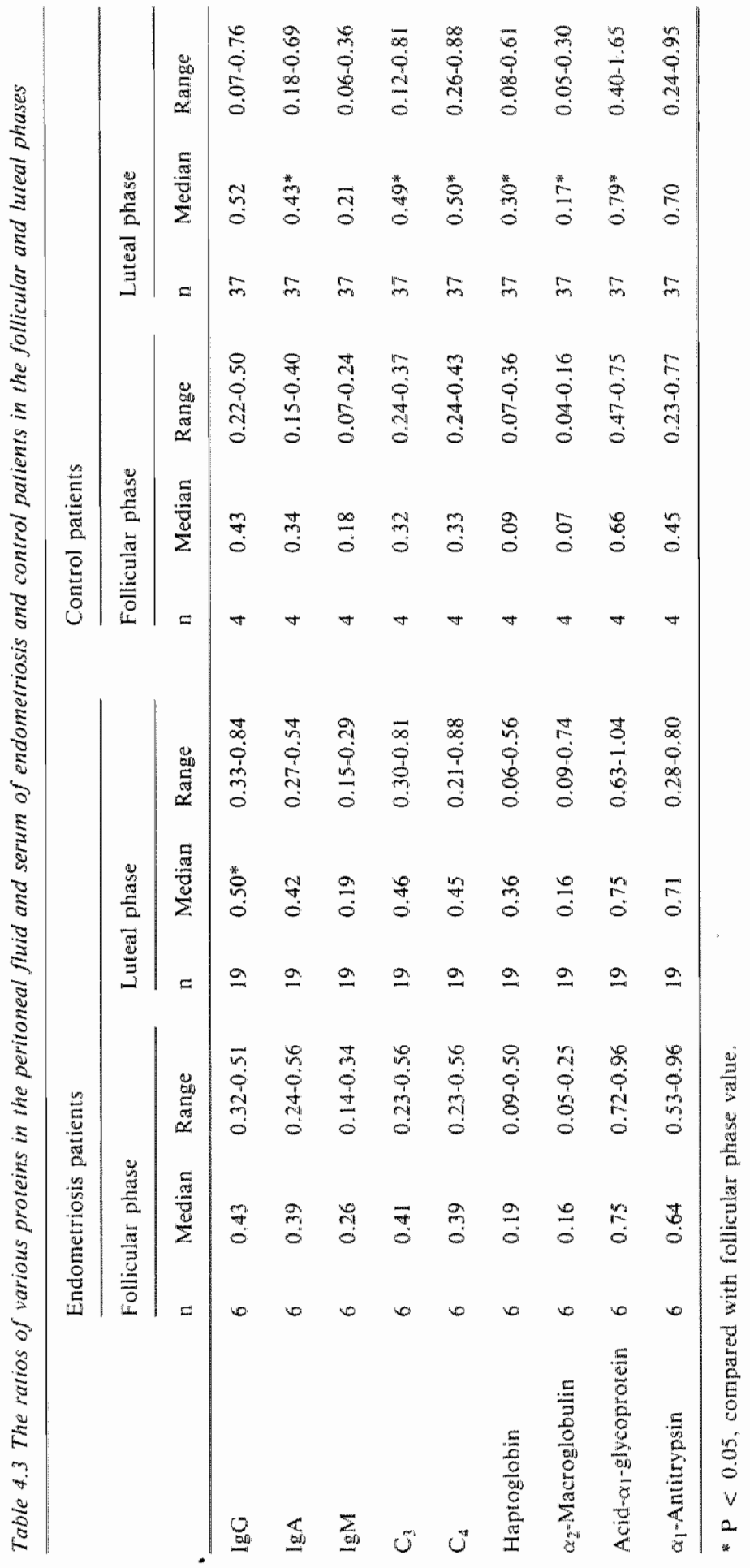




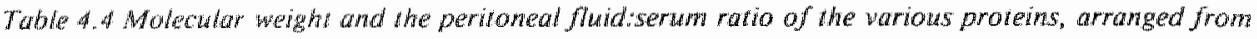
tow to high molecular weigh, in endometriosis and control patients

\begin{tabular}{|c|c|c|c|}
\hline & $\begin{array}{l}\text { Molectular } \\
\text { weight }\end{array}$ & $\begin{array}{l}\text { Endometriosis } \\
\text { patientsi }\end{array}$ & $\begin{array}{l}\text { Control } \\
\text { patients }\end{array}$ \\
\hline Acid-ap-glycoprotein & 40000 & 0.75 & 0.77 \\
\hline$\alpha_{p}$-Antitrypsin & 54000 & 0.67 & 0.65 \\
\hline $\lg G$ & 160000 & 0.48 & 0.51 \\
\hline $\lg A$ & 160000 & 0.40 & 0.42 \\
\hline $\mathrm{C}_{3}$ & 180000 & 0.44 & 0.48 \\
\hline$C_{4}$ & 260000 & 0.43 & 0.45 \\
\hline Haptoglobin & 340000 & 0.29 & 0.30 \\
\hline$\alpha_{2}$-Macroglobulin & 725000 & 0.16 & 0.1 .6 \\
\hline $\lg M$ & 900000 & 0.20 & 0.21 \\
\hline
\end{tabular}

$=-0.93, \mathrm{P}<0.01$ ) (Spearman's rank correlation test): the higher the molecular weight of a given protein, the lower was its concentration in the peritoneal fluid (Table 4.4).

\section{Discussion}

Peritoneal fluid is mainly the result of ovarian exudation, while peritoneal exudation, follicular rupture and tubal secretion contribute only a small. volume (Maathuis et al., 1978; Koninckx et al., 1980; Bouckaert et al., 1986a). The supposed inflammatory reaction secondary to peritoneal implants of endometriosis may cause an increased permeability of the subperitoneal capillaries, resulting in a change of the equilibrium between in- and outflow of fluid across the peritoneal membrane, leading to an increased peritoneal fluid volume. Since we did not find such an increase, we suggest that the inflammatory reaction is not of such a degree that it gives rise to a significant change in peritoneal fluid volume. However, an increased production of peritoneal fluid could be counterbalanced by an increased reabsorption by the subperitoneal capillaries.

The acute-phase reaction, in which the concentration of certain plasma proteins increases, is recognized as a general and non-specific response to most forms of infective and non-infective inflammatory processes, cell and/or tissue necrosis, and malignant neoplasia. The acute-phase proteins are synthesized in the liver (Pepys, 1981).

Circulating proteins reach the peritoneal cavity by exudation. The concentration of the various proteins in the peritoneal fluid depends predominantly on the hydrostatic pressure in the ovarian capillary network, the diameter of the endothelial gaps, the electrical charge of the individual proteins and their molecular weight (Bouck- 
aert et al., 1986a). In endometriosis patients the concentration of acute-phase proteins, complement factors and immunoglobulins in the abdominal cavity may be increased secondary to changes in vascular permeability. Additionally some of the acute-phase proteins and complement factors are secreted by macrophages in an advanced stage of differentiation (Nathan, 1987).

To detect possible differences in the acute-phase response in peritoneal fluid between endometriosis patients and controls, it seems appropriate, in view of the above, to consider the ratio of the concentrations of the separate proteins in peritoneal fluid and serum. This ratio reflects the various sources of the peritoneal fluid proteins, i.e. exudation or in-situ production. Our earlier finding (Bouckaert et al., 1986a) of a significant inverse relationship between the molecular weight of the specific protein and its peritoneal fluid:serum ratio was confirmed in the control group. A comparable relationship was found for endometriosis patients. Retrograde menstruation, ovulation and, in endometriosis patients, cyclic shedding of peritoneal implants cause a continuously changing intraabdominal environment and thus possibly alter intraabdominal protein concentrations. When ratios for the specific proteins were compared between endometriosis patients and controls no significant differences were found, indicating a constant and equal exudation and/or in-situ production of these proteins in both groups. Apparently the intraabdominal protein concentration is not influenced to a great extent by the presence of peritoneal implants of endometriosis.

The ratios of the individual proteins in the follicular phase of the cycle in endometriosis patients in comparison to controls suggest a contribution from sources other than the ovaries, e.g. the peritoneum and the intraabdominal macrophages, reflecting an intraabdominal inflammatory reaction, secondary to peritoneal implants of endometriosis. The cycle dependent increase of proteinexudation in the luteal phase of the cycle may outweigh the presumptive contribution of the peritoneal exudation and production by macrophages in endometriosis patients. Due to the low sample size $(\mathrm{N}=4)$ the ratios of the follicular phase of control patients could be erroneously low and thus indirectly give the impression of a high ratio in the follicular phase of the endometriosis patients.

We conclude that endometriosis does not cause marked intraabdominal inflammatory changes. We base this on the lack of a significant increase of the peritoneal fluid volume and of the peritoneal fluid:serum ratios of the various proteins determined in patients with endometriosis compared to controls. If the presence of peritoneal implants of endometriosis lowers fecundity, the mechanism likely does not involve acute-phase protein synthesis. 


\section{References}

American Fertility Sochely: Classification of endometriosis. Fertil Steril 32: 633-634, 1979

Bouckaert PXJM, Evers JLH, Doesburg WH, Schellekens LA, Brombacher PJ, Rolland R: Patterns of changes in proteins in the peritoneal fluid of women during the periovulatory phase of the cycle.

I Reprod Fert 77: 329-336, $1986 \mathrm{a}$

Biouckaert PXJM, Evers JLH, Doesburg WH, Schellekens LA, Rolland R: Patterns of changes in glycoproteins, polypeptides, and steroids in the peritoneal lluid of women during the periovulatory phase of the cycle.

$J$ clin Endocu Metab 62: 293-299, 1986b

Cassten B, Ohlsson $\mathbf{K}$ : Cyclic variation of proteinase inhibitors in human uterine fluid and influence of an IUD.

Contraception $23: 425-434,1981$

De Leon FD, Vijayakumar R, Brown M, Rao ChV, Yussman MA, Schultz G: Peritoneal fluid volume, estrogen, progesterone, prostaglandin, and epidermal growth factor concentrations in patients with and without endometriosis.

Obstet Gynecol 68: 189-194, 1986

Drake TS, Metz SA, Grunert GM, O'Brien WF: Peritoneal fluid volume in endometriosis.

Feriil Steril 34: $280-281,1980$

Fazleabas AT, Khan-Dawood FS, Dawood MJ: Protein, progesterone, and protease inhibitors in uterine and peritoneal fluids of women with endornetriosis.

Fertil Steril 47: 218-224, 1987

Halme J, Becker S, Haskill S: Altered maturation and function of peritoneal macrophages: possible role in pathogenesis of endometriosis.

Am J Obstet Gynecol 156: 783-789, 1987

Haney AF, Muscato JJ, Weinberg JB: Peritoneal fluid cell populations in infertility patients.

Fervil Steril 35: 696-698, 1981

Koninckx PR, Renaer M, Brosens IA: Origh of peritoneal fluid in women: at ovarian exudation product.

B. J Obstet Gynaecol 87: 177-183, 1980

Künzig HJ, Schmi̊lt-Rohde P, Krämer M, Prinz H: Akute-Phase-Proteine (C-Reaktives Protein, Orosomucoid, Haptoglobin)-Spezifusche Marker bei der Diagnostik cntzündlicher Adnexerkrankungen.

Geburtsh u Frauenheilk 45: $881-886,1985$

Kushner I: The phenomenon of the acute phase response.

Ann N Y Acad Sci 389: 39-48, 1982

Manthuis JB, Van Look PFA, Michie EA: Changes in volume, total protein and ovarian steroid concen* trations of peritoneal fluid throughout the human menstrual cycle.

J Endocrinol $76: 123-133,1978$

Mancini G, Carbonara AO, Heremans JF: Immunochemical quantitation of antigens by single radial immunodiffusion.

Immunochemistry 2: 235-254, 1965 
Nathan CF: Secretory products of macrophages.

J clin linvest 79: $319-326,1987$

Pepys MB: C-reactive protein fifty years on.

Lancet i: $653-657,1981$

Syrop CH, Halme J: Cyclic changes of peritoneal fluid parameters in normal and infertile patients. Obstet Gynecol 69: 416-418, 1987a

Syrop $\mathrm{CH}$, Halme J: Peritoneal fluid enwronment and infertility.

Fertil Sieril $48: 1-9,19876$

Vernon MW, Beard JS, Graves K, Wilson EA: Classification of endometriotic implants by morphologic appearance and capacity to synthesize prostaglandin $F$.

Fertil Steril 46: 801-806, 1986

Ylikorkala O, Koskimies A, Laatkainen T, Tenhunen A, Vïnikka L: Peritoneal fluid prostaglandins in endometriosis, tubal disorders, and unexplained infertility.

Obstet Gynecol 63: 616-620, 1984 


\section{Chapter 5}

\section{Fibrinolytic properties of peritoneal fluid in endometriosis of women}

G.A.J. Dunselman, P.X.J.M. Bouckaert, J.W.J. van Wersch, E.J.P. Brommer, J.L.H. Evers

(Gynecologic and Obstetric Investigation, accepted for publication)

\section{Summary}

A decreased intraabdominal fibrinolytic activity has been proposed as an etiological factor in the development of endometriosis. To test this hypothesis plasminogen, fibrinogen, $\alpha_{2}$-antiplasmin, $\alpha_{2}$-macroglobulin, plasminogen activator (t-PA) and its inhibitor (PAl) and the degradation products of fibrin were determined in the peritoneal fluid of 25 patients with and 45 patients without endometriosis. No significant difference was found for any of the parameters. Therefore, a role for the fibrinolytic system as an etiological factor in the development of endometriosis is unlikely. A high concentration of t-PA was found in comparison to normal blood levels, leading to a high concentration of fibrin degradation products in the peritoneal fluid, indicating an active system of intraabdominal fibrinolysis. A high concentration of fibrin degradation products further indicates the presence of fibrinogen and its turnover secondary to thrombin action. 


\section{Introduction}

According to Sampson's theory on the pathogenesis of endometriosis, the disease develops secondary to transtubal regurgitation and subsequent implantation of endometrial fragments on ovaries or peritoneum (Sampson, 1927). Alternatively, peritoneal irritation by retrograde menstruation may lead to endometriosis by the process of induction (Levander and Norman, 1955). Since retrograde menstruation occurs in most women regardless of the existence of endometriosis (Halme et al., 1984), other etiological factors must be present to allow development of endometriosis. Changes in cellular immunity and the luteinized unruptured follicle syndrome have been proposed as etiological factors (Steele et al., 1984; Brosens et al., 1978). Malick (1982) developed the hypothesis that a change in intraabdominal fibrinolysis could be etiologic with respect to the development of endometriosis. The capacity to lyse intraabdominal fibrin deposits, that develop secondary to peritoneal injury, is derived from plasminogen activators found within the lysozomal fraction of the mesothelial cells (Gervin et al., 1973). Plasminogen activator converts plasminogen to plasmin, which in turn degrades fibrin deposits. This has been associated with the prevention of adhesionformation (Buckman et al., 1976).

Malick (1982) suggested that a decreased intraabdominal plasminogen activator activity could be responsible for the development of endometriosis and the adhesions seen in this disease.

To test this hypothesis we studied the fibrinolytic properties of peritoneal fluid of patients with and without endometriosis.

The major disadvantage of overall tests, like the fibrin plate method, as used by Malick (1982), is that the test finding is the resultant of the effects of several components and of their interactions. To gain more insight into the separate components of the fibrinolytic system, we decided to study plasminogen, fibrinogen, $\alpha_{2}$ antiplasmin and $\alpha_{2}$-macroglobulin, as well as the levels of plasminogen activator and its inhibitor and the degradation products of fibrin.

\section{Materials and Methods}

Peritoneal fluid (PF) was collected during laparoscopy in 70 patients from the pouch of Douglas and the vesicouterine space under direct vision as previously described (Bouckaert et al., 1986). The laparoscopies were planned in the early luteal phase of the menstrual cycle, based on information regarding the length of the previous cycles and the first day of the last menstrual period. The indication for laparoscopy was infertility in 40, abdominal pain in 9 and sterilisation in 21 patients. They all had regular cycles, ranging from 23 to 35 days. None of the patients had used oral contraceptives or ovulation inducing drugs or an intrauterine contraceptive device for the lasi 
three months prior to the laparoscopy. Patients with occluded tubes were excluded. At laparoscopy all patients were carefully screened for the presence of endometriosis. The diagnosis was made on morphological grounds. Endometriosis was identified according to the classification of the American Fertility Society (AFS) (1979).

The peritoneal fluid was collected in two tubes, a polystyrene one and a glass one. The first tube contained $0.2 \mathrm{ml}$ citrate and was filled to $2 \mathrm{ml}$ with PF. After centrifugation at $1000 \mathrm{~g}$ plasminogen, fibrinogen, $\alpha_{2}$-antiplasmin, $\alpha_{2}$-macroglobulin, fibrin degradation products (FDP), tissue plasminogen activator (t-PA) and tissue plasminogen activator inhibitor (PAI) were determined in the supernatant. Prior to induction of anaesthesia a 5-ml blood sample was drawn, centrifuged and the supernatant stored at $-70^{\circ} \mathrm{C}$. After centrifugation, the supernatant of the PF in the glass tube was used to determine progesterone and oestradiol-17\%. In the serum progesterone and oestradiol $17 \beta$ were determined. The values of progesterone and oestradiol- $17 \beta$ measured in serum as related to those in peritoneal fluid, divided the cycle into two phases, i.e. the follicular and the luteal phase (Bouckaert et al, 1986). Fibrinogen was measured as described by Clauss (1957), using a Schnitger and Gross coagulometer. Plasminogen and $\alpha_{2}$-macroglobulin were assayed by an immunochemical method based upon radial immunodiffusion using M-Partigen plates (Hoechst-Behring). The Coatest antiplasmin (Kabi Vitrum Diagnostica) was used for the measurement of $\alpha_{2}$-antiplasmin by using the chromogenic substrate $\mathrm{H}_{D^{-}}$ Val-Leu-Lys-p-nitroanilide (S-2251, Kabi Vitrum Diagnostica).

The fibrin degradation products were measured using the D-dimer test (Ortho Corporation). The D-dimer test is a specific semi-quantitative beads test for the detection of degradation products of fibrin only, and not of fibrinogen. t-PA as well as PAI activity were quantitated by measuring the enzymatic activity of the formed plasmin in the presence of fibrinogen fragments with a synthetic substrate. The substrate used was S-2251 (Kabi Vitrum Diagnostica) (Drapier et al., 1979; Verheijen et al., 1982).

To identify patients with subclinical inflammatory pelvic disease C-reactive protein (CRP) was determined in PF and serum, using single radial immunodiffusion (Mancini et al., 1965).

Comparisons of the various parameters were made between patients with and without endometriosis. The results were tested statistically by the Wilcoxon rank sum test for unpaired samples. Statistical significance was defined as $\mathrm{P}<0.05$.

\section{Results}

At laparoscopy endothetriosis was diagnosed in 25 patients (AFS score 1, $N=16$; AFS score 2, $N=9$ ). Forty five patients without the disease served as controls. Based on serum and PF determinations of progesterone and oestradiol $17 \beta, 6$ patients 
Table 5. I Diswibution of parameters of the fibrinolytic system in the peritoneal fuld in endometriosis and conrol partents

\begin{tabular}{|c|c|c|c|c|c|c|}
\hline & \multicolumn{3}{|c|}{$\begin{array}{l}\text { Endometriosis } \\
\text { patients }\end{array}$} & \multicolumn{3}{|c|}{$\begin{array}{l}\text { Control } \\
\text { patients }\end{array}$} \\
\hline & $n$ & Median & Range & $n$ & Median & Range \\
\hline $\begin{array}{c}\text { Plasrninogen } \\
(\mathrm{g} / \mathrm{l})\end{array}$ & 25 & $48.0^{*}$ & 19.67 & 42 & 48.5 & $20-104$ \\
\hline $\begin{array}{c}\text { Fibrinogen } \\
(g / 1)\end{array}$ & 25 & $0.45^{*}$ & $0.15-0.87$ & 43 & 0.45 & $0.09-0.85$ \\
\hline $\begin{array}{l}\alpha_{2} \text {-Anti- } \\
\text { plasmin }(\% \% \text { ) }\end{array}$ & 25 & $42.0 *$ & $15-78$ & 42 & 46.5 & 2.85 \\
\hline $\begin{array}{l}\alpha_{2} \text {-Macro- } \\
\text { globulin }(g / 1)\end{array}$ & 25 & $0.30^{*}$ & $0.10-1.00$ & 43 & 0.30 & $0.10-1.00$ \\
\hline $\begin{array}{l}\text { L-PA } \\
\quad(1 \cup / \mathrm{ml})\end{array}$ & 21 & $2.9^{*}$ & $0.8-12.8$ & 42 & 1.9 & $0.7-10.7$ \\
\hline $\begin{array}{l}\text { PAI } \\
\quad(\mathrm{I} / \mathrm{ml})\end{array}$ & 21 & 0.01 * & $0.01-42$ & 42 & 5.5 & $0.01-40$ \\
\hline $\begin{array}{l}\text { FDP } \\
\qquad(\mathrm{mg} / \mathrm{l})\end{array}$ & 2.1 & $1000^{*}$ & $200-4000$ & 42 & 1000 & $200-16000$ \\
\hline
\end{tabular}

t-PA : tissue plasminogen activator; PAI : plasminogen activator inhibitor; FDP : fibrin degradation products

* $\mathrm{P}>0.05$, compared with controls.

in the endometriosis group were classified in the follicular and 19 in the luteal phase of the cycle. The figures for controls were 4 and 41 respectively.

CRP was below the level of detection in all PF and serum specimens, indicating the absence of an acute pelvic infection in all patients.

Table 5.1 shows the results of the parameters determined comparing patients with and without endometriosis. The results are given as median values and range. No significant difference was found between the two groups for any of the parameters.

\section{Discussion}

Malick (1982) measured fibrinolytic activity using a modification of the fibrin plate method of Astrup \& Müllertz (1952). The lysis of the fibrin plates, caused by uterine serosal tissue of patients with and without endometriosis, was less pronounced in the samples of endometriosis patients as compared to controls. She concluded that a decreased coelomic plasminogen activator activity, acquired or inherited, in con- 
junction with retrograde menstruation is etiologic with respect to the development of endometriosis and associated adhesions. This hypothesis seemed quite attractive, the more since the fibrinolytic system has been associated with intraabdominal adhesion formation (Buckman et al., 1976). Unfortunately, Malick (1982) based this hypothesis on not more than two tissue samples of only one patient with endometriosis. Using the fibrin plate method Pattinson et al. (1981) did not find detectable levels of plasminogen activator activity in PF of patients with and without endometriosis. Since fibrinogen degradation products and plasminogen were present in the samples of $\mathbf{P F}$, they concluded that fibrinolytic activity was present in the PF of endometriosis patients and controls. Batzofin et al. (1985) did not find any differences in PF plasminogen activator activity comparing endometriosis patients with controls, neither did they, comparing patients with and without adhesions. They used a method based on the degradation of ${ }^{125}$ Iodine-labeled fibrin by plasmin (Strickland and Beers, 1976). Although this method is a very sensitive one, the results may be obscured by plasmin inactivation or by the presence of inhibitors (Drapier et al., 1979). Moreover, this method does not distinguish between urokinase and $t$-PA, the two major physiological plasminogen activators (Bachman and Kruithof ${ }^{1984)}$. The fibrin plate method to assess the plasminogen activator activity, as used by Pattinson et al. (1981) and Malick (1982), possesses the same disadvantages (Bachman and Kruithof, 1984).

The above-mentioned studies assess total fibrinolytic activity by integrative assays of fibrinolysis. In our study we assessed plasminogen activator activity by measuring both t-PA and its fast inhibitor, PAI. Additionally, the end product of plasminogen activation, i.e. fibrin degradation products, and not a mixture of fibrinogen and fibrin degradation products, were determined. Finally, the precursors of plasmin and fibrin and the inhibitors of plasmin were determined.

As shown in Table 5.1 the levels of the precursors of plasmin and fibrin, plasminogen and fibrinogen, were not different in patients with endometriosis and in controls. Two major inhibitors of the fibrimolytic system, $\alpha_{2}$-antiplasmin and $\alpha_{2}$-macroglobulin, were not different in both groups either. Comparing patients with and without endometriosis we did not find significantly different levels of plasminogen activator and its inhibitor. Fibrin degradation products are the final result of fibrinolysis. The D-dimer test we used is specific for the degradation products of fibrin. Again no significantly different results were obtained in either group of patients.

From these results we conclude that no major differences in the intraabdominal fibrinolytic system as measured in the PF are discernable between patients with and without endometriosis. These results are in agreement with the results of the study of Batzofin et al. (1985).

The results of our study show that an active fibrinolytic system exists in the abdominal cavity. Until now this intraabdominal fibrinolytic activity was assumed to be present, based on the lack of clot formation in peritoneal fluid, on the presence of fibrinogen degradation products and the presence of high levels of plasminogen in 
peritoneal fuid and on the lysis of fibrin plates by PF (Pattinson et al., 1981; Batzofin et al., 1985). The concentration of fibrin degradation products in the PF of the patients under investigation and of the controls was higher than the levels normally found in plasma $(<200 \mathrm{mg} / \mathrm{ml})$, indicating a high intraabdominall fibrinolytic activity. t-PA levels in plasma measured by the above described method in our laboratory are below $0.1 \mathrm{lU} / \mathrm{ml}$. t-PA levels in the PF in our patients, with and without endometriosis, were manifold higher. This indicates either an active production and secretion of t-PA in the abdominal cavity or a low PAI level and supports the above-mentioned assumptions that an active fibrinolytic system exists in the abdominal cavity.

Plasminogen activator inhibitor and plasminogen activator as found in PF presumably have various sources. As recently reviewed (Sprengers and Kluft, 1987) PAinhibitors can be classified in at least three immunologically different groups. Sources of PA-inhibitors include endothelial cells, granulosa cells, blood platelets, vascular smooth muscle cells, macrophages and placenta. As reviewed by Bachmann and Kruithof (1984) plasminogen activators can be extracted from many animal and human tissues, including endometrium, mesothelial cells, vascular endothelium and stimulated peritoneal macrophages. Astedt and Nordenskjöld (1984) suggested ectopic endometrium as a source of plasminogen activators, since they found increased concentrations of plasminogen activators in PF of patients with endometriosis. In contrast, Ohtsuka (1980) found a decreased concentration of plasminogen activator activity at tissue level in endometriotic lesions. Since ovulation is at least in part a proteolytic enzyme mediated event (Strickland and Beers, 1976), the content of the follicle can be considered as another important source of plasminogen activator.

We conclude that there is an active system of intraabdominal fibrinolysis, as shown by a higher concentration of t-PA in PF than in blood. A high concentration of fibrin degradation products in the peritoneal fluid ensues.

The intraabdominal fibrinolytic system as measured by the concentrations in PF of plasminogen, fibrinogen, $\alpha_{2}$-antiplasmin, $\alpha_{2}$-macroglobulin, t-PA, PAI and fibrin degradation products is not different in women with endometriosis as compared to women without the disease. Therefore a role for the fibrinolytic system as an etiological factor in the development of endometriosis is unlikely. To further substantiate this conclusion, studies on tissue level yet have to exclude more subtle differences in fibrinolysis. 


\section{References}

American Fertility Society: Classification of endometriosis.

Fertil Steril 32: 633-634, 1979

Astedt B, Nordenskjöld F: Plasminogen artivators in endometriosis.

Acia Obstet Gymecol Scand Suppl 123: 23-24, 1984

Asirup $\mathbf{T}$, Müllertz $\mathbf{S}$ : The fibrin plate method for estimating fibrinolytic activity.

Arch Biochem Bioph 40: 346-351, 1952

Bachmann F, Kruithof EKO: Tissue plasminogen activator: chemical and physiological aspects. Semin Thromb Hemost 10;6-17, 1984

Batzofin JH, Holmes SD, Gibbons WE, Buttram VC Jr: Peritoncal flud plasminogen activator activity in endometriosis and pelvic adhesive disease.

Fertil Steril 44: 277-279, 1985

Brosens IA, Kominckx PR, Corveleyn PA: A situdy of plasma progesterone, oestradiol 17 beta, prolactin and LH levels, and of the luteal phase appearance of the ovaries in patients wit hendometriosis and infertility.

Brit J Obstet Gynaecol 85: 246-250, 1978

Bouckaert PXJM, Evers JLH, Doesburg WH, Schellekens LA, Brombacher PH, Rolland R: Patterns of changes in proteins in the peritoneal fluid of women during the periowulatory phase of the mensirual cycle.

J Reprod Fertil 77: 329-336, 1986

Buckman RF, Woods M, Sargent L, Gervin AS: A unifying pathogenetic mechanism in the etiology of intraperitoneal adhesions.

J Surg Res 20: 1.-5, 1976

Clauss A: Gerinnungs physiologische Schnellmethode zur Bestimmung des Fibrinogens.

Acta Haematol 17: 237-241, 1957

Drapier JC, Tenu JP, Lemaire G, Petit JF: Regulation of plasminogen activator secretion in mouse peritoneal macrophages.

Biochimie $61: 463-471,1979$

Gervin AS, Puckett CL, Silver D: Serosal hypofibrinolysis. A cause of postoperative adhesions.

Am J Surg 125: 80-88, 1973.

Halme J, Hammond MG, Hulka JF, Raj SG, Talbert 1.M: Retrograde menstruation in healthy women and in parients with endometriosis.

Obstet Gynecol 64: 151-154, 1984

Levander G, Normann P: The pathogenesis of endometriosis. An experimental study.

Acta Obstet Gynecol Scand 34: 366-398, 1955

Mancini G, Carbonara AO, Heremans JF: Immunochemical quantitation of antigens by single radial immunodifrusion.

Immunochemistry 2: 235-254, 1965

Malick JE: The etiology of endometriosis.

Journal of A O A 81: $407-412,1982$ 
Ohisults : Study on the pathogenesis of adhesions in endometriosis.

Acte Obsh Oymat Ipn $32: 1758-1766,1980$

Pattinson HA, Koninck PR, Brosens IA, Vermeylen I: Clotting and fibrinolytic activities in peritoneal fluid.

Br J Obstet Cynaecol 88: $160-166,1981$

Sampson JA: Perioneal endometriosis due to menstrual dissemination of endometrial tissue into the peritonal cavity.

An J Obstet Gynecol 14: 422-469, 1927

Sprengers ED, Klufi C: Plasminogen actuator inhibitors.

Blood 69: $381-387, \llbracket 997$

Steele RW, Dmowski WP, Marmer DJ: Immunologic aspects of thuman endometriosis. Am I Reprod Immunol $6: 33-36,1984$

Strickland S, Beers WH: Studies on the role of plasminogen acivator in ovulation.

』Biol Chem 251: 5694-5702, 1976

Verheigen JH, Mullaart E, Chang CTC, Klufi C, Wijngands $G$ : A simple, sensitive spectrophotometric assay for extrinsic (tissue-type) plasminogen activator applicable to measurements in plasma.

Thromb Haemost $48: 266-269,1982$ 


\section{Chapter 6}

\section{Functional aspects of peritoneal macrophages in endometriosis of women}

G.A.J. Dunselman, M.G.R. Hendrix, P.X.J.M. Bouckaert, J.L.H. Evers (Journal of Reproduction \& Fertility 82: 707-710, 1988)

(with permission)

\section{Summary}

Peritoneal fluid was collected in the periovulatory phase of the cycle from 25 women undergoing laparoscopy. Endometriosis was diagnosed in 13 patients (AFS score 1, $N=9 ;$ AFS score $2, N=4$ ) and 12 patients without endometriosis served as controls. In endometriosis patients the total peritoneal fluid cell number and cell concentration was significantly higher than in controls, indicating peritoneal irritation by endometrial implants.

Peritoneal fluid macrophages in patients with endometriosis showed significantly increased erythrophagocytosis and lower chemiluminescence than in controls suggesting an advanced differentiation of the macrophages in endometriosis patients. The macrophages in this stage of differentiation may interfere with gametes and $\mathrm{cm}$ bryos and thus contribute to endometriosis-associated subfertility. 
Although the association between endometriosis and infertility is accepted, its nature is far from being understood. In recent years peritoneal fluid and its cellular constituents have received considerable attention in the process of elucidating the causes of infertility; peritoneal macrophages are particularly supposed to play an important role in endometriosis-related subfertility (Haney et al., 1981; Badawy et al., 1984; Halme et al., 1982; Olive et al., 1985). Phagocytosis of spermatozoa by peritoneal macrophages has been reported to be increased in endometriosis patients (Muscato et al., 1982).

In this study we determined the cell number of the peritoneal fluid and functional aspects of peritoneal macrophages, erythrophagocytosis and chemiluminescence, reflecting the level of differentiation of the macrophages (Cohn, 1978).

\section{Materials and Methods}

\section{Patients, fluid collection and analysis}

Peritoneal fluid was collected in the periovulatory phase of the cycle from 25 women undergoing llaparoscopy. The indication for laparoscopy was infertility $(\mathrm{N}=16)$, abdominal pain $(\mathrm{N}=3)$ and sterilization $(\mathrm{N}=6)$. All patients had regular cycles varying in duration between 23 and 35 days. They had not used oral contraceptives or ovulation inducing drugs or an intrauterine contraceptive device for at least 3 months before the laparoscopy. Patients with occluded Fallopian tubes were excluded. At laparoscopy the presence or absence of endometriosis was recorded. Endometriosis was classified according to the classification of the American Fertility Society (1979).

Peritoneal fluid was collected under direct vision from the pouch of Douglas and the vesicouterine space as described by Bouckaert et al. (1986). Care was taken to collect all peritoneal fluid. The peritoneal fluid was collected in glass tubes, $1.5 \mathrm{mg}$ tetra sodium ethylene diamine tetraacetic acid (EDTA) $/ \mathrm{ml}$ were added as anticoagulant and the tubes were stored on ice.

Before induction of anaesthesia a $5-\mathrm{ml}$ blood sample was withdrawn, allowed to clot and centrifuged. The supernatant serum was stored at $-70^{\circ} \mathrm{C}$.

The periovulatory phase of the cycle in which the laparoscopy was to be performed was determined using knowledge of the length of the previous cycles and the first day of the last menstrual period. The concentrations of oestradiol-17 $\beta$ and progesterone measured in serum and peritoneal fluid allowed further subdivision of the periovulatory phase into the follicular and luteal phases (Bonckaert et al., 1986). To identify patients with subclinical inflammatory pelvic disease C-reactive protein 
was measured in peritoneal fluid and serum, using single radial immunodiffusion (Mancini et al., 1965).

The peritoneal fluid was centrifuged at $350 \mathrm{~g}$ at $4^{\circ} \mathrm{C}$ for $10 \mathrm{~min}$ to harvest the peritoneal cells. The supernatants were collected and stored at $-70^{\circ} \mathrm{C}$. The pellet was resuspended in Hank's balanced salt solution (HBSS). Peritoneal cells were counted and the viability determined by trypan blue exclusion. Cells were identified after May-Gruenewald-Giemsa fixation and staining from morphological criteria such as polymorphous nuclear cells (PMN), lymphocytes or macrophages.

\section{Erythrophagocyrosis and chemiluminescence}

Fc mediated erythrophagocytosis (sheep red blood cell phagocytosis = SRBC phagocytosis) was measured as described before (Hendrix et al., 1986). In short, peritoneal cell monolayers were prepared in $16-\mathrm{mm}$ wells on $13-\mathrm{mm}$ round glass coverslips by incubating for $1 \mathrm{~h}$ at $37^{\circ} \mathrm{C}$. After adherence, antibody-coated sheep erythrocytes were added to the monolayers and incubated for $1 \mathrm{~h}$ at $37^{\circ} \mathrm{C}$. Nonadherent erythrocytes were subsequently removed by vigorous washing with phosphate buffered saline (PBS). Each coverslip was then incubated for 10 min in a $0.85 \%(\mathrm{w} / \mathrm{v})$ ammonium chloride (Merck) solution to lyse non-internalized erythrocytes. After fixation the number of macrophages containing no erythrocytes were counted by phase-contrast microscopy. At least 200 cells were counted for each experiment. The results are expressed as the percentage of peritoneal cells containing at least one erythrocyte.

Chemiluminescence was measured with a Iumino-aggregometer, using opsonized zymosan as stimulating agent, as previously described (Hendrix et al., 1986). In short, opsonized zymosan was prepared by boiling $8 \mathrm{~g}$ zymosan (Sigma Chemical Co., St Louis, Missouri, USA) for $30 \mathrm{~min}$ in $2 \mathrm{ml} \mathrm{PBS}$, centrifuging at $350 \mathrm{~g}$ for $10 \mathrm{~min}$ and resuspending in $200 \mu \mathrm{l}$ normal human $\mathrm{AB}$ serum. After incubation for $30 \mathrm{~min}$ at $37^{\circ} \mathrm{C}$ the solution was centrifuged again and resuspended in HBSS to a final concentration of $4 \mathrm{mg} / \mathrm{ml}$. Chemiluminescence was evaluated by introducing $0.1 \mathrm{ml}$ of a cell suspension containing $2 \times 10^{\circ}$ peritoneal cells, $0.1 \mathrm{ml} \mathrm{HBSS}+$ $0.1 \%(\mathrm{w} / \mathrm{v})$ gelatin (Difco, Detroit, Michigan, USA), $0.1 \mathrm{ml}$ luminol $\left(10^{* 4} \mathrm{M}\right)(\mathrm{Lu}-$ mac, Landgraaf, The Netherlands) and $0.1 \mathrm{ml} 50 \%$ human AB serum in a siliconcoated glass vial, and placing it in the Chronolog. When the background light emission became constant, $0.1 \mathrm{ml}$ of the appropriate zymosan suspension was added and the photo-emission was scored continuously during the first 10 min of the reaction. The chemiluminescence response was recorded in duplicate for each experiment. Results are shown as a relative value (units) for the light emission calculated from the total area under the curve during the first $10 \mathrm{~min}$ of the chemiluminescence response.

\section{Analyses}

Comparisons were made between patients with endometriosis and patients without the disease, for the following values: total peritoneal cell number, cell number per 
Table 6.1 Total numbers and concentrations of peritoneal cells

\begin{tabular}{|c|c|c|c|c|c|c|}
\hline & \multicolumn{3}{|c|}{ Endometriosis samples } & \multicolumn{3}{|c|}{ Control samples } \\
\hline & $n$ & Median & Range & rit & Median & Range \\
\hline $\begin{array}{l}\text { Cell no. } \\
\times 10^{7}\end{array}$ & $\| 3$ & $2.55^{*}$ & $1.08-9.64$ & 12 & 1.46 & $0.30-5.30$ \\
\hline $\begin{array}{l}\text { Cents } \\
\qquad \times 10^{6} / \mathrm{ml}\end{array}$ & 13 & $1.35^{*}$ & $0.76-8.62$ & 12 & 0.87 & $0.30-2.65$ \\
\hline
\end{tabular}

* $\mathrm{P}<0.05$, compared with controls.

Table 0.2 Viability and percentage of macrophages in periloneal fluid

\begin{tabular}{|c|c|c|c|c|c|c|}
\hline & \multicolumn{3}{|c|}{$\begin{array}{l}\text { Endometriosis } \\
\text { samples }\end{array}$} & \multicolumn{3}{|c|}{$\begin{array}{l}\text { Comtrol } \\
\text { samples }\end{array}$} \\
\hline & nin & Median & Range & $\mathrm{n}$ & Median & Range \\
\hline $\begin{array}{r}\text { Vubility } \\
(\%)\end{array}$ & 13 & $82.0^{4}$ & $31-99$ & 12 & 80.0 & 42.97 \\
\hline $\begin{array}{c}\text { Macrophages } \\
(\%)\end{array}$ & $\mathbb{1}$ & $93.0^{*}$ & $92-98$ & 12 & 91.0 & $27 \cdot 97$ \\
\hline
\end{tabular}

$* \mathrm{P}>0.05$, compared with controls.

Table 6.3 Phagocyrosis of sheep RBCs and chemiluminescence by peritoneal fluid macrophages

\begin{tabular}{|c|c|c|c|c|c|c|}
\hline & \multicolumn{3}{|c|}{$\begin{array}{l}\text { Endometriosis } \\
\text { samples }\end{array}$} & \multicolumn{3}{|c|}{$\begin{array}{l}\text { Conitrol } \\
\text { sarmples }\end{array}$} \\
\hline & $\|$ & Median & $\mathbb{R}$ ange & In & Median & Range \\
\hline $\begin{array}{l}\text { Shetep RBCs } \\
(0 / 0)\end{array}$ & .13 & $90.0^{*}$ & 12.97 & 12 & 35.5 & $3-76$ \\
\hline $\begin{array}{l}\text { Chemilumi- } \\
\text { nescence } \\
\text { (units) }\end{array}$ & 13 & $59.0^{*}$ & $20-360$ & 12 & 145.0 & 91.299 \\
\hline
\end{tabular}

* $P<0.001$; * $P<0.0001$, compared with controls.

$\mathrm{ml}$ peritoneal fluid, percentages of macrophages in the differential counts of peritoneal cells, viability of the macrophages, SRBC phagocytosis and chemiluminescence. 
Statistical analysis was performed using the Wilcoxon rank sum test for non-paired samples.

\section{Results}

At laparoscopy, 13 patients were found to have endometriosis (Score 1, N = 9; Score 2, $N=4$; American Fertility Society, 1979); 12 patients without endometriosis served as controls.

Based on the oestradiol-17 13 and progesterone concentrations in peritoneal fluid and serum (Bouckaert et al., 1986), 5 patients in the endometriosis group were classified as being in the follicular and 8 as being in the luteal phase of the cycle. The figures for controls were 2 and 10 respectively.

Values of C-reactive protein were below the level of detection in all peritoneal fluid and serum specimens.

As shown in Table 6.1, the median value of the total cell number and the median value of the cell number per $\mathrm{ml}$ peritoneal fluid in endometriosis patients were higher than in controls, both differences were statistically significant $(P<0.05)$. The viability of the cells and the percentage of macrophages in the differential count were not significantly different in the two groups (Table 6.2).

Table 6.3 shows the results of the sheep RBC phagocytosis and of the chemiluminescence of peritoneal cells in endometriosis and controls. A statistically significant difference in SRBC phagocytosis existed between endometriosis patients and controls $(P<0.0001)$. The lower level of chemiluminescence in endometriosis patients also was statistically significant $(P<0.001)$.

\section{Discussion}

Increased total peritoneal fluid cell numbers and cell concentrations, with a percentage of macrophages of $80 \%$ and higher have repeatedly been reported in the literature in patients with endometriosis as compared to controls, although the differences were not always statistically significant (Haney et al., 1981; Badawy et al., 1981; Halme et al., 1982, 1984; Olive et al., 1985). In the present study we confirmed the increased number and the increased concentration of peritoneal cells in patients with endometriosis as compared to controls. The peritoneal cavity is normally populated by resident macrophages. Secondary to several stimuli, including shedding of endometrial tissue in addition to ovulation and retrograde menstruation, monocytes are attracted from the bloodstream and convert to differentiated macrophages, 
leading to an increased concentration of peritoneal cells. An acute inflammatory process will change the peritoneal cell number considerably. The finding in our study that C-reactive protein was below the level of detection in peritoneal fluid and in serum in patients with endometriosis and in the control group indicates that there was no acute intraperitoneal inflammatory process in either group at the time of the laparoscopy (Lehtinen et al., 1986).

The phagocytic capacity of peritoneal macrophages measured by the uptake of opsonized zymosan has been reported to be comparable in endometriosis patients and controls (Halme et all, 1984). We found an increased phagocytosis of sheep RBCs by macrophages recovered from the peritoneal fluid of patients with endometriosis as compared to controls. Viability and percentage of macrophages in peritoneal cells were the same in each group (Table 6.2). The increased ability of peritoneal macrophages to phagocytose antibodycoated particles (sheep RBCs) supports the findings of Lonclon et all. (1985) concerning macrophage-mediated sperm killing as a possible cause of subfertility.

A remarkable finding of the present investigation was the significantly reduced chemiluminescence measured in peritoneal macrophages of endometriosis patients. The dissociation that we found between an increased phagocytosis and a reduced chemiluminescence of macrophages in endometriosis patients compared with controls possibly finds its explanation in subsequent degrees of differentiation of the peritoneal macrophages. In recent years it has become clear that after stimulation macrophages undergo changes in metabolism and differentiate in a stepwise fashion (Cohn, 1978; Yamamoto and Johnston, 1984; Johnson et al., 1986). Following this concept the levels of phagocytosis and chemiluminescence measured in control patients represent a baseline steady state level. The enhanced phagocytosis and the diminished chemiluminescence in endometriosis patients indicate a next step in differentiation, the macrophages are engaged in phagocytosis and have left the stage of $\mathrm{O}_{2}^{-}$production.

The concept of a more advanced stage of differentiation of peritoneal macrophages in patients with endometriosis is supported by two reports. Fakih et all. (1987) reported on the presence of interleukin-1, a protein produced by differentiated peritoneal macrophages and a mediator of host responses, in the peritoneal fluid of patients with enclometriosis and not in that of controls without the disease. Halme et al. (1987), extending earlier observations (Halme et al., 1984), described the exsistence of larger, more mature macrophages in peritoneal fluid of patients with endometriosis.

In conclusion, we found increased sheep RBC phagocytosis and a decreased level of chemiluminescence of peritoneal macrophages in patients with endometriosis compared to controls. This is consistent with an advanced level of differentiation of peritoneal macrophages in patients with endometriosis.

These macrophages may interfere with gametes and pre-implantation embryos and thus contribute to endometriosis-associated subfertility. 


\section{References}

American Ferility Society: Classification of endometriosis. Fertil Steril 32:633-634, 1979

Badawy SZA, Cuenca $\mathbf{V}$, Marshall $L$, Munchback $R$, Rinas AC, Coble DA: Celluar components in peritoneal fluid in infertile patients with and without endometrosis.

Fertil Steril 42: 704-708, 1984

Bouckaert PXJM, Evers JLH, Doesburg WH, Schellekens LA, Rolland R: Patterns of changes in glycoptoteins, polypeptides, and steroids in the peritoneal tuid of women during the periovulatory phase of the menstrual cycle.

I clin Endocr Metab 62: 293-299, 1986

Cohn ZA: The activation of mononuclear phagocytes: fact, fancy and future.

J Immunol 121: $813-816,1978$

Fakilh H, Baggett B, Holtz G, Tsang K-Y, Lee JC, Williamson HO: Interleukin-1: a possible role in the infertility associated with endometriosis.

Fertil Steril 47: 213-217, 1987

Halme J, Becker S, Hammond MG, Raj S: Pelvic macrophages in normal and infertile women: the role of patent tubes.

Am J Obslet Gynecol 142: 890-895, 1982

Halme J, Becker S, Wing R: Accentuated cyclic activation of peritoneal macrophages in patients with endometriosis.

Am J Obstet Gynecol 148: 85-90, 1984

Halme J, Becker S, Haskill S: Altered maturation and function of peritoneal macrophages: possible role in pathogenesis of endometriosis.

Am J Obstet Gynecol 156:783-789, 1987

Haney AF, Muscato JJ, Weinberg JB: Peritoneal fluid cell populations in infertility patients.

Fertil Steril 35: 696-698, 1981

Hendrix MGR, Bruggeman CA, Van Boven CPA: Alterations of the functional state of peritoneal macrophages during rat cytomegalovirus infection in vitro.

FEMS Lett 33: 111-115, 1986

Johnsen WJ, DiMartino MJ, Hama N: Macrophage activation in rat models of inflamrnation and arthritis: determination of markers of stages of activation.

Cell Immunol 103: 54-64, 1986

Lehtinen M, Laine S, Heinonen PK, Teisala K, Miettinen A, Aine R, Punmonen R, Grönroos P, Paavonen J: Serum C-reactive protein determiration in acute pelvic inflammatory disease.

Ams J Obstet Gynecol 154:158-160, 1986

London SN, Haney AF, Weinberg JB: Macrophages and infertility: enhancement of luman macrophage-mediated sperm killing by antisperm antibodies.

Fervil Steril $43: 274-278,1985$

Mancini G, Carbonara AO, Heremans JF: Immumochemical quantitation of antigens by single radial irmmunodiffusion.

Immunochemistry $2 ; 235-254,1965$ 
Muscato JJ Maney AF, Weinberg JB: Sperm phagocytosis by human peritoneal macrophages: a possible cause of infertility in endometriosis.

Am J Obstet Gynecol 144: $503-510,1982$

Olive DL, Wainberg $\rrbracket_{4}$ Haney AF: Peritoneal macrophages and infertility: the association between cell number and pelvic pathology.

Feril Steril 44: 772-777, 1985

Yamamotlo K, Johnston RB Jr: Dissociation of phagocytosis from stimulation of the oxidative metabolic bursit in macrophages.

J exp Med 159: 405-416, 1984 


\section{Chapter 7}

\section{A rabbit model of endometriosis}

G.A.J. Dunselman, D. Willebrand, J.A. Land, P.X.J.M. Bouckaert, J.L.H. Evers (Gynecologic and Obstetric Investigation, accepted for publication)

\section{Summary}

Since not all problems in endometriosis can be studied in the human, there is need of an animal model. We transplanted endometrial tissue of the rabbit into the peritoneal cavity and studied the changes after 12 weeks. At that time endometrial implants in the rabbit had become cystic structures. The macroscopic and histological appearance was consistent with endometriosis. Hormonal supplementation turned out to be not necessary. Microsurgical techniques prevented the formation of tubo-avarian adhesions. This makes the rabbit model suitable to study the influence of endometrial implants on fertility. 


\section{Introduction}

Although endometriosis occurs spontancously in some subhuman primates, it has to be considered a basically human condition. The low prevalence of spontaneous endometriosis in monkeys curtails their use in endometriosis research (MacKenzie, 1975). In the human, ethical problems restrict the study of various unsolved issues regarding etiology, treatment modalities and the relation between endometriosis and infertility. If endometriosis is regarded as a result of retrograde menstruation whether endometrial fragments actually implant (Sampson, 1940) or liberate substances that induce the peritoneum to change into endometriosis (Levander and Normann, 1955; Merrill, 1966) - the surgical implantation of pieces of endometriurm onto the peritoneum of animals may be used as a model to study the abovementioned problems.

We report on the use of endometrial transplants in the rabbit to study the relationship between infertility and endometriosis.

\section{Materials and Methods}

Virgin female Dutch belted rabbits were used. Animal handling has been described previously (Land, 1985). Before surgery each doe received $125 \mathrm{mg}$ of ampicillin prophylactically by intravenous injection. Anaesthesia was induced with $0.2 \mathrm{mg}$ atropine $/ \mathrm{kg}$ and $0.5 \mathrm{ml}$ Hypnorm $/ \mathrm{kg}$ (10 $\mathrm{mg}$ fluanizone and $0.2 \mathrm{mg}$ phentanyl per $\mathrm{ml}$, Duphar, Amsterdam) intramuscularly. As soon as adequate anaesthesia was achieved, each doe was intubated with an endotracheal tube. A mixture of thalothane $(0.5-1.0 \%$ ), oxygen ( 1 litre $/ \mathrm{min}$ ) and nitrous oxide ( $2 \mathrm{litre} / \mathrm{min}$ ) was given through a closed loop inhalation anaesthesia system (infant ventilator, MK2, Keuskamp, Amsterdam). A lower abdominal midline incision was used to expose the viscera and the internal genitals. To prevent adhesion formation, care was taken to avoid unnecessary tissue handling, microsurgical principles were observed, the area was kept moist during the entire procedure and nonresorbable 6.0 Prolene sutures (Ethicon, Somerville, NJ) were used. In 50 rabbits a $1-\mathrm{cm}$ segment of the right uterine horn as well as adipose tissue from the juxta-uterine fat was resected. After resection, the uterine horn was reanastomosed and the defect in the fat tissue closed by microsurgical methods. In 25 rabbits (Experimental Group = Group E) the resected uterine horn was opened longitudinally and divided into four $3 \times 3 \mathrm{~mm}$ parts. These pieces of uterine tissue (consisting of endometrium, muscularis and serosa) were sutured onto the peritoneum at the right lateral abdominal wall, adjacent to the uterus and ovary, with the serosal side of the uterine tissue facing the peritoneum, and the endometrium facing the peritoneal cavity. Figure 7.1 shows the four 


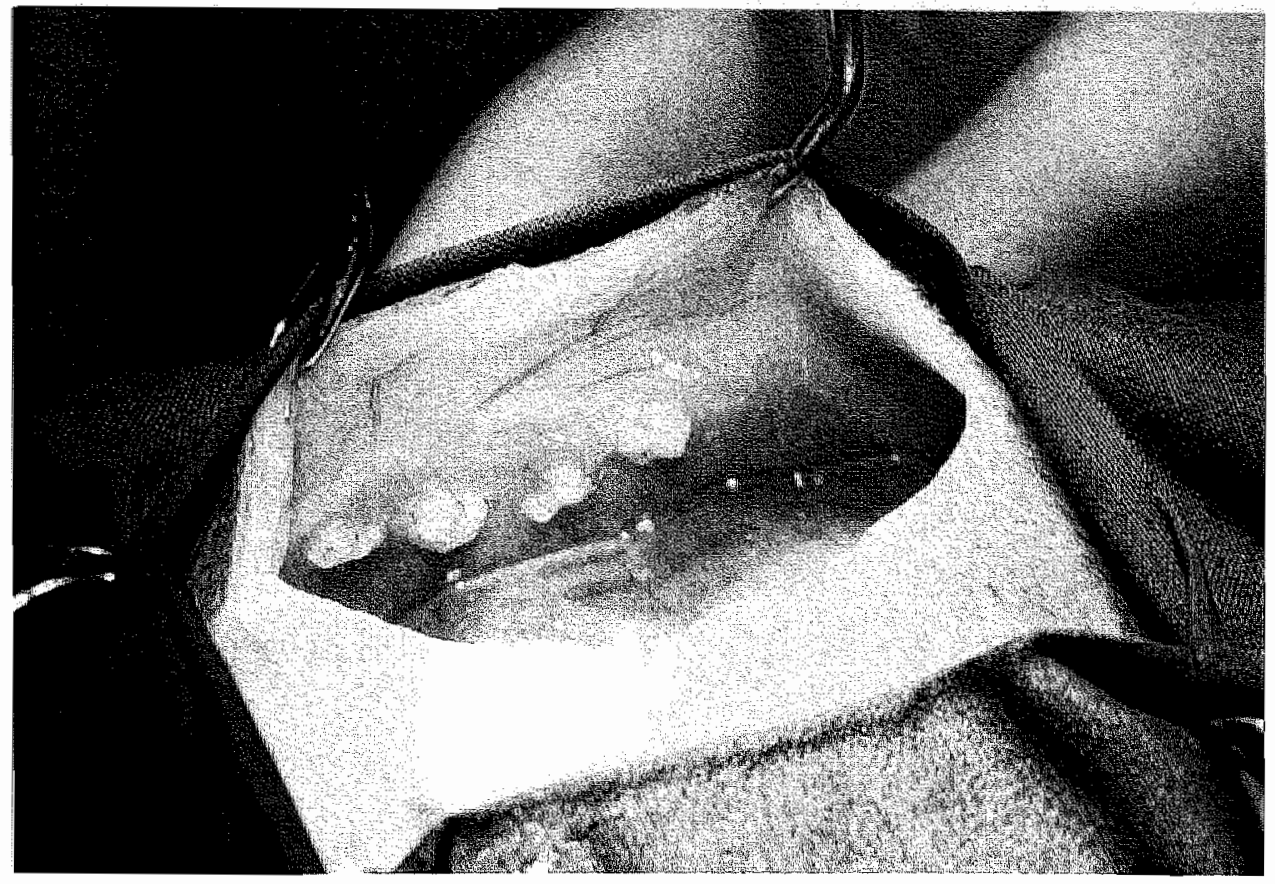

Figure 7.1. Foun transplants of unerine tissue on the peritoneum of the right lateral abdominat wall.

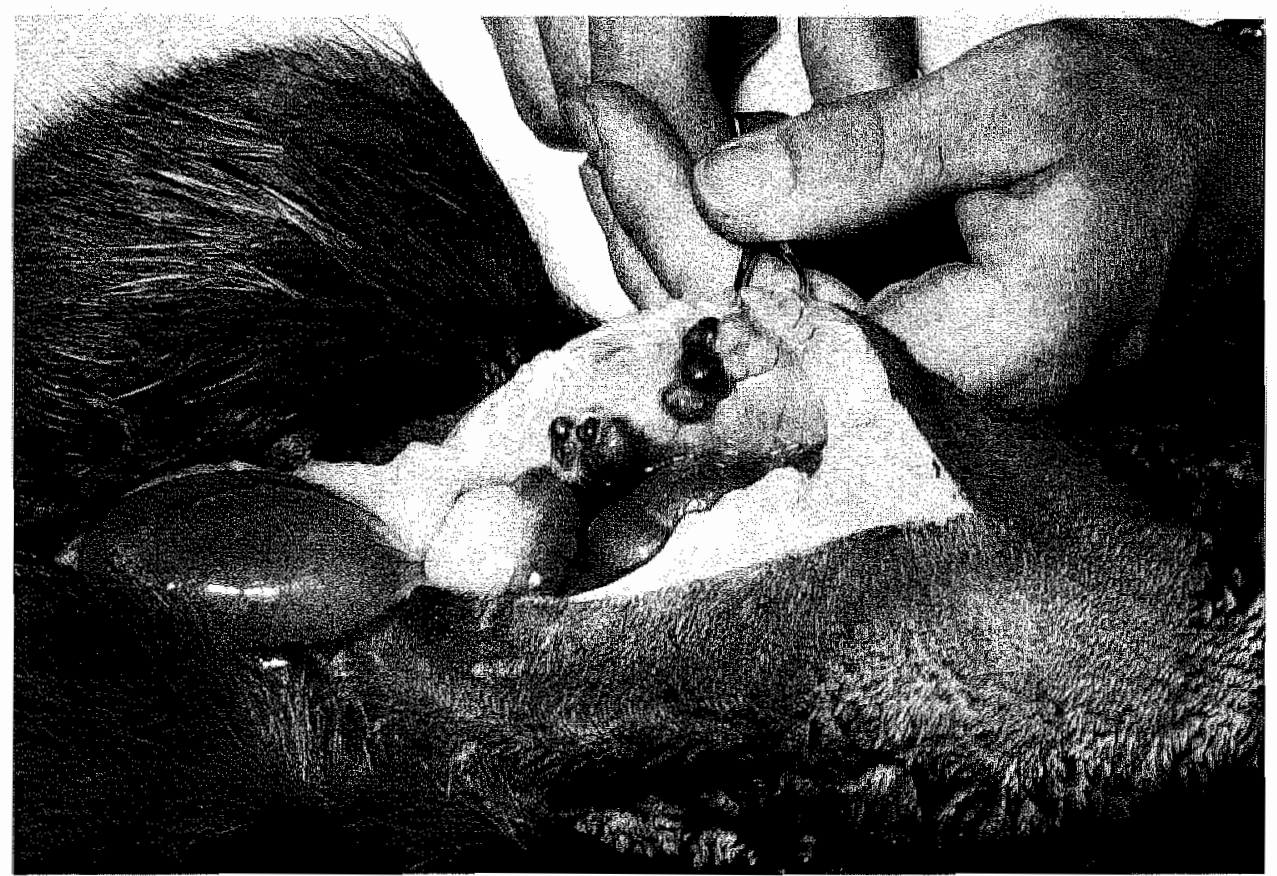

Figure 7.2. Cysts containing yellow or dark fluid replacing the wherine transplants after 12 weeks 


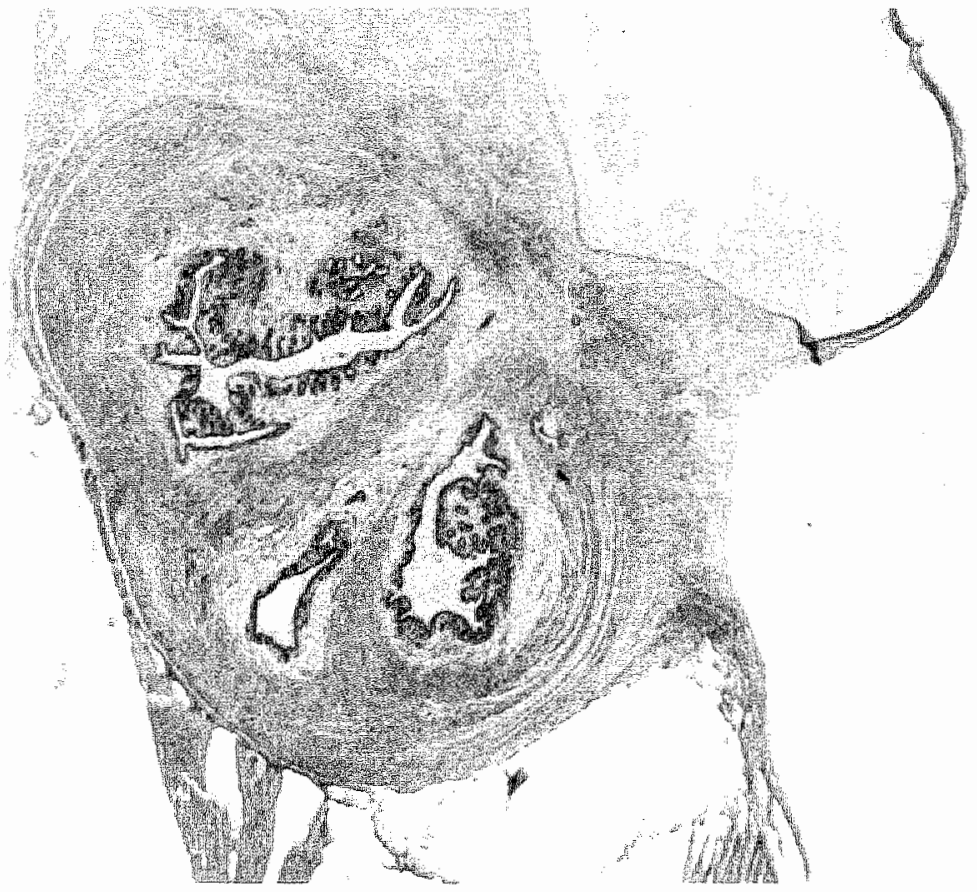

Figure 7.3a. Light microscopy of wterine vissue transplant afrer 12 weeks $(H E, 15 x)$

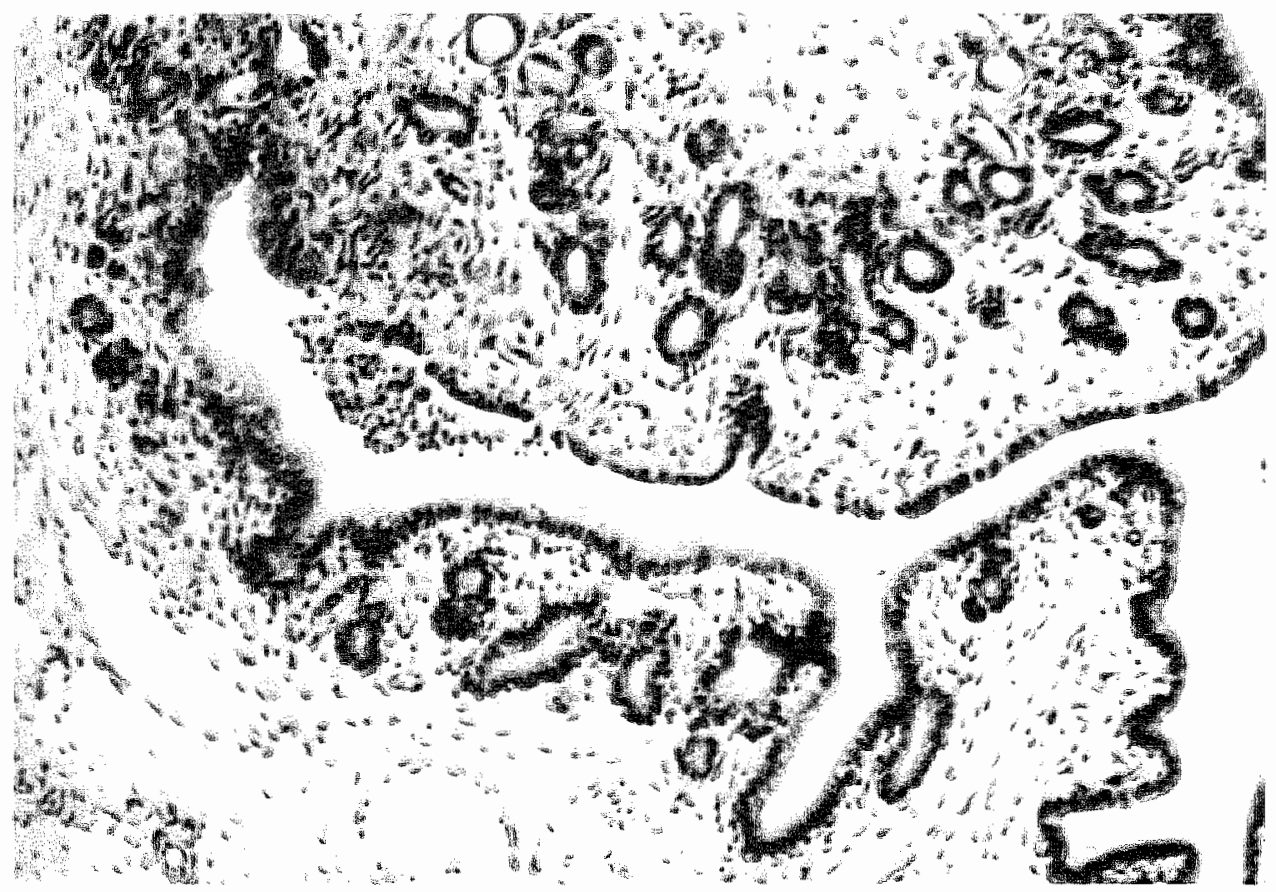

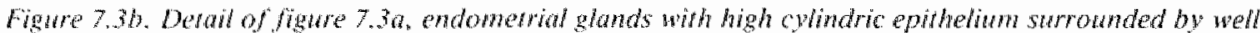
vascularized stroma $(H E, 100 x)$ 


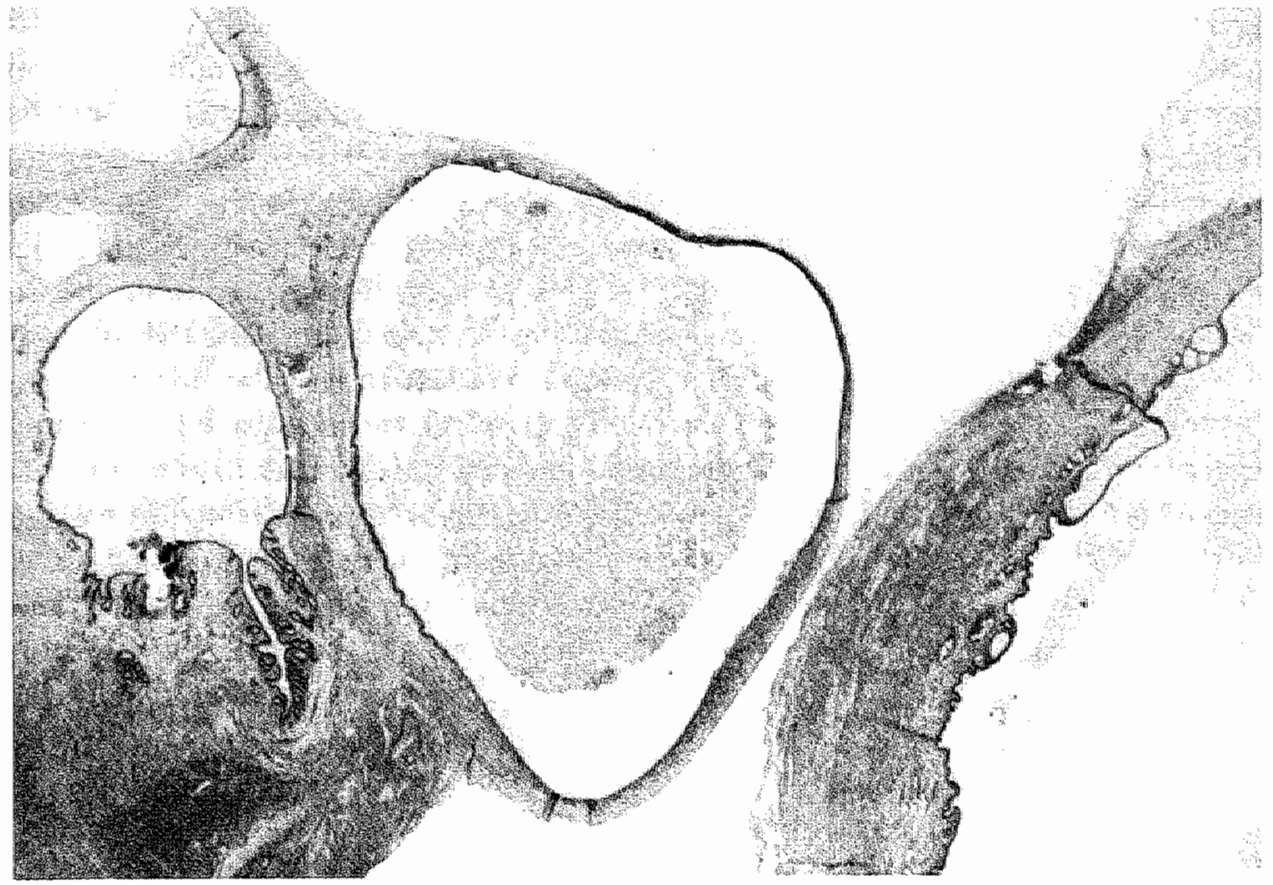

Figure 7.4a Endometrial cyst containing epidheliat cells and erythrocyles (HE, 15x)

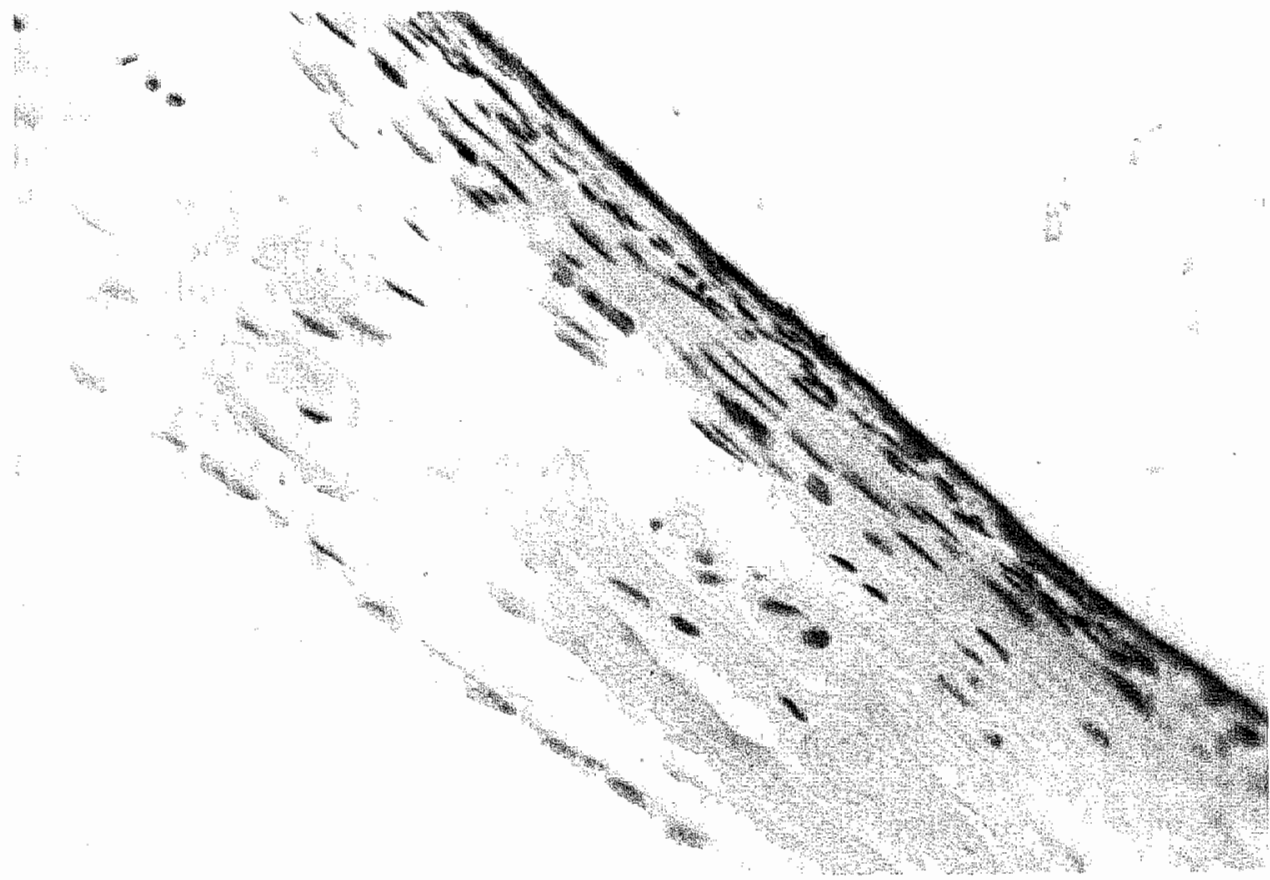

Figure $7.4 b$ Detail of figure $7.4 a$, cyst wall with flatened cpitherium lining the cyst fopj and mesolhelial cells on the outside of the cyst (botrom) (HE, 250x) 
transplanted pieces of endometrial tissue. In 25 rabbits (Control group $=$ Group $C$ ) the fat was divided into four equal parts and sutured onto the peritoneum in a comparable way. In Group $E$ the fat tissue was discarded and in Group $C$ the uterine tissue was discarded. The abdominal wall was closed in two layers with everting interrupted sutures. The fat tissue was transplanted in a similar way. The animals did not receive any hormonal supplementation either before or after surgery.

After a period of 12 weeks the does were sacrificed. Anaesthesia was induced with $0.5 \mathrm{mg} x y$ lazine $/ \mathrm{kg}$ (Rompun: Bayer, Leverkusen, West Germany) and $0.4 \mathrm{ml}$ ketamine/kg (Ketaset: Bristol Laboratories, New York) by intramuscular injection. An overdose of pentobarbitone sodium was administered intravenously and laparotomy was performed. Adhesions were scored and the gross morphology of the implants was recorded. All implants were excised, fixed overnight at room temperature in a mixture of alcohol (100\%), glacial acetic acid and formaldehyde (40\%) 15:1:4 (v/v), and routinely paraffin embedded. Serial 4 micron sections were cut and haematoxilin-eosin-stained sections of all endometrial and fat implants were examined.

\section{Results}

All rabbits survived the first laparotomy and the 12 week recovery period. In all rabbits of Group $\mathrm{E}$ cystic structures varying in diameter between 5 and $15 \mathrm{~mm}$ were found in place of the endometrial implants. The cysts were filled with a clear yellow or brownish fluid (Figure 7.2). Ovaries and oviducts were free of adhesions in all animals. Light microscopy examination of the implants revealed endometrial glands surrounded by well vascularized stroma (Figures $7.3 \mathrm{a}$ and $7.3 \mathrm{~b}$ ). The cysts were lined by flattened epithelium at the side facing the peritoneal cavity. At the abdominal wall side, high cylindric epithelium was seen. The lumen of the cysts contained epithelial cells and erythrocytes (Figure 7.4a). The cysts were covered by mesothelial cells (Figure 7.4b).

All fat transplants in group $\mathrm{C}$ only showed fat tissue, both on macroscopic and histological examination.

\section{Discussion}

The ability of endometrial tissue to proliferate after autotransplantation to various ectopic locations has been documented in the monkey, the rat and the rabbit (Schenken and Asch, 1980; Schenken et al., 1984; Vernon and Wilson, 1985). In 
studying the effects of endometriosis on fertility the three animal models all have their pros and cons. The main advantage of the monkey model is the fact that the menstrual cycle and the gross and histological appearance of the disease are similar to those in the human. The main disadvantages are the high cost and the difficulties in animal handling. The rat model offers a cheap, cycling animal with 70 to 80 estrous cycles a year, although with a very short luteal phase. The main disadvantage of the use of the rat model to study the influence of endometriosis on fertility, is that the rat ovary is surrounded by a tight bursa, which may isolate it from the surrounding peritoneal environment. Consequently peritoneal fluid constituents, affected by the presence of endometriosis, may not be able to exert their (possibly deleterious) effects on the developing follicle, the mechanism of ovulation, the pickup function of the oviduct, the gametes, fertilization and the early embryo.

The advantages of the use of the rabbit model in studying endometriosis related infertility are the low cost and the relative ease and high success rate of transplanting endometrial tissue. Normal patterns of ovulation, fertilization, tubal transport and early embryonic development have been thoroughly studied in the rabbit (Land, 1985). The double uterus of the rabbit allows for altering one side and for studying the effect of these alterations, both on the ipsilateral side and on the untouched contralateral side. The main disadvantage of the rabbit model is the fact that it is a reflex ovulator and as such does not have reproductive cycles comparable to the human.

We showed that small pieces of the uterine wall, consisting of serosa, muscularis and mucosa, after transplantation onto the peritoneum were replaced by cystic structures that are morphologically consistent with endometriosis. Histology confirmed these endometriosis-like changes. Schenken and Asch (1980) and Donnez et al. (1987) used supplementation of estrogens prior to and after the transplantation of endometrium in the rabbit. In these studies (Schenken and Asch, 1980; Donnez et al., 1987) hormonal supplementation rather than endometrial implants may have influenced early embryonic development. In our study supplementation of estrogens did not appear to be necessary for the development and growth of the implants, although the animals lack a menstrual cycle. This is in accordance with the recent findings of Hahn et al. (1985).

An additional observation was that it did not appear to be necessary to dissect the endometrium from the underlying myometrium, a procedure adopted by others using this same model (Schenken and Asch, 1980; Hahn et al., 1985). Endometrial glands require stromal cells to implant and grow (Zamah et al., 1984). In menstruating species the stromal layer is sloughed off during menstruation together with the endometrial layer, in contrast to estrous animals, where the stromal layer remains in place. This may explain the lack of spontaneous endomedriosis in estrous animals (Vernon and Wilson, 1985).

The increase in size of the original implants to the size of the implants found after 12 weeks, the formation of cysts, the proliferative changes in the glandular epithelium and the vascularization are indicative of active growth of endometrial tissue. 
Conceivably, these endometrial transplants can have an effect on the composition of peritoneal fluid. Hahn et al. (1986) showed that the fertility of rabbits was impaired, after they had received peritoneal fluid from rabbits with induced endometriosis.

In the 25 rabbits with endometrial transplants and in the 25 rabbits with fat transplants adhesions were confined to the uterine anastomosis and the small and large bowel. Ovaries and oviducts were completely free of even fillmy adhesions. This is in contrast with other studies. It is therefore not clear whether the disturbances in early embryonic development that were found by others were caused by the adhesions involving ovaries and oviducts, or by the endometrial implants per se (Schenken and Asch, 1980; Schenken and Walters, 1986; Donnez et al., 1987). It has been suggested that adhesions may affect follicle growth and ovulation (Hamilton et al., 1986). Postoperative adhesion formation rather than endometrial implants therefore may be responsible for the observations as reported in the abovementioned studies (Schenken and Asch, 1980; Schenken and Walters, 1986; Donnez et al., 1987).

In summary, endometrial implants in the rabbit offer a suitable model to study the influence of minimal and mild endometriosis on fertility, provided that meticulous surgical techniques are applied in order to prevent the formation of tubo-ovarian adhesions.

\section{References}

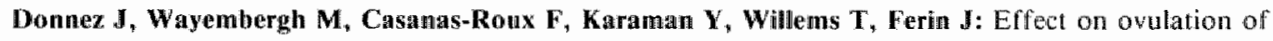
surgically induced endometriosis in rabbits.

Gynecol Obstet $\llbracket$ nvest $24: 131 \% 137,1987$

Hahn DW, Carraher RP, Foldesy RG, McGuire JL: Development of an animal model for evaluating afects of drugs on endometriosis.

Fertil Steril $44: 410415,1985$

Hahn DW, Carraher RP, Foldesy RG, MeGuire JL: Experimental evidence for fallur to implant as a machanism of infertility associated with endometriosis.

An J Obstet Oyneed 155: 1109-1113, 1986

Hamilton CJCM, Evers JLH, Hoogland H.J: Ovulatory disorders and inflammatory adnexal damage: a neglected cause of the fallure of fertility microsurgery.

Br J Obstet Gynaecol 93: 282-284, 1986

Land JA: Embryonic development in the Fallopian tube - a microsurgical study in the rabbit. Thesis, Magstricht, 1985

Levander $\mathbf{G}$, Normann P: The pathogenesis of endometriosis. An experimental study. Acta Obstet Gynecol Scand 34:366-398, 1955 
Mackenzie WF: Animal model: endomeriosis in Rhesus monkeys. Am J Pattol 80: 341.344, 1975

Merrill JA: Endometrial induction of endometriosis across millipore filters.

Am J Obstet Gynecol 94: 780-789, 1966

Sampson JA: The development of the implantation theory for the origin of peritoneal endometriosis. Am J Obstet Gynecol 40:549-557, 1940

Schenken RS, Asch RH: Surgical induction of endometriosis in the rabbit: effects on fertility and concentrations of peritoneal fluid prostaglandins.

Fertil Steril 34: $581-587,1980$

Schenken RS, Asch RH, Williams RF, Hodgen GD: Etiology of infertility in monkeys with endometriosis: luteinized unruptured follicles, luteal phase defects, pelvic athesions, and spontaneous abortions. Fertil Steril 41: 122-130, 1984

Schenken RS, Walters MD: Ovulation and tubal ovum transport in rabbits with endometriosis. Proc Soc Gynecol Invest 21.5 (abstract), 1986

Vernon MW, Wilson E.A: Studies on the surgical induction of endometriosis in the rat.

Fertil Steril 44: 684-694, 1985

Zamah NM, Dodson MG, Stephens LC, Buttram VC Jr, Besch PK, Kaufnan RH: Transplantation of normal and ectopic human endometrial tissue into athymic nude mice.

Am J Obstet Gynecol 149: 591-597, 1984 


\title{
Chapter 8
}

\section{Effect of endometriosis on ovulation, ovum pickup, fertilization and tubal transport in the rabbit}

\author{
G.A.J. Dunselman, J.A. Land, P.X.J.M. Bouckaert, J.L.H. Evers
}

(Journal of Reproduction \& Fertility 82: 193-197, 1988)

(with permission)

\section{Summary}

In 25 rabbits (Group $\mathbb{E}$ ) endometrium from the right uterine horn was transplanted onto the peritoneum. In 25 rabbits (Group C) fat was transplanted. After a recovery period of 12 weeks the does were mated, and killed 24 h later. lin Group E the implants had changed into cysts of 5 to $15 \mathrm{~mm}$ in diameter. Histological examination revealed endometrial glands and stroma in every specimen. Periadnexal adhesions did not develop in any animal. No differences between Groups $\mathrm{E}$ and $\mathrm{C}$ were found in the number of corpora lutea, the recovery rate, the fertilization rate and the transport of fertilized ova. These findings indlicate that endometrial implants in the rabbit. have no influence on the ovulatory mechanism, the pickup function of the oviduct, the fertilization rate or on the transport of fertilized ova. Taking into account the restrictions of a rabbit model, it is suggested that the decreased fecundity in mild endometriosis in the human may be caused by disturbances in postfertilization events, i.e. development of the preimplantation embryo or implantation. 


\section{Introduction}

Patients with mild endometriosis have a monthly fecundity rate which is considerably below that of the general population (Olive and Haney, 1986). The reasons for this decreased fecundity, in particular when Fallopian tubes and ovaries are free of adhesions, remain unclear. Disturbances in folliculogenesis (Rönnberg et al., 1984; Wardle et al., 1985), ovulation (Soules et al., 1976; Brosens et al., 1978; Lesorgen et. al., 1984), ovum pickup by the Fallopian tubes (Werlin et al., 1984; Suginami et al., 1986), fertilization (Wardle et al., 1985) and implantation (Chillick et al., 1985) all have been suggested as a cause. Changes in the peritoneal milieu secondary to endometrial implants might cause these disturbances. There is evidence for an increased number of more active peritoneal macrophages in patients with endometriosis (review by Berger and Rock, 1985). Prostaglandins and proteolytic enzymes produced by macrophages might cause ovulatory dysfunction and altered tubal function (ovum pickup and transport). Altered tubal transport of the fertilized ovum can lead to an untimely arrival in the uterine cavity with subsequent implantation problems. The enhanced activity of the macrophage population may affect fertilization and implantation by influencing the immune system and by phagocytosis. Hahn et al. (1986) have reported that the decrease in fecundity, which they observed in rabbits with endometrial implants, was due to implantation failure. To stucly possible causes of subfertility in endometriosis, we investigated events in the periovulatory period, i.e. ovulation, ovum-pickup, fertilization and tubal transport of fertilized ova in rabbits with mild endometriosis.

\section{Materials and Methods}

Virgin Dutch belted rabbits were used. The 50 does were caged individually at $20^{\circ}$ $\mathrm{C}$ with a photoperiod of $12 \mathrm{~h}$ light: $12 \mathrm{~h}$ dark. They were fed $150 \mathrm{~g}$ of rabbit chow daily and allowed water ad libitum. Before surgery each doe received $125 \mathrm{mg}$ ampicillin prophylactically by intravenous injection. Anaesthesia was induced with 0.2 $\mathrm{mg}$ atropine $/ \mathrm{kg}$ and $0.5 \mathrm{ml}$ Hypnorm $/ \mathrm{kg}$ (10 mg fluanizone and $0.2 \mathrm{mg}$ phentanyl per $\mathrm{ml}$ : Duphar, Amsterdam, The Netherlands) intramuscularly. As soon as anaesthesia was achieved, each doe was intubated with an endotracheal tube. A mixture of halothane $(0.5-1.0 \%$ ), oxygen ( $1 \mathrm{litre} / \mathrm{min}$ ) and nitrous oxide (2 litre $/ \mathrm{min}$ ) was given through a closed loop inhalation anaesthesia system (infant ventilator, MK2; Keuskamp Amsterdam, The Netherlands).

In all 50 rabbits a $1 \mathrm{-cm}$ segment of the right uterine horn as well as adipose tissue from the juxta-uterine fat was resected. After resection, the uterine horn was reanastomosed and the defect in the fat tissue closed by microsurgical methods. In 
25 rabbits (Group $E$ ) the resected uterine horn was opened longitudinally and divided into four equal parts. These pieces of uterine tissue (consisting of endometrium, muscularis and serosa) were sutured onto the peritoneum at the right lateral abdominal wall, adjacent to uterus and ovary, with the serosal side of the uterine tissue facing the peritoneum, and the endometrium facing the peritoneal cavity, using 6.0 Prolene (Ethicon, Sommerville, NJ, USA). In 25 rabbits (Group C) the fat was divided into four equal parts and sutured onto the peritoneum in a comparable way. In Group $\mathrm{E}$ the fat tissue was discarded and in Group $\mathrm{C}$ the uterine tissue was discarded. The abdominal wall was closed in two layers with everting interrupted sutures. After a recovery period of 12 weeks the does were mated with a buck of proven fertility. To ensure and synchronize ovulation the does were given 125 i.u. hCG (Pregnyl: Organon, Oss, The Netherlands). The does were killed 24 th after mating, i.e. $12 \mathrm{~h}$ after ovulation (Harper, 1961). Anaesthesia was induced with 0.5 mg xylazine/kg (Rompun: Bayer, Leverkusen, West Germany) and $0.4 \mathrm{ml}$ ketamine/ $\mathrm{kg}$ (Ketaset: Bristol Laboratories, Syracuse, NY, USA) by intramuscular injection. An overdose of pentobarbitone sodium was administered intravenously and laparotomy was performed.

The abdominal cavity was carefully inspected for adhesions. The adhesions were scored, considering both extent and type of adhesions, as absent, mild (filmy adhesions) or moderate (dense adhesions). Adhesions from bladderfat, intestines and uterus to the endometrial implants were considered to have less consequenses for fertility, than adhesions from ovaries and oviducts to endometrial implants.

The implants were excised for histological examination. The patency of the right reanastomosed uterine horn was tested. The ovaries and oviducts were excised. The ovaries were examined under a stereomicroscope (Wild M8) in order to count the number of corpora lutea in each ovary. The oviducts were divided into three parts representing the ampullary segment, the ampullary-isthmic junction and the isthmic segment. The three segments of both oviducts were flushed with $5 \mathrm{ml}$ HEPESbuffered Whittingham's T6 culture medium adjusted to $\mathrm{pH} 7.4$ (Quinn et al., 1984). The flushings were checked for the presence of ova and embryos under a stereomicroscope (Wild M8). The numbers of fertilized ova and the segment from which they were retrieved were noted. From these data the tubal transport index 24 hours after mating was determined. The recovery rate, the fertilization rate and the tubal transport index were determined for each oviduct separately. Criteria for fertilization were the presence of spermatozoa in the perivitelline space, the presence of two polar bodies, the presence of two pronuclei, or cleavage.

The results obtained were compared between the right and left oviducts in each group, and between the right oviducts and the left oviducts for Groups $C$ and $E$. Statistical analysis was performed using the Wilcoxon rank sum test for paired samples comparing right and left sides. The Wilcoxon rank sum test for unpaired samples was used to compare Groups C and E. 
Table 8. Iffect of endometrial implants on number of corpora lutea, recovery rate, fertilization rate and tubat transport of fertilized ova in rabbits

\begin{tabular}{|c|c|c|}
\hline & $\begin{array}{l}\text { Group } E \\
(N=25)\end{array}$ & $\begin{array}{l}\text { Group } C \\
(N=25)\end{array}$ \\
\hline \multicolumn{3}{|l|}{ No. of corpora lutera } \\
\hline Right ovary & $4.56 \pm 1.6$ & $3.88 \pm 1.5$ \\
\hline Left ovary & $3.96 \pm 1.5$ & $4.44 \pm 1.4$ \\
\hline \multicolumn{3}{|l|}{ Recovery rate $(0 \% 0)$} \\
\hline Right owiduct & $103.20 \pm 27.2$ & $104.12 \# 28.8$ \\
\hline Left oviduct & $114.60 \pm 86.7$ & $106.72 \pm 24.4$ \\
\hline Right + left oviduct & $100.8 .8 \pm 9.7$ & $102.64 \pm 10.7$ \\
\hline \multicolumn{3}{|l|}{ Fertilization rate $(\%)$ ! } \\
\hline Right oviduct & $90.24 \pm 24.4$ & $91.68 \div 22.8$ \\
\hline Lefit oviduct & $89.36 \pm 24.9$ & $93.20 \pm 22.1$ \\
\hline \multicolumn{3}{|l|}{ Tubal transport index $(\%)$} \\
\hline Right oviduct & $97.90 \pm 10.2(24)$ & $98.33 \pm 5.7(24)$ \\
\hline Left oviduct & $100 \pm 0(24)$ & $96.33 \pm 9.4(24)$ \\
\hline
\end{tabular}

Values are mean \pm s.d.

* (No. of ova and embryos recovered from oviduct/ no. of corpora lutea)x 100

1 (No. of fertilized ova/ no. of ova recovered from oviduct) $x 100$

* No. of fertilized ova recowered from the ampullary-isthmic junction/ total no of fertilized ova recovered from all. 3 segments of oviduct) $x 100$

\section{Results}

The mean duration of the operation was $53 \pm 8 \mathrm{~min}$ in Group E and $51 \pm 6 \mathrm{~min}$ in Group C. Bodyweights at autopsy were $2981 \pm 212 \mathrm{~g}$ in Group $\mathrm{E}$ and $2896 \pm$ $338 \mathrm{~g}$ in Group $\mathrm{C}(\mathrm{P}>0.05)$.

In all rabbits of Group $\mathbb{E}$, the implants of the uterine tissue appeared to have developed into cysts filled with clear yellow or dark brown fluid. The diameter of the cysts ranged from 5 to $15 \mathrm{~mm}$. Histological examination revealed endometrial glands and stroma in every specimen. In Group $\mathrm{C}$ the fat tissue had not changed since the operation and no endometrial tissue had developed.

In Group $\mathbb{E}$ rabbits adhesions were absent in 4 animals, milld in 8 (only filmy adhesions) and moderate in 13 (dense adhesions). The equivalent figures for Group $\mathrm{C}$ does were 17 absent, 6 mild and 2 moderate $(P<0.001$, Chi-square test). However, the ovaries and oviducts were completely free of adhesions in every animal in both groups. The reamastomosed uterine horns were patent in every animal. As shown 
in Table 8.1 , the number of corpora lutea, the recovery rates and the fertilization rates did not differ significantly when the results obtained from the right sides of the animals were compared to those from the untouched left sides for rabbits in Groups $E$ and $C$. In the flushings of 4 oviducts no fertilized ova were found. There were also no differences in tubal transport index for the right and left sides of rabbits in Groups $\mathrm{C}$ and $\mathrm{E}$ or between groups.

Comparison of animals with no adhesions to animals with mild adhesions and to animals with moderate adhesions in Groups $\mathrm{E}$ and $\mathrm{C}$ showed no differences regarding number of corpora lutea, recovery rate, fertilization rate and tubal transport of fertilized ova.

\section{Discussion}

In rabbits, Schenken and Asch (1980) found a 50\% decrease in fertility rate in rabbits with surgically induced endometriosis. The decrease in fertility was concluded to be due to failure of ovulation which was, according to the authors, not related to adhesions. However, 4 out of 5 rabbits with adhesions in their study did not ovulate. A significantly reduced ovulation rate in rabbits with endometriosis confirmed these findings (Schenken and Walters, 1986). The fertilization rates were not significantly different between groups of rabbits with and without endometrial implants, but the recovery rate in the endometriosis group was severely reduced (Schenken and Walters, 1986). This reduced recovery rate was considered to be caused by ovarian or fimbrial adhesions. Werlin et al. (1984) found reduced ovum recovery rates in monkeys with induced endometriosis when adhesions involved the fimbriae and ampulla. Schenken et al. (1984) reported a reduced incidence of ovulatory cycles in monkeys with moderate and severe endometriosis, in contrast to animals with microscopic and mild endometriosis, in which the incidence of ovulatory cycles was not different from control animals. These results are in agreement with the findings of our study: there was no difference in number of corpora lutea in rabbits with endometrial implants, but without adnexal adhesions, compared to control animals. Because of the absence of adnexal adhesions the endometrial implants in our study might mimic more closely the stages of minimal and mild endometriosis in the human.

The recovery rates of embryos in our study did not differ between the groups studied and suggest an adequate pickup function of the oviducts in all animals. The tuboovarian relationship, considered to be critical to ow prm pickup, was not disturbed, presumably because of the absence of periadnexal adhesions. Therefore, the differences observed by previous investigators (Schenken and Asch, 1980; Schenken et al, 1984; Werlin et al, 1984; Schenken and Walters, 1986) might have been due to imperfect surgical technique. We have demonstrated, by applying meticulous 
microsurgical techniques, that endometrial implants per se do not influence the recovery rate in rabbits. However, the recovery rate exceeded $100 \%$ for one or both sides. If the cumulative recovery rate for both sides is $100 \%$, transmigration of ova from one ovary to the contralateral oviduct had presumably occurred, but if the recovery rate at both sides is over $100 \%$, poly-ovulation or undercounting of corpora lutea may have been the cause. Undercounting was reduced to a minimum in our study by inspecting the ovaries for newly ruptured follicles under a stereomicroscope. Polyowular follicular development has been described for rabbits (Adams, 1960; Al-Mufti et al., 1988).

From in-vitro fertilization studies conflicting data have been reported on the fertilization of ova recovered in endometriosis patients. Normal fertilization rates have been found in patients with mild endometriosis (Chillik et al., 1985; O'Shea et all, 1985; Matson and Yovich, 1986), but Wardle et al. (1985) have shown that even mild endometriosis affects the quality of oocytes and reduces the fertilization rate. In our model of mild endometriosis the fertilization rates of rabbits in the experimental group were not different from those in the control group. This is in agreement with the findings of Hahn et al.(1986). From their and our study it can be concluded that the reduced fecundity, at least in rabbits with endometrial implants, is due to postfertilization problems.

Tubal transport of the preimplantation embryo may be hampered in patients with mild endometriosis. Transport of ova through the Fallopian tube is effected by both muscular contractions and ciliary activity. Ovarian steroids, adrenergic innervation and prostaglandins (PG) interact to influence oviductal contractility. In the rabbit, $\mathrm{PGF}_{2 x}$ accelerates tubal tramsport of fertilized ova and subsequently reduces the implantation rate (Chang and Hunt, 1972; Salomy and Goldstein, 1978). In women $\mathrm{PGF}_{20}$ in pharmacological doses has a stimulatory effect on the contractility of the muscle layer of the Fallopian tube (Coutinho and Maia, 1971), but subsequent alteration of ovum transport could not be demonstrated (Croxatto et al., 1978). The role of endogenous PG in the spontaneous motility of the human Fallopian tubes is controversial (Elder et al., 1977). Moreover, peritoneal fluid PG concentrations in endometriosis are reported to be unchanged by some (Sgarlata et al., 1983; Rock et al., 1986), and increased by others (Drake et al., 1981; Ylikorkala et al., 1984). Therefore a causal relationship between peritoneal fluid PG and altered tubal transport, resulting in impaired fertility in endometriosis, is as yet unproven. The conflicting results obtained in measuring peritoneal fluid PG can be partly explained by methodological problems (Rock et al., 1986). However, the existence of two types of endometriosis, i.e. intra- and retroperitoneal, as described by Vasquez et al. (1984) might also be responsible for the differences found. Schenken and Asch (1980) found increased levels of peritoneal fluid PGF in rabbits with surgically induced endometriosis. They suggested that the increased levels of PGF could alter ovum transport. In a subsequent study, however, Schenken and Walters (1986) did not find a difference in tubal transport of fertilized ova in rabbits with endometriosis compared to controls. The results of our study are in agreement with the data 
reported by Schenken and Walters (1986): at $24 \mathrm{~h}$ after mating, i, e. $12 \mathrm{~h}$ after ovulation, over $95 \%$ of fertilized ova were retrieved from the ampullary-isthmic junction on both sides in all animals studied (Table 8.1). Comparison of these data with figures reported in the literature (Land et al., 1987 ) reveal no marked differences with normal tubal transport in the rabbit. The results obtained indicate that in the rabbit endometrial implants without periadnexal adhesions, have no influence on tubal transport of fertilized ova during the first $24 \mathrm{~h}$ after mating.

Our results, obtained with rabbits with mild endometriosis, have to be interpreted with some caution in trying to explain endometriosis-associated subfertility in the human. The endometrial implants in the rabbit, although histologically consistent with endometriosis, are not necessarily identical with endometriosis.

Taking these restrictions into account, it is suggested that, since no differences were found in ovulation, ovum pickup, fertilization and tubal transport in the rabbit with endometrial implants, the decreased fecundity found with mild endometriosis in the human may be attributed to other, not implant-related, properties of this enigmatic disease, or may be caused by post-fertilization problems, e.g. disturbances in early embryonic development or implantation.

\section{References}

Adams CE: Studies on prenatal mortality in the rabbit, Oryctolagus cuniculus; the amoun of loss before and after implantation.

J Endocrinol 13: 296-308, 1.960

Al-Mufti $W$, Bomsel-Helmreich 0, Christides JPh: Oocyte size and intrafollicular position in polyovular follicles in rabbits.

J Reprod Fert 82: 15-25, 1988

Berger NG, Rock IA: Peritoneal fluid environment in endometriosis.

Sern Reprod Endocrinol 3: 313-318, 1985

Brosens IA, Koninckx PR, Corveleyn PA: A study of plasma progesterone, oestradiol-17/3, prolactin and LH levels, and of the luteal phase appearence of the ovaries in patients with endometriosis and infertility. Br J Obstet Gynaecol 85: 246-250, 1978

Chang MC, Hunt DM: Effect of prostaglandin $F 2 \alpha$ on the early pregnancy of rabbiss.

Nature, London $236: 120-121,1972$

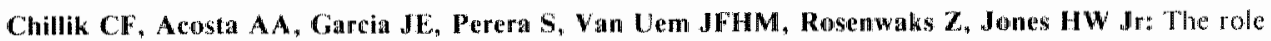
of in vitro fertilization in infertile patients with endometriosis.

Fertil Sleril 44: 56-61, 1985

Coutinho EM, Maia HS: The contractile response of the thuman uterus, fallopian tubes, and ovary lo prostaglandins in vivo.

Fertil Steril 22: 539-543, 197j 


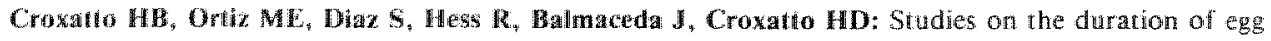
inasport by the human oviduct.

Am I Obstet Gynecol $132: 629-634,1978$

Drake TS, Oprien WF, Ramwall PW, Mez SA: Periloneal fluid thromboxane B2 and 6-ketoprostaglandin Flow in endometriosis.

Am J Obstet Cynecol 140: $401-404,1981$

Elder MG: Myat L, Chat dhuri $G$ : The role of prosidaglandins in the spontaneous motility of the fallopian tube.

Fertil Steril 28: $86-90,19 \% 7$

Hahn DW, Carraher RP, Foldesy RG, MCGuire JL: Experimental evidence for failure to implamt as at mechanism of infertility associated with endometriosis.

Am J Obstet Gynecol 155: 1109-1113, 1986

Harper MJK: The time of ovulation in the rabbit following the injection of luteinizing hormone.

J Endocrinol $22: 147-152,1961$

Land JA, Evers JLH, Boekx WD, Brosens IA: Ovum transpott after microsurgical anastomosis of the rabbit oviduct.

J Reprod Med 32: 103-106, 1987

Lesorgen PR, Wu CH, Green PJ, Gocial $\mathbf{B}$, Lerner L. Peritoneal fluid and serum steroids in infertility patients."

Fertil Steril $42: 237-242,1984$

Matson PL, Yovich JL: The treatment of infertility associated with endometriosis by in vitro fertilizalion.

Fertil Steril $46: 432-434,1986$

Olive DL, Haney AF: Endometriosis - Associated infertility: A critical review of therapeutic approaches. Obstet Gynecol Surv 41:538-555, 1986

O'Shea RT, Chen C, Weiss T, Jones WR: Endometriosis and invitro fertilisation. Lancet $\mathrm{ii}: 723,1985$

Quinn P. Warnes GM, Kerin JF, Kirby C: Culture factors in relation to the success of human in vitro Cortilization and embryo transfer.

Fertil Steril $4 \|: 202 \cdot 209,1984$

Rock IA, Rezai N, Berger NA, Dubin NH: Cul-de-sac fluid in women wh endometriosis: fithid volume and prostanoid concentration during the proliferative, ovulatory, and periovulatory phase of the menstrual cycle. Proc Endometriose 86, 19 (abstract), 1986

Rönnberg L, Kauppilsa A, Kajaniemi H: Luteinizing hormone recepor disorder in endometriosis. Fertil Steril 42: $64-68,1984$

Salomy M, Goldstein PJ: Prevention of pregnancy in rabbits using vaginal application of prostaglandin F2a.

Fertil Steril 29:456-458, 1978

Schenken RS, Asch RH: Surgical induction of endometriosis in the rabbit: effects on fertility and concenirations of peritoneal fluid prostaglandins.

Fertil Steril $34: 581-587,1980$

Schenken RS, Walters MD: Ovulation and tubal transport in rabbits with endometriosis.

Proc Soc Gynecol lnvest, 215 (abstract), 1986 
Schenken RS, Asch RH, Williams RE, Hodgen GD: Etiology of infertitum in monkeys with endometriois: Iuteinized unruptured folloles, luteal phase defects, pelvic adhestons, and spontaneous abortions. Fertil Steril $41:$ 122 130, 1984

Sgarlat CS, Hertelendy $F$, Mikhail G: The prostanoid content in peritoneal fluid and plasma of women with endometriosis.

Am J Obstet Gynecol 147: $563-585,1983$

Soules MR, Malinak LR, Bury R, Poindlexter A: Endometriosis and anovulation: A coexisting problem in the infertile femalle.

Am J Obsitet Gynecol 125:412-417, 1976

Suginami H, Yano K, Watamabe K, Matsura S: A factor inhibing ovun capture by the oviductal finbriae present in endometriosis peritoneal fluid.

Fertil Steril $46: 1140-1146,1986$

Vasquez G, Cornillie F, Brosens IA: Peritoneal endometriosis: scanning electron microscopy and histology of minimal pelvic endomerriotic lesions.

Fertil Steril $42: 696-703,1984$

Wardle PG, MeLaughlin EA, McDermott A, Mitchell JD, Ray BD, Hall MGR: Endonetriosis and ovulatory disorder: reduced fertilisation in vitro compared with tubal and unexplained infertility. Lancet ii: $236-239,1985$

Werlin IB, DiZerega GS, Hodgen GD: Endometriosis: effect on ovulation, ovun pickup, and transpont in monkeys: an interim report.

Fertil Steril 35: 2635, 1984

Ylikorkala $\boldsymbol{O}$, Koskimies $A$, Laatkainen $\mathbf{T}$, Tenhunen $\mathbf{A}$, Vinikka L: Peritioneal fluid prostaglandins in endometriosis, tubal disorders, and unexplained infertility.

Obstet Gynecol $63: 616-620,1984$ 


\title{
Chapter 9
}

\section{Effect of endometriosis on early embryonic development in the rabbit}

\author{
G.A.J. Dunselman, J.A. Land, J.C.M. Dumoulin, P.X.J.M. Bouckaert, \\ J.L.H. Evers \\ (Human Reproduction, accepted for publication)
}

\section{Summary}

The reasons for subfertility in patients with mild endometriosis remain unclear. Peritoneal fluid constituents may alter tubal transport and embryonic cleavage, with subsequent implantation disturbances. We used an animal model to study the influence of endometrial implants on early embryonic development. In 25 rabbits endometrium from the right uterine horn was transplanted onto the peritoneum (Experimental Group $=$ Group E). In 25 rabbits fat was transplanted (Control Group $=$ Group C). After a recovery period of 12 weeks the does were mated, and sacrificed $24 \mathrm{~h}$ later. In the experimental group the implants had changed into cysts of 5 to $15 \mathrm{~mm}$ in diameter. Histological examination revealed endometrial glands and stroma in every specimen. Periadnexal adhaesions did not develop in any animal. No marked differences were found between Groups $\mathrm{E}$ and $\mathrm{C}$ in embryonic cleavage stage, $24 \mathrm{~h}$ after mating. Additional culturing of the embryos for $48 \mathrm{~h} \mathrm{in}$ a suitable culture medium, revealed normal further development of the embryos.

Bearing in mind the restrictions of a rabbit model, extrapolating to the human, it is suggested that the decreased fecundity in mild endometriosis is not caused by altered early embryonic cleavage rate. This offers indirect evidence for implantation disturbances as a cause of endometriosis-associated subfertility. 


\section{Introduction}

If ovaries and tubes are encapsulated in adhesions, as can be the case in severe forms of endometriosis, ovulation, ovum pickup, fertilization and tubal transport are likely to be impeded. Impaired fertility in mild endometriosis, however, is difficult to explain. Changes in peritoneal fluid and its constituents might influence tubal transport and embryonic cleavage. Prostaglandins produced by peritoneal serosa, endometriotic tissue and macrophages are considered to play a role in the subfertility associated with endometriosis (De Leon et al., 1986) by altering ovarian function and/or tubal transport and possibly by interfering with implantation. Altered tubal transport of the fertilized ovum can lead to an untimely arrival of the fertilized ovum in the uterine cavity with subsequent implantation disorders. Considering synchronization of embryonic and maternal environment at implantation, the cleavage rate of the developing embryo may be a critical factor as well.

In this paper we report on embryonic development of fertilized ova in the first 24 $\mathrm{h}$ after mating in an animal model of mild endometriosis. To study the possibly detrimental effects of the contact in the periovulatory phase between gametes, embryos and the altered peritoneal environment upon embryonic development, the embryos were further cultured in vitro in a suitable culture medium for an additional $24 \mathrm{~h}$.

\section{Materials and Methods}

Virgin Dutch belted rabbits were used. The 50 does were caged individually at $20^{\circ} \mathrm{C}$ with a photoperiod of $12 \mathrm{~h}$ light: $12 \mathrm{~h}$ dark. They were fed 150 grams of rabbit chow daily and allowed water ad libitum. Before surgery each doe received $125 \mathrm{mg}$ of ampicillin prophylactically by intravenous injection. Anaesthesia was induced with 0.2 $\mathrm{mg}$ atropine $/ \mathrm{kg}$ and $0.5 \mathrm{ml}$ Hypnorm $/ \mathrm{kg}$ ( $10 \mathrm{mg}$ fluanizone and $0.2 \mathrm{mg}$ phentanyl per ml, Duphar, Amsterdam) intramuscularly. As soon as anaesthesia was achieved, each doe was intubated with an endotracheal tube. A mixture of halothane (0.5-1.0\%), oxygen ( $\|$ litre/min) and nitrous oxide ( 2 litre/min) was given through a closed loop inhalation anaesthesia system (infant ventilator, MK2, Keuskamp, Amsterdam).

In all 50 rabbits a $1-\mathrm{cm}$ segment of the right uterine horn as well as adipose tissue from the juxta-uterine fat was resected. After resection, the uterine horn was reanastomosed and the defect in the fat tissue closed by microsurgical methods. In 25 rabbits (Group E) the resected uterine horn was opened longitudinally and divided into four equal parts. These pieces of uterine tissue (consisting of endometrium, muscularis and serosa) were sutured onto the peritoneum at the right lateral abdominal wall, adjacent to uterus and ovary, with the serosal side of the uterine tissue fac- 
ing the peritoneum, and the endometrium facing the peritoneal cavity, using 6.0 Prolene (Ethicon, Sommerville, NJ, USA). In 25 rabbits (Group C) the fat was divided into four equal parts and sutured onto the peritoneum in a comparable way. In Group $\mathbb{E}$ the fat tissue was discarded and in Group $\mathrm{C}$ the uterine tissue was discarded. The abdominal wall was closed in two layers with everting interrupted sutures. After a recovery period of 12 weeks the does were mated with a buck of proven fertility. To ensure and synchronize ovulation the does were given $125 \mathrm{IU}$ of human chorionic gonadotropin (Pregnyl: Organon, Oss, The Netherlands). The does were killed $24 \mathrm{~h}$ after mating, i.e. $12 \mathrm{~h}$ after ovulation (Harper, 1961). Anaesthesia was induced with $0.5 \mathrm{mg} x y l a z i n e / \mathrm{kg}$ (Rompun: Bayer, Leverkusen, West Germany) and $0.4 \mathrm{ml}$ ketamine/kg (Ketaset: Bristol Laboratories, New York) by intramuscular injection. An overdose of pentobarbitone sodium was administered intravenously and laparotomy was performed.

The abdominal cavity was carefully inspected for adhesions. The implants were excised for histological examination. The patency of the right reanastomosed uterine horn was tested. The ovaries and Fallopian tubes were excised. The ovaries were examined under a stereomicroscope (Wild M8) to count the number of corpora lutea in each ovary. The oviducts were divided into three parts representing the ampullary segment, the ampullary-isthmic junction and the isthmic segment. The three segments of both oviducts were flushed with $5 \mathrm{ml}$ of HEPES-bulfered Whittingham"s T6 culture medium adjusted to pH 7.4 (Quinn et al., 1984). The flushings were checked for the presence of ova and embryos under a stereomicroscope (Wild M8). The number of ova and embryos recovered from each oviduct was related to the number of corpora lutea in the ovary at the same side in order to calculate the recovery rate. The number of fertilized ova, the cleavage stage of each embryo and the segment from which it was retrieved were recorded. From these data the embryonic development $24 \mathrm{~h}$ after mating was determined for each tube separately. Criteria for fertilization were the presence of sperm in the perivitelline space, the presence of two polar bodies, the presence of two pronuclei or cleavage (Land, 1985). Thereafter the embryos were transported to bicarbonate buffered Whittingham's T6 culture medium (Quinn et al., 1984) supplemented with $5 \mathrm{mg}$ Bovine Serum Albumin (BSA) per $\mathrm{ml}$ and incubated at $37^{\circ} \mathrm{C}$ in a humidified atmosphere containing $5 \% \mathrm{CO}_{2}$. After $48 \mathrm{~h},(72 \mathrm{~h}$ after mating), the embryonic cleavage stage was determined.

The results obtained were compared between the right and left oviducts in each group, and between the right oviducts and the left oviducts for Groups E and C. Statistical analysis was performed using the Wilcoxon rank sum test for paired samples comparing right and left sides. The Wilcoxon rank sum test for unpaired samples was used to compare Groups E and $\mathrm{C}$. 


\begin{tabular}{lll}
\hline & Group E & Group C \\
& $(N=25)$ & $(N=25)$ \\
\hline $\begin{array}{c}\text { Recovery rate }(\%)^{*} \\
\text { Right owiduct } \\
\text { Left oviduct }\end{array}$ & $103.20 \pm 27.2$ & $104.12 \pm 28.8$ \\
\hline
\end{tabular}

Values are mean sie s.d.

* (No. of ova and embryos recovered from owiduct/ no. of corpora lutea) $x 100$

Table 9.2 Effect of endometrial implants on embryonic development of fertilized ova in the first 24 h after maving and after $48 \mathrm{~h}$ in cullure in rabbits

$\begin{array}{ll}\text { Group } \mathrm{E} & \text { Group C } \\ (\mathrm{N}=24) & (\mathrm{N}=24)\end{array}$

Embryonic development

index $(\% \text { \% })^{\text {is }}$
Right oviduct
$68.50 \pm 33.9$
$80.04 \pm 30.5$
Left oviduct
$60.45 \pm 36.9$
$70.37 \pm 31.9$

Embryonic cleavage

index $(\%)$
Right oviduct
$74.29 \pm 39.3$
$82.64 \pm 29.5(22)$
Left oviduct
$77.29 \pm 34.2$
$74.50 \pm 37.2(22)$

Values are mean \pm s.d.

* (no of 2 -cell embryos retrieved $24 \mathrm{~h}$ after mating/no of fertilized ova)x 100

* (no of morula stage embryos after $48 \mathrm{~h}$ culture/no of fertilized owa cultured) 100

\section{Results}

In all rabbits of Group $\mathrm{E}$ the endometrial implants appeared to have developed in cysts consistent with endometriosis. Histological examination revealed endometrial glands and stroma in every specimen. In Group $\mathrm{C}$ the fat tissue had not changed since the operation and no endometrial tissue had developed.

In both Groups $\mathrm{E}$ and $\mathrm{C}$ the ovaries and oviducts were completely free of adhesions. The operated uterine horn was patent in all animals. The results of the parameters investigated are shown in Tables 9.1 and 9.2. The recovery rates did not differ significantly when the results obtained from the right sides of the animals were compared to those of the untouched left sides, for rabbits in Groups $\mathrm{E}$ and $\mathrm{C}$. In the flushings of 4 oviducts no fertilized ova were found. Comparing the right to the 
left side in Groups $\mathrm{E}$ and $\mathrm{C}$ revealed no marked differences in embryonic development $24 \mathrm{~h}$ after mating. Comparison of the right and the left side respectively between Group $E$ and $C$ showed no differences either. The embryos of 2 rabbits in Group $C$ were not transferred to the culture medium. The percentage of embryos that reached the morula stage after 48 h culture, i.e. $72 \mathrm{~h}$ after mating. did not differ between the groups investigated (Table 9.2).

\section{Discussion}

Data obtained from studies on reduced fecundity in mild endometriosis in the human (Muse and Wilson, 1982) and in the experimental animal model for endometriosis (Vernon and Wilson, 1985) suggest that endometriotic implants may exert their unfavourable effects during the early stages of pregnancy. Apart from disturbances in ovulation, fertilization and tubal transport, the development of the preimplantation embryo may be hampered.

After fertilization embryonic cleavage takes place in the Fallopian tube. The influence of endometriosis on embryonic cleavage during tubal transport is unknown. Theoretically a decreased as well as an increased rate of cleavage can influence implantation by creating asynchrony between the developing embryo and the uterine environment. Changes in the composition of peritoneal fluid may influence embryonic cleavage. Gametes are under the influence of the peritoneal milieu for a short period in the periovulatory phase of the cycle. In endometriosis patients this hostile milieu might affect subsequent embryonic development and implantation. After culturing two-cell mouse embryos in medium supplemented with $5 \%$ peritoneal fluid of endometriosis patients for 24,48 and $72 \mathrm{~h}$, less advanced cleavage stages have been found as compared to cleavage stages of embryos cultured in medium supplemented with $5 \%$ peritoneal fluid of controls (Morcos et al., 1985). The pregnancy rate in IVF has been reported to be the same in patienis with mild endometriosis as compared to patients with occluded tubes (Chillik et al., 1985; Matson and Yovich, 1986). This might be explained by the fact that neither the oocyte, recovered from the preovulatory follicle, nor the spermatozoa come into direct contact with the hostile peritoneal milieu. After fertilization the process of early embryonic development takes place in the, perhaps more favourable, culture medium. However, good results have been obtained in infertile patients with mild endometriosis treated with gamete intrafallopian transfer (Asch, personal communication), when shortly after oocyte recovery the gametes were placed in the Fallopian tube. These favourable results might be due to the fact that the gametes have been exposed to the peritoneal milieu for a considerably shorter time period than during the normal process of ovulation and ovum pickup.

Im our study, the percentage of two-cell embryos retrieved from the oviduct $24 \mathrm{~h}$ 
after mating, did not markedly differ between Groups $\mathrm{E}$ and $\mathrm{C}$. Comparing the right and the left sides respectively between Groups $\mathrm{E}$ and $\mathrm{C}$ revealed no differences either. These figures are comparable with those found in the literature (Land, 1985). Culturing embryos in peritoneal fluid for more than $24 \mathrm{~h}$, however, seems to be an unrealistic procedure. Taking into account the fluid currents in the Fallopian tube we hypothesized that tubal fluid in endometriosis patients is not different from controls, and that possible changes in peritoneal fluid composition do not affect tubal fluid composition. Therefore we decided to culture the embryos further, after the initiai $24 \mathrm{~h}$, in a balanced salt solution, Whittingham's T6. The percentage of fertilized ova and embryos that reached the morula stage after culture in this medium for 48 h was not different among the groups investigated.

Changes in folliculogenesis and oocyte maturation caused by the presence of peritoneal and ovarian endometriosis might, however, without decreasing the oocyte's fertilizability, influence embryonic cleavage to an extent not yet discernible 24 or 72 h after mating. In our study in rabbits with endometrial implants no differences were found regarding embryonic cleavage rate in the periods investigated. But as time elapses slight alterations, not yet apparent soon after fertilization, may become more pronounced and cause asynchrony at implantation. The design of our study did not allow to examine implantation, since the embryos were flushed from the oviducts $24 \mathrm{~h}$ after mating. In the rat the presence of ectopic endometrial tissue significantly reduced the number of day 14 embryos (Vernon and Wilson, 1985). A comparable reduction, due to a failure of implantation or to early spontaneous abortion secondary to the presence of endometrial implants, was found by Hahn et al. (1986) in the rabbit.

In conclusion, results obtained in an experimental model of mild endometriosis indicate that endometrial implants in the rabbit do not influence the embryonic cleavage rate cluring the first $24 \mathrm{~h}$ in vivo, nor during the next $48 \mathrm{~h}$ in an artificial tubal environment.

Interpreting results, obtained in an experimental rabbit model of endometriosis, to explain causes of subfertility in human endometriosis remains precarious. Endometrial implants in the rabbit histologically mimic, but do not necessarily have to be identical to human endometriosis. Moreover, rabbits are reflexovulators and lack menstrual cyclicity. Consequently no cyclic changes occur in the ectopic, implanted, endometrium.

Bearing in mind these restrictions, and provided that the endometrial implants in the rabbit constitute a valid model of endometriosis in the human, the results of the present investigation suggest endometriosis-associated subfertility not to be caused by alterations in early embryonic development. Our previous study in the same rabbit-model of endometriosis (Dunselman et al., 1988) did not show differences in ovulation, ovum pickup, fertilization and tubal transport. Therefore, either early embryonic effects only will become manifest during later stages of development or subsequent embryonic development and/or implantation will be affected directly by endometriosis. 


\section{References}

Chillik CF, Acosta AA. Garcia JE, Perera S, Van Uem JFHM, Rosenwaks Z, Jones HW Jr: The role of in vitro fertilization in infertile patients with endometriosis.

Fertil Steril 44: 56-61, 1985

De Leon FD, Vijayakumar R, Brown M. Rao ChV, Vussman MA, Schultz G: Peritoneal fluid volume, estrogen, progesterone, prostaglandin, and epidermal growth factor concentrations in patients with and without endometriosis.

Obstet Gynecol 68: 189-194, 1986

Dunselman GAJ, Land JA, Bouckaert PXJM, Evers JLH: Effect of endometriosis on ovulation, ovum pickup, fertilization and tubal transport in the rabbit.

J Reprod Fert 82: 193-197, 1988

Hahn DW, Carraher RP, Foldesy RG, MoGuire JL: Experimental evidence for failure to implant as a mechamism of infertility associated with endometriosis.

Am J Obstet Gynecol 155: 1109-1113, 1986

Harper MJK: The time of ovulation in the rabbit following the injection of luteinizing hormone.

J Endocrinol 22: 147-152, 1961

Land JA: Embryonic development in the Fallopian tube - a microsurgical study in the rabbit.

Thesis, Maastricht, 1985

Matson $\mathbf{P L}$, Yovich $\mathbf{J L}$ : The treatment of infertility associated with endometriosis by in vitro fentilization.

Fertil Steril 46: 432-434, 1986

Morcos RN, Gibbons WE, Findley WE: Effect of peritoneal fluid on in vitro cleavage of 2-cell mouse embryos: possible role in infertility associated with endometriosis.

Fertil Steril 44: 678-683, 1985

Muse KN, Wilson EA: How does mild endometriosis cause infertility?

Fertil Steril 38: 145-152, 1982

Quinn P, Warnes GM, Kerin JF, Kirlyy $\mathbf{C}$ : Culture factors in relation to the success of human in vitro fertilization and embryo transfer.

Fertil Steril 41: 202-209, 1984

Vernon MW, Wilson EA: Studies on the surgical induction of endometriosis in the rat.

Fertil Steril 44: $684-694,1985$ 



\section{Chapter 10}

\section{General discussion}

Endometriosis is often, but not exclusively, found in infertile patients. Although epidemiological and clinical data suggest a cause and effect relationship, it has not been demonstrated conclusively that endometriosis does produce infertility. A third, as yet unknown, mechanism might be responsible for both endometriosis and infertility. If, however, endometriosis does cause infertility, this is most likely effectuated by an alteration of the intraabdominal milieu, the microenvironment in which reproductive processes take place. We assumed that these changes in the intraabdominal milieu would be reflected in the peritoneal fluid composition. Results from the first part of this thesis lend support to the theory that certain intraabdominal changes occur in patients with macroscopically visible endometriosis, i.e. numbers and concentrations of peritoneal cells increase and advanced stages of differentiation of peritoneal macrophages develop. Other possible indices of changes in the intraabdominal environment, peritoneal fluid volume and concentrations of peritoneal fluid acute-phase proteins, appeared not to be affected or only to a minor degree by the presence of endometriosis.

It has been suggested that non-visible, microscopic, endometriosis may account in part for what usually is referred to as unexplained infertility. Therefore, we compared the results of the parameters determined for three subgroups of patients, i.e. infertile patients with endometriosis, infertile patients without endometriosis, and fertile controls without endometriosis in addition to the comparisons as described in the chapters 4,5 and 6 . Because of the cyclic variation in peritoneal fluid volume and peritoneal fluid constituents, only patients in the postovulatory phase of the cycle were compared.

Peritoneal fluid volume in the postovulatory phase of the cycle was not significantly different between infertile patients with and without endometriosis. Peritoneal fluid volume of infertile patients, with and without endometriosis, was shown to be significantly higher than that of fertile patients without endometriosis.

Comparison of the concentrations of the individual proteins in serum and perifoneal fluid and the $\mathrm{p} / \mathrm{s}$ ratios for these proteins between the three subgroups did not reveal a significant difference for any of the proteins measured. The same applied to the peritoneal fluid concentrations of the parameters of intraabdominal fibrinolysis. The total number and concentration of peritoneal cells, the erythrophagocytosis and the chemiluminescence of macrophages have also been compared between the subgroups. Total numbers and concentrations of peritoneal cells were comparable in infertile patients with and in infertile patients without endometriosis, but they were higher in infertile patients - with and without endometriosis-, than in fertile controls 
without the disease. Peritoneal macrophages of infertile patients with endometriosis showed a significantly advanced level of differentiation, compared to both infertile palients without visible endometriosis and to fertile controls.

From these results it is concluded that it is not the presence of visible endometriosis but rather the fertility status of the patient that is related to the changes of the intraabdominal milieu as measured by peritoneal fluid volume, total numbers and concentrations of peritoneal cells. The advanced differentiation of the macrophages, however, seems to be predominantly related to the presence of visible endometriosis. It remains to be explained why increased peritoneal fluid volumes, increased numbers and concentrations of peritoneal celis were found in infertile patients with and without visible endometriosis, whereas an advanced stage of differentiation of macrophages was found only in the patient group with macroscopic endometriosis. What is recognized at laparoscopy as visible enclometriosis represents the sequelae of repeated episodes of cyclic changes in the endometrial implants. In this stage of the disease not only quantitative changes occur in the inflammatory system: soluble mediators that are prodluced continuously by the implants attract monocytes from the peripheral blood. After their arrival in the peritoneal cavity the macrophages try to restore homeostasis, they support the proliferation of fibroblasts and the formation of scar tissue in an attempt to infiltrate, block off and delimit the areas of irritant activity. These are functions of macrophages in an advanced stage of differentiation. From the findings of this study it appears that quantitative changes, increased numbers of peritoneal cells, occur in both groups of patients with and without visible endometriosis, whereas qualitative changes, an advanced stage of differentiation of peritoneal macrophages, occur only when macroscopically visible endometriosis is present.

Peritoneal fluid concentrations of the different proteins determined were not related to the fertility status of the patient: comparable protein concentrations, mainly determined by their molecular weights, were found in all three subgroups investigated. The proteins involved in the fibrinolytic system appeared not to be affected by the presence of endometriosis, nor by the fertility status of the patient. Conceivably the fibrinolytic system constitutes a normal defense mechanism of the peritoneal cavity.

It is thus apparent that the intraabdominal milieu of patients with unexplained infertility shares characteristics with that of infertile patients with endometriosis.

These observations may be explained in two different ways. In the first place, patients with unexplained infertillty may harbor foci of non-visible endometriosis. The existence of microscopic endometriosis has been suggested by Acosta et al. (1973), while addressing the issue of surgical treatment of endometriosis. Microscopic endometriosis has been documented by Brosens et al. (1984) and Murphy et al. (1986). These foci of non-visible endometriosis may alter the intraabdominal environment of patients with unexplained infertility in a way comparable to macroscopic endometriosis. Vernon and coworkers (1986) suggested these microscopic lesions to be even more active than the older lesions which are recognizable to the naked eye. On the other hand, and possibly not mutually exclusive, a change in the intraab- 
dominal milieu and the presence of endometriosis may represent two pathologic entities governed by the same denominator. Retrograde menstruation may be the cause of both a chronic inflammatory state in the abdominal cavity and of the presence of endometriosis. Since retrograde menstruation is probably a common event (Blumenkrantz et al., 1981; Halme et al., 1984) the ability of endometrial cells to implant must be regulated by an as yet unknown mechanism. Implantation may be dependent on obstructed menstrual flow resulting in an increased amount of menstrual debris reaching the abdominal cavity and on the capacity of the individual patient to clear the abdominal cavity from this menstrual debris. Implantation or rejection of endometrial cells may be under the control of the cell-mediated immune system (Dmowski et al., 1981; Steele et al., 1984; Zeller et al., 1987). To date no tests are available to identify those women who are at risk to develop microscopic and/or macroscopic endometriosis nor to identify those women who will develop endometriosis related infertility.

Peritoneal macrophages of patients with endometriosis show an advanced stage of differentiation. These macrophages originate from the bone marrow. It is conceivable that peripheral monocytes are changed also. Indeed, Zeller et al. (1987), recently reported altered peripheral monocytes in patients with endometriosis. They suggested that endometriosis is a systemic rather than a local intraabdominal disease. These results have not yet been confirmed by others.

In conclusion, the changes in the intraabdominal environment are not related exclusively to the presence of visible endometriotic implants. The intraabdominal changes appear to be related to retrograde menstruation and/or to the secretory activity and shedding of the endometriotic lesions and the exudation of the peritoneal mesothelial lining. Qualitative changes of the macrophages appear to be a marker of macroscopic endometriotic lesions.

We did not study the impact of these changes on fertility. The literature on endometriosis-related infertility must be interpreted with caution. It is attractive to formulate a cause and effect relationship between two entities that are so often found to be coincidental. A third mechanism may be responsible for both endometriosis and infertility.

Changes in peritoneal fluid constituents found in patients with endometriosis are too easily linked to results of animal research or in vitro studies. The available literature on peritoneal fluid constituents in endometriosis patients does not correlate changes in these constituents with the subsequent occurrence of pregnancy, with the exception of a retrospective study by Syrop and Halme (1986) who showed that the occurrence of pregnancy was related to the volume of peritoneal fluid and not to the number of peritoneal cells. The higher the peritoneal fluid volume at the initial laparoscopy the lower the chances to get pregnant. Nevertheless, far reaching conclusions are invariably drawn regarding the negative influence of the findings on fertility. There are no reports in the literature on peritoneal fluid constituents before and after treatment of endometriosis, that relate the presence or absence of these constituents to the occurrence of pregnancy. The changes found in the intraabdomi- 
nal milieu may well be epiphenomenal to the disease and, as discussed above, might represent a marker of retrograde menstruation as well.

These findings will have a strong bearing on the treatment of endometriosisassociated infertility in the uncomplicated stage. In view of the above, it seems unrealistic to think that we can treat endometriosis-associated infertility by eliminating all visible endometriotic lesions at laparoscopy. On the other hand, elimination of macroscopic lesions might reduce the advanced differentiation of the peritoneal macrophages and allow, at least temporarily, a pregnancy to occur. Microscopic لesions remain however, and the disease will return with time.

If we accept that retrograde menstruation is the common denominator of both the presence of visible endometriosis and of the infertility seen in some patients with endometriosis (and possibly in patients with so-called unexplained infertility) a therapeutic approach may be formulated. The management of an infertile patient with newly diagnosed minimal or mild endometriosis can be conservative for a period of time, whether or not after coagulation or laser vaporization of all visible lesions at the initial laparoscopy. All possible efforts should be made to overcome those additional infertility factors, that are more commonly found in endometriosis patients, like inappropriate follicular development, Juteal phase inadequacy and male subfertility. If this is not successful, it may be sufficient to stop retrograde menstruation for a period of time in order to 'clear' the abdominal cavity. The commonly used hormonal treatment combines amenorrhea with an effect on the endometrial implants. It is unclear which of the two is the most beneficial with regard to infertility. After two to four months of medical treatment for endometriosis, pregnancy should be pursued with all possible means, i.e. making use of ovulation detection and, if necessary, of ovulation induction. If this fails as well the next step may be in vitro fertilization, gamete intrafallopian transfer or intrauterine insemination. It has been shown that in patients with mild endometriosis and in patients with unexplained infertility intrauterine insemination combined with mild ovarian hyperstimulation results in a high number of pregnancies per cycle, exceeding the results of in vitro fertilization and embryo transfer or gamete intrafallopian transfer (Dodson et al., 1987). It remains to be investigated whether these results can also be achieved by either intra uterine insemination alone or by mild ovarian hyperstimulation alone. The latter approach has shown to be effective in patients with long-standing idiopathic infertility (Welner et al., 1988).

It has been outlined before that it is difficult to study the influence of changes in the intraabdominal milieu secondary to endometriosis on fertility in the human. The different stages of early embryonic development camnot be investigated in detail. In vitro fertilization studies in endometriosis patients can solve these problems only incompletely.

An animal model of endometriosis may be a useful tool to study the different aspects, although, as has been outlined before, extrapolations between animal models and human conditions must be made with utmost care. 
Theoretically, endometrial implants in the rabbit may change the intraabdominal environment in a way dissimilar to what occurs in human subjects. As discussed above, the changes in intraabdominal milieu in the human are related to both retrograde menstruation and to the endometrial implants per se. In the rabbit, a noncycling animal, the abdominal cavity is not subjected to repeated episodes of retrograde menstruation. If changes occur in the intraabdominal milieu in the rabbit model of endometriosis then they are caused exclusively by the endometrial implants. Consequently, the rabbit model we used allows to study the influence of endometrial implants per se on fertility.

If endometrium implants cause a reduction of fertility in the rabbit, like it is presumed to do in the human, then this reduction takes place after the early embryonic period, as shown by the results of our study. It remains possible, however, that the effects of disturbances in early embryonic development become manifest only after a certain period of time, leading to problems at the time of implantation or in the early postimplantation period. The anti-implantation effect is supposed to be related to the presence of immunoglobulins and complement in the endometrium in patients with endometriosis (Weed and Arquembourg, 1980; Mathur et al., 1982; Bartosik et al., 1987). Early pregnancy loss may have accounted for the reduced fertility seen in a comparable rabbit model by other investigators (Hahn et al., 1986).

Peritoneal fluid research in patients with endometriosis performed to detect a possible cause and effect relationship between endometriosis and infertility and to study the etiology of endometriosis is hampered by several problems. In the first place, endometriosis still lacks a precise definition and classification. In the revised classification of the American Fertility Society (R-AFS)(1985) the group of minimal endometriosis invariably harbors a wide spectrum of macroscopically different lesions. All these lesions probably have their own biological potential and have a different impact on the composition of the peritoneal fluid. On top of this problem is the possible presence of microscopic endometriosis in fertile and infertile patients. Another problem in studying peritoneal fluid constituents is the complex regulation of peritoneal fluid volume, protein concentration and cell content. Absorption of the peritoneal fluid is by the venous side of the same subperitoneal capillaries that produce it. Proteins and cellular constituents are removed via the lymphevessels at the right side of the diaphragm (Review by Kroon, 1986). Insufficient data are available about the regulation of this in- and outflow across the peritoneum and about the turnover of proteins.

Peritoneal fluid used for the study of the intraabdominal environment in which early embryonic development takes place should be collected at a moment of the cycle that is well defined in relation to the process of ovulation. If comparisons are to be made between patients with and without endometriosis care should be taken to accurately diagnose presence or absence of the disease. Familiarity with the early stages of minimal endometriosis is mandatory. Sufficient biopsies should be taken to exclude microscopic disease. To outline the influence of certain changes on fertili- 
ty, the parameters studied should be related to the occurrence of pregnancy. But, most of all, the complex regulatory mechanisms of peritoneal fluid volume and its constutuents should be studied in detail.

Novak"s statement in 1931 about progress in understanding endometriosis is equally applicable today, and, perhaps even more so, to the study of peritoneal fluid in relation to endometriosis-associated infertility:

"Investigators have apparently worked themselves into a scientific cul-de-sac from which they can be rescued only by discovery of some new method of attacking the problem".

\section{References}

Acosta AA, Buttram VC Jr, Besch PK, Malinak LR, Franklin RR, Vanderheyden JD: A proposed classification of pelvic endometriosis.

Obstet Gynecol 42 : 19-25, 1973

American Fertility Society: Revised American Fertility Sociery Classification of Endometriosis: 1985. Fertil Steril 43: 351-352, 1985

Bartosik D, Damjanov I, Viscarello RR, Riley JA: Immunoproteins in the endometrium: Clinical correlates of the presence of complement fractions $\mathrm{C} 3$ and $\mathrm{C4}$.

Am I Obstet Gynecol 156: 11-15, 1987

Blumenkrantz MJ, Gallagher N, Bashore RA, Tenckhoff H: Retrograde menstruation in women undergoing chronic peritoneal dialysis.

Obstet Gynecol 57: 667-670, 1981

Brosens II, Vasquex, G, Gordts S: Scanning electron microscopic study of the pelwic peritoneum in unexplained infertility and endometriosis.

Fertil Steril 41: 21S, 1984

Dodson WC, Whitesides DB, Haghes CL Jr, Easley HA III, Haney AF: Superowulation with intauterine insemination in the treatment of infertility: a possible alternative to gamete intrafallopian transfer and in witro fertilization.

Fertil Steril 48: 441 445, 1987

Dmowski WP, Steele RW, Baker GF: Deficient cellular immunity in endonetriosis.

Am J Obstet Gynecol 141: 377-383, 1981

Hath DW, Carratier RP, Foldesy RG, McGuire JL: Experimental evidence for failure to implant as a mechanism of infertility associated with endometriosis.

Am J Obstet Gynecol 155: 1109-1113, 1986

Hallme J, Hammond MG, Hulka JF, Raj SG, Talbert I.M: Retrograde menstruation in healthy women and in patients with endometriosis.

Obstet Gynecol 64: 151-154, 1984 
Kroon BBR: Oker het ontstaan en do behandeling van maligne aseites.

Thesis, Amsterdam, 1986

Mathur S, Peress MR, Williamson HO, Youmans CD, Maney SA, Garvin AJ, Rust PF, Fudeuberg HH:

Autoinmunity to endometrium and ovary in endometriosis.

Clin exp Immunol 50: 259-266, 1982

Murphy AA, Green WR, Bobbie D, Cruz ZC delia, Rock JA: Unsuspected endomelriosis documented by scanning electron microscopy in visually normal peritoneum.

Fertill Steril 46: $522-524,1986$

Nowak E: Pelvic endometriosis. Spontaneous rupture of endometrial cysts, with a report of three cases. Am J Obstet Gynecol 22: 826-837, 1931

Steele RW, Dmowski WP, Marmer DJ: Immunologic aspects of endonetriosis.

Am J Reprod Immunol 6: 33-36, 1984

Syrop CH, Halme $\mathbb{J}$ : A comparison of peritoneal fluid parameters of inferile patients and the subsequen oceurrence of pregnancy.

Fertil Steril 46: 631-635, 1986

Vernon MW, Beard JS, Graves K, Willson EA: Classification of endometriotic implants by morphologic appearance and capacity to synthesize prostaglandin $\mathrm{F}$.

Fertil Steril 46: 801-806, 1986

Weed JC, Arquembourg PC: Endometriosis: can it produce an autoimmune response resulting in infervility?

Clin Obstet Gynecol 23: 885-893, 1980

Welner S, DeCherney AH, Polan ML: Human menopausal gonadotropins: A justifiable therapy in ovulatory women with long-standing idiopathic infertility.

Am J Obsitet Gynecol 158: 111-116,1988

Zeller JM, Henig I, Radwanska E, Dmowski WP: Enhancement of human monocyte and peritoneal macrophage chemiluminescence activities in women with endometriosis.

Am J Reprod Immunol Microbiol 13: 78-82, 1987 

Chapter 1 offers a short introduction in which a definition of endometriosis is given. In the first part of chapter 2 the literature is reviewed regarding pathogenesis and etiology, classification, epidemiology, symptomatology, diagnosis, management and recurrence. The second part of chapter 2 contains a review of the literature on the relationship between endometriosis and infertility and on the pathophysiological changes in the abdominal cavity as reflected in the peritoneal fluid that take place in patients with endometriosis. The third part of chapter 2 gives a review of the literature on the use of different animal models of endonetriosis.

The aim of this thesis is outlined in chapter 3 . In the first place changes in the intraabdominal milieu secondary to the presence of endometriosis were documented. Furthermore the influence of peritoneal implants of endometrium on early embryonic development was studied in the rabbit.

Chapter 4 and 5 describe changes in peritoneal fluid volume and its constituents in the presence of endometriosis. Peritoneal fluid was collected at laparoscopy performed in the course of an infertility workup $(\mathrm{N}=40)$, for abdominal pain $(N=9)$ and for sterilization $(N=21)$. In chapter 4 it is shown that there is no difference in peritoneal fluid volume and in peritoneal fluid/serum ratios of acutephase proteins between 25 women with and 45 women without endometriosis. The concentration of the individual proteins in the peritoneal fluid is shown to be predominantly dependent on their molecular weight in both groups. It is concluded that endometriosis does not cause marked intraabdominal inflammatory changes, as far as these might be reflected in changes in intraabdominal protein concentrations.

In chapter 5 parameters of fibrinolysis measured in peritoneal filuid are compared between 25 women with endometriosis and 45 women without the disease. No differences were found between the two groups. It is concluded that changes of the fibrinolytic system do not play a role in endometriosis. In all. patients a high concentration of tissue plasminogen activator in peritoneal fluid in comparison to normal blood levels was found, leading to a high concentration of fibrin degradation products in peritoneal fluid. This indicates an active system of intraabdominal fibrinolysis, irrespective of the presence of endometriosis and thus possibly reflecting a normal intraabdominal defense mechanism.

In chapter 6 functional aspects of peritoneal macrophages are studied in 13 women with and 12 women without endometriosis. In women with endometriosis the total number and the concentration of peritoneal cells were significantly higher than in controls, indicating peritoneal irritation by endometrial implants. Peritoneal fluid 
macrophages of women with endometriosis showed significantly increased erythrophagocytosis and lower chemiluminescence. This suggests an advanced stage of differentiation of these macrophages. Macrophages in this stage of differentiation possibly interfere with gametes and embryos and thus contribute to endometriosis-associated subfertility.

Chapters 7,8 and 9 are devoted to experimental aspects.

In chapter 7 the rabbit model of endometriosis that was used to study the influence of endometrial implants on fertility is described. Twelve weeks after implantation of endometrial tissue into the peritoneal cavity of rabbits cystic structures were found in place of the implants. These cysts were macroscopically and histologically consistent with endometriosis. Moreover, no periadnexal adhesions developed. It is concluded that the rabbit model is suitable to study the influence of endometrial implants on fertility.

In chapter 8 and 9 results obtained in the above mentioned experimental model are described. In 25 rabbits with endometrial implants and in 25 rabbits with fat implants the number of corpora lutea, the recovery rate, the fertilization rate and the transport of fertilized ova 24 hours after mating were determined. No differences were found between the two groups, as shown in chapter 8 . From the results obtained it is concluded that endometrial implants in the rabbit have no influence on the ovulatory mechanism, the pickup function of the oviduct, the fertilization rate or on the transport of fertilized ova.

In chapter 9 the influence of endometrial implants versus the influence of fat implants on the embryonic cleavage stage $24 \mathrm{~h}$ after mating is described. No differences were found between the two groups. Additional culturing of the embryos for 48 hours in a suitable culture medium revealed a further development of the embryos, that did not differ between the two groups studied.

Taking into account the restrictions of a rabbit model of endometriosis it is suggested that the decreased fecundity in mild endometriosis in the human may be caused by disturbances that take place after the early embryonic period. It remains possible that the effects of disturbances in early embryonic development become manifest only after a certain period of time, leading to problems at the time of implantation or in the early postimplantation period.

In chapter 10 an attempt is made to integrate the previous chapters with the existing literature. The possibility that patients with unexplained infertility harbor microscopic foci of endometriosis is supported by findings of the present investigation. The intraabdominal changes detected are not related exclusively to the presence of visible endometriotic implants.

It is emphasized that a cause and effect relationship between endometriosis and infertility cannot be concluded from the available literature. A third mechanism may be responsible for both endometriosis and infertility. Likewise, most reports on peritoneal fluid constituents in endometriosis do not correlate changes in these constituents with the subsequent occurrence of pregnancy. The consequences of these observations with regard to the treatment of endometriosis are shortly discussed. 


\section{Samenvatting}

Hoofdstuk 1 bestaat uit een korte inleiding, waarin het ziektebeeld endometriosis wordt gedefinieerd.

In het eerste gedeelte van hoofdstuk 2 wordt een overzicht gegeven van de literatuur betreffende pathogenese en etiologie, classificatie, symptomatologie, diagnose, behandeling en recurrentie. Het tweede gedeelte bespreekt de literatuur betreffende het verband tussen endometriosis en infertiliteit en betreffende de pathofysiologische veranderingen die optreden in de buikholte in de aanwezigheid van endometriosis, zoals weerspiegeld in de peritoneumvloeistof. Het derde gedeelte van hoofdstuk 2 bevat een overzicht van de literatuur betreffende het gebruik van verschillende dierexperimentele modellen van endometriosis.

Het doel van het onderzoek beschreven in dit proefschrift wordt uiteengezet in hoofdstuk 3: het in kaart brengen van de veranderingen die plaatsvinden in het intra-abdominale milieu ten gevolge van de aanwezigheid van endometriosis, en hel bestuderen van de invloed van endometrium implantaten op de vroegembryonale ontwikkeling in een konijnemodel van endometriosis.

Hoofdstuk 4 en 5 beschrijven veranderingen in peritoneumvloeistofvolume en bestanddelen ervan ten gevolge van de aanwezigheid van endometriosis. Peritoneumvloeistof werd verzameld tijdens laparoscopie. De laparoscopie werd verricht in het kader van een infertiliteitsonderzoek $(N=40)$, voor buikpijn $(N=9)$ of voor sterilisatie $(\mathrm{N}=21)$. In hoofdstuk 4 wordt aangetoond dat er geen verschil bestaat in peritoneumvloeistofvolume en in peritoneumvloeistof/serum ratio's van acutefase eiwitten tussen 25 vrouwen met en 45 vrouwen zonder endometriosis. De concentratie van de verschillende eiwitten in de peritoneunvloeistof wordt voornamelijk bepaald door het molecuulgewicht van de eiwitten in beide groepen. Hieruit wordt geconcludeerd dat endometriosis geen uitgesproken intra-abdominale ontstekingsverschijnselen veroorzaakt, voor zover deze worden weerspiegeld in veranderingen in intra-abdominale eiwitconcentraties.

In hoofdstuk 5 worden parameters van de fibrinolysis, gemeten in de peritoneumvloeistof, vergeleken tussen 25 vrouwen met en 45 vrouwen zonder endometriosis. Er werden geen verschillen aangetoond tussen de twee groepen. Hieruit wordt geconcludęerd dat het fibrinolytische systeem geen rol speelt bij endometriosis. Bij alle patienten werd een hoge concentratie tissue plasminogen activator in de peritoneumvloeistof gevonden in vergelijking met de waarden die normaal in het perifere bloed worden aangetroffen. Dit had een hoge concentratie fibrine-afbraakproducten in de peritoneumvloeistof tot gevolg. Deze bevindingen wijzen op een actief systeem van intra-abdominale fibrinolysis. Echter dit was onafhankelijk van de aanwezigheid 
van endometriosis. Deze actieve fibrinolysis kan beschouwd worden als een fysiologisch intra-abdominaal afweermechanisme.

In hoofdstuk 6 worden functionele aspecten van peritoneale macrofagen bestudeerd bij 13 vrouwen met en 12 vrouwen zonder endometriosis. Bij vrouwen met endometriosis waren het totale aantal en de concentratie van intra-abdominale cellen significant hoger dan bij de controlegroep, wat mogelijk wijst op irritatie van het peritoneum door endometriosis.

De macrofagen in de peritoneumvloeistof van vrouwen met endometriosis vertoonden een significant verhoogde erythrofagocytosis en een significant verlaagde chemiluminescentie. Dit is een aanwijzing voor een gevorderd stadium van differentiatie van deze macrofagen.

Macrofagen in dit stadium van differentiatie kunnen interfereren met gameten en embryo's om bij te dragen aan de verminderde vruchtbaarheid die gezien wordt bij vrouwen met endometriosis.

De hoofdstukken 7, 8 en 9 zijn gewijd aan experimentele aspecten.

In hoofdstuk 7 wordt het konijnemodel van endometriosis beschreven dat werd gebruikt om de invloed van endometriumimplantaten op de fertiliteit te bestuderen. Twaalf weken na implantatie van endometriumweefsel in de buikholte van konijnen werden cystes aangetroffen op de plaats van de implantaten. Deze cystes vertoonden macroscopisch en histologisch overeenkomst met endometriosis. Bovendien ontstonden geen adhesies rond tubae en ovaria. De conclusie luidt dat het konijnemodel een geschikt model is om de invloed van endometriumimplantaten op de fertiliteit te bestuderen.

In hoofdstuk 8 en 9 worden de resultaten beschreven verkregen met behulp van het hierboven genoemde model. Bij 25 konijnen met endometriumimplantaten en bij 25 konijnen met vetimplantaten werden de volgende parameters bepaald: het aantall corpora lutea, het aantal embryo's teruggevonden bij spoelen van de tubae, het bevruchtingspercentage en het transport van de bevruchte eicellen 24 uur na dekken van het konijn. Er werden geen verschillen gevonden tussen de twee groepen. Hieruit: wordt geconcludeerd dat endometriumimplantaten bij het konijn geen invloed hebben op het ovulatiemechanisme, de opvang van de eicel, het aantal eicellen dat bevrucht wordt en op de snelheid van transport van de bevruchte eicellen door de eileiders.

In hoofdstuk 9 wordt de invloed van endometriumimplantaten beschreven versus de invloed van vetimplantaten op het delingsstadium van de embryo's gedurende de eerste 24 uur na dekken van het konijn. Er werden geen verschillen gevonden tussen de twee groepen. Vervolgens werden de embryo's doorgekweekt in een geschikt kweekmedium gedurende 48 uur. Ook hierbij werden geen verschillen tussen de twee groepen aangetoond.

De beperkingen van een konijnemodel van endometriosis in aanmerking genomen kan men veronderstellen dat de verminderde vruchtbaarheid bij endometriosis veroorzaakt wordt door stoornissen die optreden na de vroegembryonale periode. Het blijft mogelijk dat de effecten van stoornissen in de vroegembryonale periode pas 
tot uiting komen na enige tijd, aanleiding gevend tot problemen ten tijde van de implantatie of in de periode direct volgend op de implantatie.

In hoofdstuk 10 wordt gepoogd de inhoud van de voorgaande hoofdstukken in de context te plaatsen van de bestaande literatuur. De mogelijkheid dat patienten met onbegrepen infertiliteit microscopische endometriosis hebben wordt ondersteund door de bevindingen van het hier beschreven onderzoek. De aangetoonde intraabdominale veranderingen zijn niet uitsluitend gekoppeld aan de aanwezigheid van macroscopische endometriosis.

Benadrukt wordt dat een oorzakelijk verband tussen endometriosis en infertiliteit niet volgt uit de beschikbare literatuur. Een derde mechanisme kan verantwoordelijk zijn voor zowell de endometriosis als de infertiliteit. Een tekortkoming van de geraadpleegde literatuur bleek te zijn dat veranderingen in peritoneumvloeistofsamenstelling bij patienten met endometriosis niet worden gecorreleerd aan het optreden van zwangerschappen. De consequenties van deze bevindingen voor de behandeling van endometriosis worden besproken. 
Met dank aan: Roussel BV Nederland

Schering $B V$ Nederland Sterling Wimthrop BV Nederland 


\section{Curriculum Vitae}

21 april 1951 Geboren te Helmond

1969

Eindexamen gymnasium- $\beta$, St Carolus Borromeus college te Helmond

1969-1976 Studie geneeskunde, Rijksuniversiteit Utrecht

1974 Werkzaam in het ziekenhuis N.S. Aparecida, Vila de Rondônia, Brazilië

1976

ECFMG examen

1976

Artsexamen, Rijksuniversiteit Utrecht

1977

1977-1978 Arts-assistent Chirurgie, Urologie, Gynaecologie, Ziekenhuis De Lichtenberg, Amersfoort

1978

Nationale tropencursus voor artsen, Koninklijk Instituut voor de Tropen, Amsterdam

1979-1982 Werkzaam in het Holy Family Hospital, Berekum, Ghana

1982-1985 A-opleiding Obstetrie en Gynaecologie, De Wever Ziekenhuis Heerlen, Opleider: Dr L.A. Schellekens

1985-1987 A-opleiding Obstetrie en Gynaecologie, Ziekenhuis St. Annadal, vanaf 1.1.1986 Academisch Ziekenhuis Maastricht, Opleider: Prof. Dr J. de Haan

1987

Inschrijving specialistenregister

Als staflid verbonden aan de vakgroep Obstetrie en Gynaecologie van het Academisch Ziekenhuis Maastricht 